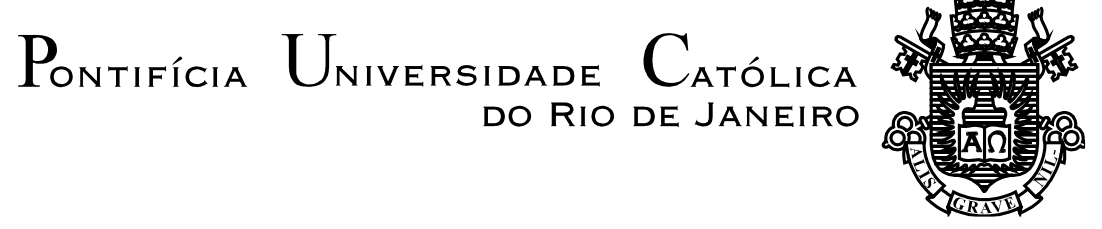

Isabel Leslie Rose

\title{
ANOTHER CRACK AT THE TOUGH NUT A new approach to tough and other object-gap constructions
}

Dissertação de Mestrado

Dissertation presented to the Programa de PósGraduação em Estudos da Linguagem of the Departamento de Letras, PUC-Rio as partial fulfillment of the requirements for the degree of Mestre em Letras/Estudos da Linguagem.

Advisor: Profa. Cilene Aparecida Nunes Rodrigues 


$$
\text { Pontifícia } \text { Universidade }_{\text {do Rio de Janeiro }}
$$

\section{Isabel Leslie Rose}

\section{ANOTHER CRACK AT THE TOUGH NUT A new approach to tough and other object-gap constructions}

Dissertation presented to the Programa de PósGraduação em Estudos da Linguagem of the Departamento de Letras do Centro de Teologia e Ciências Humanas da PUC-Rio, as partial fulfillment of the requirements for the degree of Mestre.

Profa. Cilene Aparecida Nunes Rodrigues

Advisor

Departamento de Letras - PUC-Rio

Prof. Jairo Morais Nunes

USP

Prof. Andrés Leandro Saab

UBA, AR

Profa. Monah Winograd

Coordinator of the Setorial do Centro de Teologia

e Ciências Humanas - PUC-Rio

Rio de Janeiro, May 25th, 2018 
All rights reserved.

\section{Isabel Leslie Rose}

The author holds a Bachelor of Arts degree in Romance Languages (University of Alberta, Canada) and combined civil law/common law degrees (B.C.L./LL.B, McGill University, Canada). She works as a legal language consultant in Rio de Janeiro, Brazil, and has translated the Brazilian Civil Code into English (2 ed. Rio de Janeiro: Editora Renovar, 2012).

Bibliographic data

Rose, Isabel Leslie

Another crack at the tough nut : a new approach to tough and other object-gap constructions / Isabel Leslie Rose ; advisor: Cilene Aparecida Nunes Rodrigues. - 2018.

134 f. ; $30 \mathrm{~cm}$

Dissertação (mestrado)-Pontifícia Universidade Católica do Rio de Janeiro, Departamento de Letras, 2018.

Inclui bibliografia

1. Letras - Teses. 2. A sintaxe de construções tough e de outras estruturas com objeto lacunado. 3. Nominalização. 4. Adjunção e relações estruturais simétricas. 5. Rotulação. I. Rodrigues, Cilene Aparecida Nunes. II. Pontifícia Universidade Católica do Rio de Janeiro. Departamento de Letras. III. Título. 


\section{Acknowledgements}

In this endeavor, I give heartfelt thanks to

My advisor, Professor Cilene Rodrigues, for her intellectual generosity and rigor, for the challenges she proposed and for the support she gave me in meeting those challenges;

CAPES and PUC-Rio, for the financial support they granted;

The professors and staff of the Departamento de Letras and the PPGEL, especially Professor Érica Rodrigues, for knowledge gained, and Chiquinha, for her encyclopedic knowledge of all things departmental and unflagging help and good cheer;

The members of the examining Commission; and

My family and friends, in Rio and in Canada, who gave me love and support throughout. 


\section{Abstract}

Rose, Isabel Leslie; Rodrigues, Cilene Aparecida Nunes (Advisor). Another Crack at the Tough Nut: A new approach to tough and other object-gap constructions. Rio de Janeiro, 2018. 134p. Dissertação de Mestrado Departamento de Letras, Pontifícia Universidade Católica do Rio de Janeiro.

Superficially, tough constructions (TCs) like John is easy to please present the format [DP COPULA A $V_{I N F}$, but their distinctive characteristic is that the subject DP is interpreted as the logical object of the verb in the infinitive. Many theoretical studies have examined the syntactic structure of TCs and the semantic relations supported by that structure, but to date no theory provides a good explanatory description for TCs and related object-gap constructions like pretty predicates, gapped degree phrases, and ready predicates. The objectives of this thesis are (a) to discuss, in light of the data, the different theoretical proposals on TCs and related constructions, providing a systematic overview of current knowledge on the grammar of these constructions in English and a number of Romance languages, such as French, Spanish and Romanian, and (b) to present a new theoretical approach, starting from a contrarian position on the premises adopted in earlier studies. Under the proposed analysis, formation of the predicate in TCs and related constructions involves nominalization of the verb in the infinitive and adjunction of maximal projections, resulting in a symmetrical structure. In this symmetrical structure, the semantic link between syntactic subject and logical object is established at Logical Form, in function of the nominalized verb's argument structure and the category of the concatenated adjective. The theoretical model presented in this thesis unifies TCs, pretty predicates, gapped degree phrases and ready predicates, suggesting that these constructions share the processes of nominalization and adjunction of maximal projections, and differ in the semantic relationships between their elements. It also offers a principled explanation for the behavior of for-phrases in these object-gap constructions and for the fact that only TCs (and some gapped degree phrases) appear prenominally, in attributive use.

\section{Keywords}

Syntax of tough constructions and other object-gap structures; nominalization; adjunction and symmetric structural relations; labeling. 


\section{Resumo}

Rose, Isabel Leslie; Rodrigues, Cilene Aparecida Nunes. Roendo um Osso Duro: uma nova análise para as construções tough e outras estruturas com objeto lacunado. Rio de Janeiro, 2018. 134p. Dissertação de Mestrado Departamento de Letras, Pontifícia Universidade Católica do Rio de Janeiro.

As denominadas construções tough (tough constructions - "TCs"), como John is easy to please, apresentam o formato superficial [SD COPULA Adj VInf], tendo como característica distintiva o fato de que o SD (sintagma determinante), sujeito do predicado, é interpretado como objeto lógico do verbo no infinitivo. Muitos estudos teóricos examinaram a sintaxe dessa estrutura e as relações semânticas tecidas a partir dela, mas até o momento nenhuma teoria explica de forma satisfatória as TCs e estruturas relacionadas, com objeto lacunado, como pretty predicates, gapped degree phrases e ready predicates. Os objetivos desta dissertação são: (a) discutir, à luz dos dados, as diferentes propostas teóricas para TCs e construções relacionadas, buscando sistematizar nosso conhecimento atual sobre a gramática dessas construções em inglês e em algumas línguas românicas, como o francês, o espanhol, e o romeno; (b) apresentar uma nova abordagem teórica, construída a partir da negação das premissas adotadas em estudos anteriores, sugerindo que, em TCs e estruturas relacionadas, a formação do predicado envolva nominalização e adjunção de projeções máximas, resultando em estruturas simétricas. Na análise proposta, o elo semântico entre o sujeito sintático do predicado e o objeto lógico do verbo no infinitivo se realiza na Forma Lógica, em função da estrutura argumental do verbo nominalizado e da categoria do adjetivo concatenado simetricamente. A modelagem teórica apresentada permite unificar TCs, pretty predicates, gapped degree phrases e ready predicates, propondo que essas construções compartilham os processos de nominalização e de adjunção de projeções máximas, diferenciando-se nas relações semânticas entre seus elementos. Permite também uma explicação mais adequada para o comportamento de for phrases e para o fato de que apenas as TCs (e algumas gapped degree phrases) aparecem em posição prenominal, com uso atributivo.

\section{Palavras-chave}

A sintaxe de construções tough e de outras estruturas com objeto lacunado; nominalização; adjunção e relações estruturais simétricas; rotulação. 


\section{Table of Contents}

1 Introduction

2 Tough Constructions and the object gap family: the premises and the puzzles

2.1. Tough constructions and their sisters: Rosenbaum (1965)

2.2. Tough constructions and their cousins: Lasnik and Fiengo (1974) 14

2.2.1. Object gap constructions

2.2.2. Lasnik and Fiengo's theory: Complement Object Deletion 17

2.2.3. The TC data: some empirical puzzles 20

2.2.4. More object-gap constructions - ready predicates, rare predicates, and nominal Attributives with Infinitive Constructions - and some anomalies

2.2.5. What makes a TC tough: the essential characteristics of TCs and their similarities and differences to other object-gap constructions

3 Tough Construction Theories

3.1. Theoretical Puzzles

3.2. Chomsky: Wh-movement and the Null Operator Theory

3.2.1. The double for-phrase problem

3.2.2. Sonatas and violins: wh-movement conundrums, the theta-role problem and the reanalysis proposal

3.3. Variations on the null operator theory

3.3.1. Rezac and $\bar{A}$-Agree

3.4. Argument movement analyses: $A-\bar{A}-A$ 65

3.4.1. Hornstein's sideward movement theory 65

3.4.2. Obata and Epstein's feature-splitting analysis 67

3.4.3. Hartman and the defective intervention argument 68

3.4.4. Hendrick and the smuggling approach 71

3.4.5. Brillman: Comparing GDPs and TCs 71 
3.4.6. TCs and middles 72

3.5. Combining Null Operator and Argument Movement Theories $\quad 75$

3.5.1. Hicks and the Complex Null Operator 75

3.6. Some proposals from Romance languages 76

3.6.1. TCs and passives $\quad 76$

3.6.2. TCs and nominals $\quad 80$

3.6.3. Romanian tough constructions: similarities to English TCs 83

4 A contrarian exploration of TCs and other object-gap constructions $\quad 87$

4.1. Saying no to Rosenbaum 88

4.2. A contrarian proposal: the one-size-fits-all model 90

4.2.1. A contrarian alternative to Premise C: the non-verbal predication paradigm 93

4.2.2. A contrarian alternative to Premise $D$ : the infinitival is a PP, not a $\mathrm{CP}$

100

4.2.3. The for-phrase is a PP adjunct 112

4.2.4. Prenominal TCs: revisiting reanalysis 121

5 Conclusion $\quad 126$

5.1. Discoveries made on the contrarian exploration 126

5.2. Future expeditions 128

6 Bibliography 130 


\section{1 \\ Introduction}

Tough constructions (TCs) have been a puzzle - a tough nut to crack, as one researcher put it (Boutault 2011) - since the earliest days of generative grammar. The problem of tough constructions has been described in detail many times, so this introduction does no more than outline it in the simplest of terms.

The classic formulation of the TC problem begins with pairs of sentences like (1), and a question: how is it that John, clearly the object of the verb please in (1a), appears as the subject of (1b)?
(1)
a. It is easy to please John
b. John is easy to please

In the transformational era of generative grammar, the premises of the TC debate were settled and researchers concentrated on the data in their attempts to discover transformational rules that would describe the derivation of TCs and other objectgap constructions. In the government and binding era, attention turned to theoryinternal questions and, in particular, the application of the Projection Principle and Theta-Theory to TCs. Now, in the Minimalist Program, Case theory and phases have offered new arenas for syntacticians interested in TCs to explore.

Despite the evolution of generative grammar, TCs continue to be a challenge. Even within the framework of the Minimalist Program, theoretical models of TCs posit novel or null (or both) lexical items (Chomsky 1977;1981;1986, Rezac 2006, Hicks 2009 and Keine and Poole 2017) or TC-specific movement of arguments (Hornstein 2001). Theories generally address only TCs in predicative structures and do not examine TCs in attributive environments. The rare exceptions (Giurgea 2013, for example) deal with languages other than English. While a few proposals do look at other "object gap" constructions (Brillman 
2015), most do not. None of the theories put forward seems to have significantly greater explanatory power than the others.

In this thesis, I hope to contribute to the study of TCs within the Minimalist framework by identifying and describing, in a systematic way, the various problems and puzzles presented by TCs, and reviewing the main theoretical proposals made for TCs, relying mainly on work on English, but also drawing on investigations into TC-like structures in other languages. ${ }^{1}$ Guided by the problems and puzzles and drawing on data, observations and insights found in the rich literature on the subject, I then explore a different theoretical approach to TCs.

Chapter 2 of the thesis focuses on the work done in the transformational era, in which the premises of the TC question and many of the empirical puzzles raised by TCs were identified by early researchers, although the chapter incorporates data reported in later studies. Chapter 2 closes with a proposed working definition of TCs and a comparative table showing the similarities and differences between TCs and other object-gap constructions. Chapter 3 reviews and comments on the theoretical puzzles posed by TCs under government and binding theory and, later, the Minimalist Program, and the theories proposed to answer those puzzles, largely in chronological order. Chapter 4 takes a contrarian stance on TCs, and explores the implications of re-examining the premises that frame the TC question by sketching out a unified syntactic model for TC and other object-gap constructions, and marshalling arguments to support the proposed model. Chapter 5 reviews the preliminary results of the contrarian exploration, and identifies questions for future investigation.

\footnotetext{
${ }^{1}$ Rezac (2006) and Hicks (2009) both give very useful overviews of previous work on TCs in English.
} 


\section{2 \\ Tough Constructions and the object gap family: the premises and the puzzles}

With tough constructions' long history, most theoretical proposals do not devote much time to a detailed description of the constructions, relying instead on references to previous studies. This chapter is dedicated to the first two major analyses of TCs, Rosenbaum's (1965) and Lasnik and Fiengo's (1974). It was those studies, made when Generative Grammar was still in the transformational era, that defined TCs and demarcated the field of debate.

Rosenbaum (1965) framed the TC question and set out its basic premises; Lasnik and Fiengo (1974) observed similarities between TCs and two other object gap constructions. They also challenged Rosenbaum's analysis of TCs, and the data they presented (along with some observations by later authors) raise some interesting puzzles.

Our objective will be to set out, in a systematic way, the premises underlying the TC problem, the similarities and differences between TCs and other object-gap constructions, and the puzzles raised by the data on TCs. We will find that while TCs can be seen as one member of a family of object-gap structures, they are indeed puzzling structures, and it is difficult to specify their properties precisely and exhaustively.

\subsection{Tough constructions and their sisters: Rosenbaum (1965)}

In his doctoral dissertation, The Grammar of English Predicate Complement Constructions, Rosenbaum (1965) identifies "special problems" associated with sentential complements in predicates formed from adjectives such as "clever", "wise", and "honorable" (Rosenbaum 1965: 190). In Rosenbaum's words, "the specific problem concerns the relatedness of the sentences in [(2)] with the sentence in [(3)]" (Rosenbaum 1965:191): 
(2) a. to leave early was wise of John

b. it was wise of John to leave early

(3) John was wise to leave early

Rosenbaum answers his question by hypothesizing that they are related, and that in fact sentence (3) is derived from the sentences in (2) by extraposing the "sentence complement" to leave early in sentence (2a), leaving behind an expletive it, and producing sentence (2b). The prepositional phrase of John then replaces the expletive $i t$, and $o f$ is deleted. The result is sentence (3).

Essentially the same analysis applies to the class of adjectives that include difficult and easy (Rosenbaum 1965: 194) - the classical examples of tough constructions. Rosenbaum starts from the following triad of sentences:

(4) a. for John to hit Bill is difficult

b. it is difficult for John to hit Bill

c. Bill is difficult for John to hit

The clausal formulation in sentence (4a) is the base. The expletive formulation in sentence (4b) is the result of application of the extraposition transformational rule. The TC in sentence (4c) results when "the final noun phrase of the complement sentence (Bill) replaces the expletive it, following the application of the extraposition transformation." A simplified schema of the three steps is shown below:

(5)

$\mathrm{a}\left[\mathrm{NNP}_{\mathrm{N}}\right.$ it] [s for John to hit Bill]] [AUX is] [A difficult]]

$\mathrm{b}[$ [NP [N it] fs for John to hit Bill]] [AuX is] [AP [A difficult] [s for John to hit Bill]]

$\mathrm{c}[$ [NP [N it Bill]] [AUX is] [AP [A difficult] [s for John to hit Bill]]

Rosenbaum's description of the TC transformational rule is reproduced in (6): 
(6)

\begin{tabular}{|c|c|c|c|c|c|c|c|}
\hline $\mathrm{W}$ [NP [N it]] & AUX & ADJ & {$[\mathrm{s}[+\mathrm{C}]$} & NP & AUX & [vP V (PREP) & $\mathrm{NP}] \mathrm{X}] \quad \mathrm{Y}$ \\
\hline 2 & 3 & 4 & 5 & 6 & 7 & 8 & $10 \quad 11$ \\
\hline
\end{tabular}

The schema in (6) corresponds to sentence (4b), since Sentence $X$ has already been extraposed from its initial position in NP to its position next to ADJ, at the end of the string.

The basic premises of Rosenbaum's analysis, then, are that:

a. TCs and the clausal and expletive formulations are syntactically related;

b. TCs are derived from the expletive (and ultimately the clausal) formulation;

c. The infinitival is the complement of the tough element; and

d. The infinitival is a sentence (or, in more recent terminology, a complementizer phrase).

Although Rosenbaum himself questions whether tough constructions and their clausal and expletive "sister" formulations are related, the treatment he gives them established the syntactic framework of the TC question, and the framework he proposed in his 1965 dissertation has remained essentially unchanged in the subsequent 50 years.

\section{2.}

\section{Tough constructions and their cousins: Lasnik and Fiengo (1974)}

The next major study of tough constructions is Lasnik and Fiengo's (1974) "Complement Object Deletion", in which the authors present data to refute the long-distance argument movement theory put forward by Rosenbaum (1965) and refined on by Postal. ${ }^{2}$ In the first part of their paper, Lasnik and Fiengo (L\&F)

\footnotetext{
2 Postal (1971) looks at tough constructions in his Cross-Over Phenomena and endorses Rosenbaum's (1965) analysis. Postal's interest in TCs is inspired by his examination of NP movement and co-referentiality, and his ambition to state in a concise, generally-applicable rule the cases in which one NP can and cannot "cross over" another, co-referential NP. Unsurprisingly,
} 
compare TCs with two other types of object-gap constructions, namely pretty predicates, and the gapped degree phrases formed by too and enough (GDPs). ${ }^{3}$ Then, after formulating their complement object deletion theory, L\&F present data that is inconsistent with a movement analysis of TCs. These data are the earliest TC puzzles, and we will supplement them with problems observed in later research.

\subsection{1.}

\section{Object gap constructions}

\subsubsection{1.}

\section{TCs, pretty predicates, and GDPs}

The object-gap constructions examined by L\&F (1974) are TCs, pretty predicates and GDPs. Like TCs, in pretty predicates and GDPs the subject of the matrix sentence is co-referential with an object gap in the infinitival in the predicate; unlike TCs, however, neither pretty predicates or GDPs have expletive or clausal “sister" formulations (L\&F 1974: 535-6):

(7) a. Mary is pretty to look at

b. *It is pretty to look at Mary

c. *To look at Mary is pretty
a. This mattress is too thin to sleep on
b. $\quad *$ It is too thin to sleep on this mattress
c. $\quad$ *To sleep on this mattress is too thin

TCs and pretty predicates differ from GDPs in that their gap can never be filled: any attempt to do so produces an ungrammatical sentence, regardless of whether the element in the gap is co-referential with the matrix subject or not:

TCs refuse to conform, since the tough-movement rule generates structures like Himself is tough for Harry to like (Postal 1971: 155), which are clearly ungrammatical.

${ }^{3}$ Although we will also look at some other types of object-gap constructions not mentioned by $\mathrm{L} \& \mathrm{~F}$, in the following section we will focus on pretty predicates and GDPs as presented by L\&F. 
(9) a. * $\mathrm{John}_{1 / 2}$ is easy to please $\underline{\text { him }}_{1}$

b. *John is easy to please Mary

(10) a. *Mary $1 / 2$ is pretty to look at her 1

b. *Mary is pretty to look at $\underline{\text { Sue }}$

As L\&F point out, the gap in GDPs is "optional", but filling the gap depends on the presence of a for-phrase (L\&F 1974: 585):

(11) a. This problem is too abstract for Bill to solve

b. This problem is too abstract for Bill to solve it

c. *This problem is too abstract to solve it

For-phrases are a significant difference between pretty predicates and TCs, however: TCs allow a for-phrase while pretties do not, as shown in (12) and (13):

(12) John is easy for Bill to please

(13) *Mary is pretty for Bill to look at

Thus, with respect to licensing of for-phrases, TCs pattern with GDPs. However, GDPs seem to be much more flexible structures than either TCs or pretty predicates. First, the matrix subject can also be the subject of the verb in the infinitival (14). Second, intransitive verbs (15) and passivized verbs (16) are also allowed. Lastly, there insertion (17) can occur within the infinitival clause (L\&F 1974):

(14) Mary ${ }_{1}$ is shrewd enough 1 to win the election

(15) Einstein $_{1}$ is too well-known 1 to travel unnoticed

(16) Bill $_{1}$ is popular enough to be elected

(17) Mary is too clever for there to be any disagreement concerning her intelligence. 
There are other object-gap constructions - ready predicates, rare predicates and Attributives with Infinitival Constructions - which were not explored by L\&F, but we will examine them later, in section 2.2.4.

\subsection{2.}

\section{Lasnik and Fiengo's theory: Complement Object Deletion}

L\&F argue that in TCs, pretty predicates and GDPs, the embedded verbal complement, which is identical to the subject of the matrix sentence, is present in deep structure, but is deleted under an identity-based rule that they take to be governed by a Deletion Principle (L\&F 1974: 556):

\section{Deletion Principle}
A. If there is required identity between the two strings, and if there is a rule deleting one string under identity with the other, then that rule is obligatory.
B. If there is not required identity between the two strings, and if there is a rule deleting one string under identity with the other, then that rule is optional.

Case A of the Deletion Principle applies to TCs and pretty predicates; Case B applies to GDPs.

As we have seen, the gap in TCs and pretty predicates can never be filled, and the gap is invariably coreferential with the matrix subject. Accordingly, there is "required identity" between the gap in the infinitival string and the subject in the matrix string. In contrast, the object "gap" in GDPs can be filled in some circumstances (cf. (14) above), and the items that fill the gap can even be coreferential with the matrix subject (cf. (18b) below). Identity between the gap in the infinitival string and the subject in the matrix string is thus not required, and if it does occur (as in sentences (18a) and (18b) and (19a) and (19b) below), deletion is optional (L\&F 1974: 557):

(18) a. Senator Foghorn 1 is too persuasive for us to like

b. Senator Foghorn 1 is too persuasive for us to like $\operatorname{him}_{1 / 2}{ }^{4}$

\footnotetext{
${ }^{4}$ Interestingly enough, although the pronoun can be coreferential with the matrix subject, it need not be: him could refer to the candidate that Senator Foghorn endorses.
} 
c. Senator Foghorn 1 is too persuasive for us to like the idea of voting for $\operatorname{him}_{2}$

(19) a. President Nixon $_{1}$ is conservative enough for us to vote for

b. President Nixon $_{1}$ is conservative enough for us to vote for him 1

c. President Nixon $_{1}$ is conservative enough for us to vote for the candidate he endorses for governor 2

Without a for-phrase, however, an object gap in a GDP must be coreferential with the matrix subject, and therefore there is "required identity" and Case A of the Deletion Principle applies.

According to L\&F, the obligatory deletion of the complement object in TCs and pretty predicates can be explained by the fact that their complements are VPs rather than sentences, while too and enough degree constructions can select either VPs or sentences as complements. When a GDP's complement is a VP, deletion under the identity rule is required, but when the complement is a sentence, deletion of the complement object is not obligatory.

The most obvious empirical difficulty with L\&F's analysis is that it is the presence of a for-phrase in GDPs that distinguishes sentence complements (in which deletion of the object is not required) from VP complements (in which deletion is required) as we saw in the sentences in (11) above. A for-phrase is also allowed in TCs, however, which would suggest that they too can have sentence complements and filled gaps, contrary to the facts.

To get around this difficulty, L\&F argue that the for-phrase in TCs introduces a mere experiencer or evaluator (p. 549):

In both cases, it is demonstrable that whenever a for phrase is present, it is not the syntactic subject of the complement.

(72) a. John is easy for Bill to please.

b. John is easy to please, for Bill.

c. For Bill, John is easy to please. 
This assertion is too broad, I think. In L\&F's (72a), Bill is not evaluating how easy John is to please, as in (72b) and (72c); rather, John is such that Bill can easily please him. If that is so, then the for-phrase introduces the agent of the action in the complement infinitival and the VP versus sentence distinction on which the Deletion Principle rests fails to hold. The difference in meaning becomes clearer when a second for-phrase is introduced:

(20) a. *John is easy for Bill for Sam to please

b. John is easy for Sam to please, for Bill

c. For Bill, John is easy for Sam to please

In sentences (20b) and (20c), Bill is quite clearly the evaluator of how easy John is for Sam to please, while Sam appears to be the agent of the action of pleasing. In contrast, sentence (20a) is ungrammatical, possibly because the agent and evaluator roles cannot be assigned between Bill and Sam.

At any rate, the complement object deletion analysis may have its weaknesses, but it is interesting in that, unlike Rosenbaum's theory and all subsequent TC theories, it does not posit a syntactic dependency between the matrix sentence and the infinitival: rather than linking the object position of the infinitival's verb to the matrix subject position by movement of syntactic items, there is simply insertion of a referring expression in the two positions, with the iteration in the infinitival being deleted. It also raises the possibility that the infinitival in TCs is not a clause but rather a VP - a hypothesis that will find support from researchers working on TC-like structures in Romance languages (cf. Authier and Reed (2009)).

But the most valuable contribution in L\&F's paper is its data: not only do they examine pretty predicates and GDPs and compare them with TCs, in refuting the long-distance movement theory of TCs, they present data that remains unexplained until today. 


\subsection{3.}

\section{The TC data: some empirical puzzles}

In arguing against a movement analysis of TCs, L\&F contend, essentially, that the $\mathrm{TC}$ is an adjectival predicate denoting a characteristic, and that it displays the syntactic and semantic behavior of other characteristic-denoting adjectives, like brave, tall and honest. Thus, argue L\&F, TCs are not derived from their expletive and clausal counterparts. ${ }^{5}$ In this section, we will look at the evidence they present to support their argument, supplementing the discussion with data offered by other researchers, especially Nanni (1980).

\subsubsection{1.}

\section{No expletive formulation means no landing site for moved arguments}

One of the most convincing arguments that L\&F make against "tough movement" transformational analyses (and long-distance movement arguments generally) is that they do not account for sentences such as "Mary is pretty to look at" because "It is pretty to look at Mary" is ungrammatical (p. 535). They have a good point: if there is no "expletive formulation" of pretty predicates (or GDPs) to correspond to the expletive formulation of TCs, then there is no landing site for the moved embedded object.

Even today, pretty predicates and GDPs continue to present something of a dilemma for TC theories: if a theory relies on the expletive it in the matrix to provide a landing site for the moved argument, then the theory cannot explain the object gaps in pretty predicates and GDPs, despite the apparent similarities in all three structures. On the other hand, if the theory does not rely on the landing site provided by the expletive it, the theory would, at least in principle, also apply to pretty predicates and GDPs, even though these "cousin" structures do not have expletive correlates. In effect, most analyses of TCs tend to focus on TCs alone

${ }^{5} \mathrm{~L} \& \mathrm{~F}$ assert that TCs and the expletive formulation represent two different syntactic frames, (a) for TCs and (b) for expletive formulations (L\&F 1974: 567-8):
(a) $\quad \mathrm{NP}_{\mathrm{i}}$ be $\{\mathrm{ADJ} / \mathrm{N}\}$ (for NP) to $\mathrm{VP}[\mathrm{V} \mathrm{X}$
(b) it be $\{\mathrm{ADJ} / \mathrm{N}\}$ (for NP) to $\mathrm{VP}$. i Y] 
and do not deal with pretty predicates, or attempt to distinguish TCs, pretty predicates and GDPs. ${ }^{6}$

\subsubsection{2. \\ Syntactic and semantic mismatches between the expletive formulation and TCs}

Although TCs do have an expletive "sister", and thus a landing site for the argument moving out of the infinitival, TCs and their expletive sisters show significant semantic and syntactic mismatches, which is surprising if TCs are derived from the expletive formulation by argument movement.

\subsubsection{1.}

\section{Progressive aspect, try, and modals}

L\&F point out, for example, that the movement analysis, which presupposes that

TCs are derivationally related to the clausal subject and expletive formulations, does not account for the grammaticality of TCs with the progressive aspect of the copula (p. 543), or in sentences where the verb try ${ }^{7}$ appears in the matrix clause (p. 544):

(21) a. John is being easy to please

b. $\quad$ *It is being easy to please John

c. $\quad *$ To please John is being easy

(22) a. John tries to be easy to please

b. *John tries (for) it to be easy to please $\{\mathrm{John} / \mathrm{him}\}$

c. *John tries (for) to please $\{\mathrm{John} / \mathrm{him}\}$ to be easy

\footnotetext{
${ }^{6}$ Hicks (2009) contends that his proposal also accounts for pretty predicates. Chomsky (1981) seems to equate GDPs and TCs. Brillman (2015) compares TCs and GDPs, but does not address pretty predicates.

${ }^{7}$ There are many configurations that embed the TC further away from the matrix subject in another infinitival:

(i) John likes to be easy to please

(ii) John is eager to be easy to please

(iii) John is pleased to be easy to please
} 
Under a long-distance movement analysis, ${ }^{8}$ the sentences in (22) are hard to explain because it is not at all clear how John would escape the infinitival to become the subject of the matrix sentence.

L\&F also observe that modals can take either the root or the epistemic reading in TCs but only the epistemic in the expletive formulation. Sentence (23), for example, can be read to mean either that John is required to be easy to please or that one can conclude he is easy to please, but (24) can only have the epistemic meaning.

(23) John must be easy to please

(24) It must be easy to please John

\subsubsection{2. "Indefinite subjects" and the quantifier scope reconstruction problem}

L\&F also note that TCs having indefinite NPs are ungrammatical, and that this is true generally of predicates denoting characteristics (pp. 544-5):

(25) a. It was a delight to talk to someone interesting

b. *Someone interesting was a delight to talk to

(26) a. It was a delight to talk to John

b. John was a delight to talk to

Although generic properties can be predicated of a class (p. 546):

Beavers are hard to kill

\footnotetext{
${ }^{8}$ The sentences in (22) could be analyzed as cases of control if they were derived under the null operator theory (since John in the matrix sentence could be said to control the null operator that would move by wh-movement from the object position in the embedded verb to spec-C in the infinitival clause), but at the time of L\&F's work, the null operator theory had not been developed. In any case, the discrepancy in the thematic roles assigned to the null operator (theme) and the matrix subject (agent) would difficult to account for even under a null-operator theory, since it would presumably persist even at LF, when John (and its agent role) is interpreted in the object position of the verb please.
} 
L\&F speak in terms of indefiniteness and genericity in their discussion of sentences (25) to (27), but the question seems to be more related to specificity or determinability.

Sentences (28) (29b) and (29c) show that an "indefinite subject" can be grammatical in TCs as long as they designate an identifiable class, even if that class is the empty set or a universal (sentence (28)). If the entity or class of entities cannot be specified, then the TC is ungrammatical, as seen in sentences (29a) and (30a). This only makes sense: it is hard to see how a characteristic could be predicated of an entity or class of entities that cannot be identified.

(28) a. Nobody is a delight to talk to

b. Everybody is a delight to talk to

(29) a. *Anybody is a delight to talk to

b. Anybody at the conference is a delight to talk to

(30) a. *A person is a delight to talk to

b. A person from Rio de Janeiro is a delight to talk to

The point that $L \& F$ make is quite a simple one, in the end: if the subject is indefinite (i.e. non-specific), any attempt to ascribe a characteristic to the subject must necessarily fail, and that is precisely what happens in attempts to insert nonspecific subjects in TC predicates, in the same way affirmations like (31) and (32) fail:

(31) *Anybody is intelligent

(32) *A person is brave

L\&F do not refer to quantifier scope expressly but their examples of "indefinite subjects" (which might better be described as Quantifier Phrases ${ }^{9}$ ) bring up the problem of quantifier scope reconstruction in TCs, discussed in Postal (1974), who noted the alteration in scope following what he calls "Tough Movement" (Postal 1974: 224):

\footnotetext{
${ }^{9}$ Radford 2006: 56 et seq.
} 
(33) a. It will be easy for me to find some girls

b. Some girls will be easy for me to find

c. It would be difficult for Jim to talk to few girls

d. Few girls would be difficult for Jim to talk to

As Postal points out, only wide scope is available for the quantifiers in (33b) and (33d), while in (33a) and (33c), both narrow and wide scope are available.

The failure to reconstruct can also be perceived in cases where it interacts with Binding Conditions. Pesetsky (2013), for instance, observes that the subject of TCs does not reconstruct in cases involving Condition $\mathrm{C}$ violations, as illustrated in (34) (example taken from Poole et al. 2016):
a. *It is difficult for her $r_{i}$ to please Mary's father
b. Maryi's father was difficult for her ${ }_{i}$ to please

Since scope reconstruction is, in principle, available in A-chains, the fact that in TCs quantifiers cannot take narrow scope (i.e. scope below the tough item) weighs heavily against the argument movement theory on the derivation of TCs (Fleisher 2013; Poole et al. 2016).

The scope reconstruction problem is particularly severe for argument-movement theories, but it is something of a stumbling block even for null-operator theories. Under null operator theories, the matrix subject is syntactically and semantically linked to the object position in the infinitival's verb, so that semantically (presumably at LF) the matrix subject can be interpreted as the verb's internal argument. It is not clear what in the semantic and syntactic link prevents the scope of quantification from being calculated below the tough element if the matrix subject has at least a logical presence in that position. 


\subsubsection{3.}

\section{Intentionally and adverbial modifiers}

Yet another puzzle is revealed by the insertion of the adverb intentionally in TCs and their expletive and clausal sisters. L\&F make use of the adverb intentionally to provide further evidence against movement (pp. 546-7):
a. John is intentionally easy to please
b. *It is intentionally easy to please John
c. *To please John is intentionally easy

If (35a) were derived by movement of John from its underlying position in (35b) (or, according to Rosenbaum's hypothesis, from (35c) after extraposition of to please John), then we would expect both (35b) and (35c) to be grammatical. They are not, however.

It could be argued that the effects in (35) are explained by the fact that the subject in (b) and (c) is impersonal and so does not have volition. However, the intentionally test provides another interesting datum that L\&F do not discuss in their paper: insertion of the adverb (or another expression of volition like on purpose) in the infinitival of the TC produces an ungrammatical sentence:

(36) *John is easy to please intentionally

(37) *John is hard to talk to on purpose

Even inserting a for-phrase does little to improve the acceptability of the sentences:

(38) *John is easy for Bill to please intentionally

(39) *John is hard for Bill to talk to on purpose

Although the literature does not mention the fact, the insertion of adverbial modifiers within the infinitival clause in object-gap constructions seems to be 
more restricted that in finite clauses and in infinitivals without gaps. Quickly, for example, is sometimes felicitous and sometimes not:

(40) a. *John is easy to talk to quickly

b. I talked to John quickly before class

c. I took a moment to talk quickly to John

(41) a. The shelves are easy to assemble quickly

b. I assembled the shelves quickly

c. I was able to assemble the shelves quickly

(42) a. *The flowers are pretty to look at quickly

b. I looked quickly at the flowers

c. I had a chance to look quickly at the pretty flowers

The varying acceptability of adverbs and adverbial phrases may have to do with their semantic orientation: if they are agent-oriented, they will tend to be unacceptable, but if they are event-oriented, they are more acceptable. Thus, while quickly in (40a) can only be taken to describe the pace at which the agent talks, quickly in (41a) describes how rapidly the shelves change state from unassembled to assembled. Sentence (43a) offers an example of an adverbial phrase modifying the action itself, independently of the agent (example inspired by Ahn and Sailor 2014: 8):

(43) a. Jenna is difficult to describe in a few words

b. I described Jenna in a few words

c. I wasn't able to describe Jenna in a few words

At any rate, these results are surprising if the infinitival in TCs is taken to be clausal, as it usually is in English (Rosenbaum 1965; Chomsky 1977, 1981, 1986; Hornstein 2001; Rezac 2006; Hicks 2009, among others). If the infinitival is clausal (and the clause is formed from a transitive verb), then it should have an external null argument (the subject) as well as an internal argument (the object), even if the external argument is simply a generic null argument PRO, referring to 
a generic agent. In such an environment, adverbs of volition should be acceptable because they modify the agent's state of mind in performing the action expressed by the verb. The fact that sentences (36) to (39) are ungrammatical strongly suggests that the infinitival lacks an external argument, which in turn might indicate that the infinitival component of TCs is not a full clause.

What precisely the infinitival might be if it is not a clause is not clear. Not coincidentally, however, it is precisely the evidence pointing to the absence of an external argument that leads Authier and Reed (2009) to hypothesize that the infinitival in French TCs is a nominal. In section 3.6.2 of this thesis we will explore Authier and Reed's hypothesis in more detail.

\subsubsection{3.}

\section{TCs in attributive use: more puzzling data}

L\&F only touch on the attributive use of object-gap structures. After noting that all three structures, TCs, pretty predicates and GDPs, can be used in secondary predication environments, ${ }^{10}$ they assert that the structures "can occur in attributive position as well” (p. 569):
a. Mary is an easy woman to please
b. Mary is a pretty woman to look at
c. Mary is too smart a woman to fool

The assertion that all three object-gap structures can occur in the attributive position may be too strong. In reality, the sentences in (44) are examples of what is referred to as "discontinuous spell-out", which occurs when the object-gap structure is split, with the adjective (or nominal tough element) appearing before a noun, and the infinitival appearing after. It is also worth noting that the adjective in sentence (44c) is not in the attributive position because it precedes the

\footnotetext{
${ }^{10} \mathrm{~L} \& \mathrm{~F}$ give the following examples of object-gap structures in secondary predication: I call Mary easy to please (TC); I call Mary pretty to look at (pretty predicate); I call Mary too smart to fool (GDP).
} 
indefinite article. In fact, the variant "too smart of a woman" suggests that "a woman" is an adjunct to "too smart". 11

Attributive use in which the entire A+INFINITIVAL string appears in the canonical attributive position seems to be limited to TCs and GDPs. ${ }^{12}$ Pretty predicates are not acceptable in attributive use:
a. Mary is an easy-to-please woman
b. *Mary is a pretty-to-look-at woman
c. ?Mary is a too-smart-to-fool woman

Although (45c) may sound a bit awkward, a Google search of the GDP string "the too cute to resist" had 12,100 hits, and the set of things that are too cute to resist includes, along with the expected kittens, puppies, pandas and dolls, check-in counter attendants and kids. ${ }^{13}$ There is no dispute in the literature that TCs can be used attributively, but a Google search of common expressions like "easy to assemble furniture" and "easy to use tools" demonstrates that attributive use of TCs is frequent. ${ }^{14}$

The prenominal use of TCs (and GDPs) is particularly puzzling in light of the well-known fact that complements to adjectives are generally disallowed in attributive environments in English, ${ }^{15}$ as illustrated by the examples in (46) (Nanni 1980: 573-4):

\footnotetext{
${ }^{11}$ A Google search of the string "too smart of a person to" had 14,300 hits versus 18,600 for "too smart a person to"; of "too smart of a man to" had 8,990 hits versus 17,600 for "too smart a man"; and of "too smart of a woman to" had 5,320 hits versus 9,640 for "too smart a woman to". Search performed 11 July 2017 at $16 \mathrm{~h} 43$.

${ }^{12} \mathrm{NP}+$ INFINITIVAL TCs are not acceptable in the attributive position: * Mary is a bitch-to-please woman.

${ }^{13}$ Search performed 2 September 2017.

"I don't know whose the star of this father-daughter relationship anymore...the NBA basketballer or the too-cute-to-resist Riley Curry!!" https://thewyldshop.com/blogs/blog/whos-yo-daddy

"By now I really need something to eat so we followed the suggestion of the too-cute-to-resistguy that checked us in at Enterprise and headed for the best BBQ sandwich in San Antonio" http://sisteronthego.blogspot.com.br/2013/10/

14 "easy to assemble furniture" - approximately 140,000 hits; "easy to use tools" - approximately 548,000 hits. Search performed 11 February 2018.

${ }^{15}$ The fact that complements to adjectives are disallowed in the attributive environment is well attested, but as far as I have been able to determine, there is no generally-accepted theory as to why this should be so. One line of inquiry suggests that it is the adjective that selects the noun, so that nominals modified by attributive adjectives are actually headed by A, not N. This would
} 
(46) a. The teacher was concerned about her student

b. *The concerned about her student teacher

c. Miss Grundy was hard on her students

d. *A hard on her students teacher

e. The lawyer was uncertain about her client

f. *The uncertain about her client lawyer

g. John is suspicious of his wife

h. $\quad *$ The suspicious of his wife husband

i. The tourists were eager to examine the ruins

j. $\quad *$ The eager to examine the ruins tourists

k. The boys were anxious to dance

1. *The anxious to dance boys

It is thus surprising that the infinitival in TCs, which is generally taken to be a complement to the tough element, should be grammatical in attributive use.

The intriguingly atypical behavior of TCs and GDPs is further compounded by the fact that although their infinitival is grammatical in the attributive environment, a for-phrase is not: ${ }^{1617}$

(47) a. *The shelves are part of the store's easy-for-you-to-assemble line.

b. *These are easy-for-you-to-use tools.

c. *Take a look at these too-cute-for-you-to-resist kittens

certainly explain why attributive adjectives cannot have complements. See, for example, Abney 1987, Truswell 2005. For a critique of the Adjective head hypothesis and an alternative proposal based on movement, see Radford 1989.

${ }^{16}$ In contrast to "easy to assemble shelves", "easy for you to assemble shelves" had zero hits, and "easy for you to use tools" had one hit, which was not a TC ("The REPL also imports the pipeoperators from Ammonite-Ops by default to make it easy for you to use tools like grep interactively" www.ammonite.io). Both "easy for anyone to assemble shelves" and "easy for anyone to use tools" had no hits. Google search performed 11 February 2018.

17 The grammaticality of GDPs in prenominal use is not a consistent as TCs', at least in my judgment. For example, while "a too-cute-to-resist kitten" is acceptable to me, "a cute-enough-toadopt kitten" is less so. Similarly, while "these easy-for-anyone-to-use tools" is unacceptable to me, I judge "that too-cute-for-anyone-to-resist kitten" as marginally acceptable. 
As an aside, I note that the ungrammaticality of for-phrases in prenominal TCs is a strong argument against the position that the for-phrase in TCs is a complementizer for ${ }^{18}$ If the for is a complementizer for, then it is, by definition, part of the clausal complement to the tough element in TCs (or the adjective in GDPs) and should therefore be just as acceptable in an attributive environment as a clausal complement without a for-phrase. The evidence is clear, however, that for-phrases are not grammatical in the attributive position.

In fact, as Nanni points out (1980:575), it is not just for-phrases that are disallowed: adverbs and other PPs also result in ungrammaticality, even if they might be acceptable in predicative TCs:
a. *An easy to quickly clean room
b. *A hard to find in the attic manuscript
c. *A simple to neatly sew pattern
d. *A tough to open with a knife package

Indeed, it is precisely these features of TCs that led Nanni (1980) to suggest that TCs have two derivations, one transformational and the other lexical. In Nanni's analysis, TCs in predicative use are derived transformationally by movement, in which the object of the verb in the infinitival shifts into the matrix subject position. In prenominal use, however, TCs are lexical items composed of an adjective and an infinitival and are derived by rules operating in the lexical component of the grammar. Once formed, lexically-derived TCs have no internal syntactic structure (they are "reanalyzed" as simple adjectives), and this accounts for the fact that for-phrases, other PPs and adverbs are disallowed in prenominal use.

Nanni's reanalysis approach came under criticism, particularly by Robert Levine (see Hicks 2009: 543-4), ${ }^{19}$ who pointed out that the reanalyzed adjective had no

\footnotetext{
${ }^{18}$ Most researchers take the infinitival in TCs to be clausal in nature - either a TP or a CP - and some treat the for in TC for-phrases as a complementizer for (Hartmann 2011 and Brillman 2015, for example).

19 Hicks 2009: 544; reproduced from Levine, R.D. A note on right node raising, tough constructions and reanalysis rules. Linguistic Analysis13:159-172, p. 169.
} 
internal structure and therefore could not account for configurations in which the tough complex adjective has a discontinuous spell-out. To illustrate, Nanni's contention is that in sentences like (49), easy to please behaves like a single constituent. The criticism is that sentence (50) is equally grammatical and semantically equivalent to (49), but easy to please is no longer an unbroken string.

(49) How easy to please John is

(50) How easy John is to please

Although criticism of the reanalysis approach was based on the discontinuous spell-out configuration, it seems to have passed unnoticed that TCs in discontinuous spell-out do not behave identically to attributive TCs, as the sentences in (51) and (52) show: ${ }^{20}$

(51) a. John is easy to please and friendly, too

b. John is a friendly, easy-to-please guy

c. *John is a friendly, easy guy to please

(52) a. The shelves are easy to assemble and attractive too

b. The attractive, easy-to-assemble shelves

c. *The attractive, easy shelves to assemble

What's more, TCs in discontinuous spell-out seem to be acceptable only as predicates in copular constructions, while DPs and QPs modified by attributive TCs are acceptable in other syntactic environments:

(53) a. I'm looking for a friendly, easy-to-please roommate

b. *I'm looking for a friendly, easy roommate to please

(54) a. The easy-to-assemble shelves are being delivered Wednesday

b. *The easy shelves to assemble are being delivered Wednesday

(55) a. We've got a bunch of easy-to-read books

b. We've got a bunch of easy books to read

\footnotetext{
${ }^{20}$ Although one researcher has more recently argued for its revival based on data from the Dutch (Zwart 2012).
} 
The sentences in (55) are especially intriguing because they are both grammatical - but only (55a) has a TC. In (55b), the infinitival looks much more like an infinitival relative clause rather than the infinitival component of a TC, and this distinction is more apparent in the sentences in (56):

(56) a. We've got a bunch of good-to-read books

b. We're got a bunch of good books to read

For-phrases also exhibit interesting behavior in discontinuous spell-out TCs. While they do not seem to be unacceptable, a discontinuous spell-out TC with a for-phrase does not seem to be quite equivalent to the "basic" TC with a forphrase:
a. Those are easy shelves for John to assemble
b. The shelves are easy for John to assemble
c. The Lion, The Witch, and the Wardrobe is an easy book for John to read.
d. The Lion, The Witch, and the Wardrobe is easy for John to read.

In (57b) and (57d), it seems clear that it is the action of assembling or reading that will be easy for John; in contrast, in (57a) and (57c) it is possible to interpret the infinitival as a relative clause, particularly in (57c), which could be taken to mean that The Lion, The Witch, and the Wardrobe is a book for John to read that happens to be easy.

In any event, it appears that the reanalysis approach to prenominal TCs may have been abandoned too hastily, since the data show that there are distinct differences between TCs in attributive use and TCs in discontinuous spell-out.

The fact that discontinuous spell-out is not equivalent to attributive use is highlighted by the second part of the attributive puzzle: although pretty predicates do have discontinuous spell-out, they are not acceptable in prenominal use. Where a Google search of the string "pretty flowers to smell" had 1,030,000 hits, the string "pretty to smell flowers" had 0 hits. The possibly more likely string "pretty 
flowers to look at" had 1,720,000 hits; in contrast the attributive variant "pretty to look at flowers" 193,000 hits, many with intervening punctuation (e.g. "Flowers aren't just something pretty to look at. Flowers are good for your mental health!"). ${ }^{21}$

Why pretty predicates cannot be used attributively while TCs and (some) GDPs can is not at all clear: in other words, why do pretty predicates follow the "no complements to adjectives in attributive use" rule, while TCs and GDPs do not, when their syntax is so similar, at least superficially?

\subsubsection{4.}

Some semantic differences between TCs, pretty predicates and GDPs

Although there is little to distinguish pretty predicates from TCs and GDPs, L\&F point to a semantic difference. They argue that TCs "describe an entity in terms of action on or change of state of that entity. Words like tough and a bitch describe the action" (p. 560). Put another way, "John is easy to please" is a proposition about John's "pleasability", not about his "easiness". The semantic core of the proposition seems to be in the infinitival, not in the tough element, which serves instead to specify the ease or difficulty of John's "pleasability", rather like the expressions "tough customer" (a person who is hard to deal with or to convince) and "tough sell" (something that is difficult to sell or to persuade others to accept).

L\&F's argument that the tough element describes the action in the infinitival is not universally accepted, however. Hicks (2009: 537) asserts that "it is well documented that the infinitival clause may often in fact be omitted in TCs", and gives the example in (58):

(58) a. This problem is difficult

b. This problem is difficult to solve

\footnotetext{
${ }^{21}$ Google search performed 21 May 2017.
} 
A flaw in Hicks's argument is that problems are usually categorized as difficult or easy, and this facilitates omitting the infinitival. Omitting the infinitival is not as felicitous when the subject of the sentence is not usually described in terms of difficulty or easiness:

(59) a. ?This table is difficult

b. This table is difficult to assemble

Hornstein's (2001) analysis of TCs also diverges from L\&F's assertion that the tough element qualifies the action in the infinitival. For Hornstein, the infinitival acts as a sort of "circumstantial adverb", which sets the scene for the interpretation of the matrix sentence. Sentence (60), for example, would be interpreted as “as far as one's reading Moby Dick is concerned, Moby Dick is easy" (Hornstein 2001: 111)

(60) Moby Dick is easy to read

The difficulty with the circumstantial adverb gloss is that it doesn't capture the emphasis on Moby Dick's readability rather than its easiness: one could equally well gloss sentence (61) as "As far as looking at them goes, the flowers are pretty".

(61) The flowers are pretty to look at

But in contrast to TCs, sentence (61) is a proposition about the flowers' prettiness, not about their "lookability". In pretty predicates, the infinitival serves to specify the aspect of the subject's prettiness: the flowers might be pretty to look at, but not to smell. L\&F point out that the class of adjectives and nouns that form pretty predicates "... denote a subjective evaluation; the subject evaluation is almost always that of the speaker" (p. 567) and adjectives such as rectangular and black, which establish objective criteria for evaluation, do not produce grammatical pretty predicates:

(62) a. *This room is rectangular to live in 
b. *Coal is black to look at

Perhaps the ungrammaticality of for-phrases in pretty predicates can be attributed to the fact that the class of pretty adjectives reflects a subjective evaluation of the speaker. If "the flowers are pretty to look at" is essentially a proposition about the flowers' prettiness, then the fact that Joe is the one who is looking at them should not affect how pretty they are. In contrast, in a TC like "John is easy to please", which is about John's "pleasability", Joe might have more skill at pleasing John than, say, Bill.

GDPs seem to fall closer to TCs than to pretty predicates. The main import of a sentence like "The kittens are too cute to resist" seems to be that the kittens are irresistible, and that they owe their irresistibility to their cuteness, not that they are cute in their irresistibility. Likewise, "Mary is too smart to fool" is a proposition that says at least as much about Mary's "foolability" as it does about her smartness.

\subsection{4.}

\section{More object-gap constructions - ready predicates, rare predicates, and nominal Attributives with Infinitive Constructions - and some anomalies}

Before attempting to synthesize the essential characteristics of TCs and their similarities and differences to other object gap constructions, we should look at three other types of object-gap constructions, in addition to the TCs, pretty predicates and GDPs examined by L\&F.

\subsubsection{1.}

\section{Ready predicates}

Ready predicates in particular are an intriguing group of constructions because although they have received no attention in the TC literature, ${ }^{22}$ the infinitival in ready predicates shows exactly the same characteristics seen in GDPs:

\footnotetext{
${ }^{22}$ The only reference to ready predicates in the literature on TCs seems to be a passing observation in Chomsky 1977 (p. 103) of their "optional" gap.
} 
(63) The house is ready

(64) The house is ready to buy (gapped infinitival)

(65) The house is ready for John to buy (gapped infinitival with subject forphrase)

(66) The house is ready for John to buy it ("filled" gap co-indexed with matrix subject)

(67) *The house is ready to buy it ("filled" gap without subject for-phrase)

(68) The house is ready to be shown (passivized verb)

(69) The house is ready for there to be a showing (there insertion)

Another characteristic shared by GDPs and ready predicates is that in the presence of a for-phrase, the object gap can be filled not only with a pronoun that is coreferential with the matrix subject, but also with a referring expression:

(70) The house is ready for John to buy flooring

(71) The house is too expensive for John to afford the best quality finishings: he won't have much money left after paying the purchase price

The obvious implication, of course, is that ready predicates are degree predicates, just as GDPs are, and that the infinitival serves to express the degree of readiness, in the same way that the degree word (too or enough) plus the infinitival expresses the degree of the characteristic (cleverness, softness, hardness, etc.) expressed by the adjective in GDPs. Put another way, ready inherently conveys a degree, unlike adjectives like clever or soft, which require a degree word to introduce a scale.

Like GDPs, ready predicates do not have expletive or clausal "sister" formulations. A significant difference between GDPs and ready predicates, however, is that ready predicates are not grammatical in attributive use unless they are fixed expressions such as "ready-to-wear fashion" or "ready-to-eat food" (Huddleston and Pullum 2002: 551): "The ready-to-sell house", for example, is 
not acceptable. This difference is not surprising, however, since ready in the sense of prepared, disposed, or available is not acceptable in attributive use. ${ }^{23}$

\subsubsection{2.}

\section{Rare predicates}

Rare predicates are one of two classes of object-gap constructions identified by Nicholas Fleisher (Fleisher 2015; Fleisher 2011).

Although rare and other adjectives of frequency (common, uncommon, odd, unusual) have often been judged as ungrammatical in TCs, Fleisher presents data to show that they do in fact occur (Fleisher 2015: 73):

(72) a. this kind of detuning is rare to hear in chipmusic in general

b. Today, in the PC world there are two types of discs that are common to encounter: ISO 9660/Joliet and UDF

c. Such columns of light are not uncommon to see, and a retrospective of past APODs that have featured picturesque sun pillars can be found here

d. There are soft woods, hard woods; groups of native grasses grow here that are unusual to find growing in the same vicinity

Rare predicates appear to behave much as TCs do: they have expletive correlates, and although for-phrases are not common, they are possible, as Fleisher's data show (Fleisher 2015: 75-76):

(73) a. That kind of straight-up statement is exceedingly rare for a politician to make

b. It is exceedingly rare for a politician to make that kind of straight-up statement

(74) a. [Black Sea Bass] are not uncommon to encounter these days

b. It is not uncommon to encounter Black Sea Bass these days

\footnotetext{
${ }^{23}$ ready. (n.d.) Collins English Dictionary - Complete and Unabridged, 12th Edition 2014. (1991, 1994, 1998, 2000, 2003, 2006, 2007, 2009, 2011, 2014). Retrieved 14 February 2018 from https://www.thefreedictionary.com/ready
} 
The feature of rare predicates that distinguishes them from TCs is that the matrix subject necessarily denotes a kind or class of entity rather than an individual: "that kind of straight-up statement"; "Black Sea Bass"; "groups of native grasses". Essentially, Fleisher argues that rare predicates are a type of TC, and his data supports that conclusion.

\subsubsection{3.}

\section{Attributives with Infinitive Constructions}

The second group of object-gap constructions identified by Fleisher are Attributives with Infinitive Constructions (AICs), which are also composed of an adjectival element, a nominal element, and an infinitival, with an optional forphrase (Fleisher 2011: 342):
a. Middlemarch is a long book to assign
b. Bob is a short guy for the Lakers to draft

AICs can be subdivided into two categories, nominal AICs, and "clausal" AICs, exemplified in (76) (Fleisher 2011: 343):
a. Middlemarch is a long book to assign (nominal AIC)

b. Middlemarch is a bad book to assign (clausal AIC)

According to Fleisher, nominal AICs carry an implication of unexpectedness or inappropriateness, so that "we have the sense that Middlemarch is unexpectedly or inappropriately long for the purpose at hand, i.e. for an act of assigning. The purpose in question is always expressed by the gapped infinitival clause in a nominal AIC." In this, they resemble too GDPs (Middlemarch is too long a book to assign), except that in nominal AICs the action expressed in the infinitival is assumed to occur, while a too construction negates the action in the infinitival (Fleisher 2011: 349). If a student says, for example, that Middlemarch is a long book to assign, one would be justified in thinking that the book has been assigned; 
but if that same student says Middlemarch is too long to read, one would be justified in thinking that she doesn't plan to read it.

The other defining characteristic of nominal AICs is that they are formed with "adjectives that do not independently select infinitival-clause arguments, while clausal AICs may only be formed with adjectives that are able to select such arguments. Evidence comes from a difference in the acceptability of impersonal paraphrases involving an extraposed infinitival-clause subject." (Fleisher 2011: 343). In other words, nominal AICs do not have expletive companion formulations, while clausal AICs do:

(77) a. Middlemarch is a long book to assign (nominal AIC)

b. *It is long to assign Middlemarch

c. Middlemarch is a bad book to assign (clausal AIC)

d. It is bad to assign Middlemarch

Nominal AICs are fascinating constructions, and form an illuminating contrast to both TCs and pretty predicates. In TCs and pretty predicates, one of the elements in the predicate modifies the other, so that we have a semantic core and a qualifier. If I assert that Middlemarch is long to read, then I make the assertion that Middlemarch is long, and that it is long in the reading and therefore a pretty predicate. Similarly, if I assert that Middlemarch is hard to read, then I make the assertion that it is to read, and the reading of it is hard, and therefore a TC. But if I assert that Middlemarch is long to assign, then I do not assert that it is long in any of the ways that a book is usually long (i.e. to read, to write, or to listen to) nor that it is a book to assign. I could perfectly well say that The Lion, The Witch and The Wardrobe is a long book to assign, even though I consider it to be a short book, because it would be long if it was assigned to a class of new readers.

The fact that the meaning of nominal AICs is more than the sum of their adjectival and infinitival parts is reflected in the fact that they are not grammatical without the nominal element that describes their class, while TCs and pretty predicates are: 
(78) a. Middlemarch is long to read. (pretty predicate)

b. Middlemarch is hard to read. (TC)

c. *Middlemarch is long to assign. (nominal AIC)

The intriguing aspect of Middlemarch is a long book to assign is that the length of Middlemarch is judged not in relation to the book in itself (i.e. long is not attributive), nor against the action expressed by the infinitival (i.e. assigning Middlemarch is not a lengthy activity), but in relation to an unexpressed argument of the verb assign, those to whom the book will be assigned and who will read it.

This aspect of AICs is even clearer in another of Fleisher's examples (Fleisher, 2011: 345, sentence (8a)):

(79) That is a smart sofa to buy

Fleisher classifies this sentence as a clausal AIC because the noun does not meet the selectional restrictions of smart and therefore "... the only available interpretation of the sentence is a clausal-AIC interpretation, with the adjective modifying the infinitival clause, not the noun."

A fuller understanding of the semantic relationships in (79) can be extracted, I think, from the contrast between the following two NPs:

(80) A smart phone

(81) A smart purchase

Although their syntax is superficially identical, in (80) smart is predicated of the overt nominal element phone, while in (81), smart is predicated of the purchaser, a covert element in the argument structure of the overt nominal element purchase. This, it seems to me, is precisely the same relationship that is established in (79): smart is predicated not of the noun sofa or of the infinitival to buy, but of the buyer of the sofa. 
Fleisher's AICs show that it is possible to establish predicational relationships with arguments of an infinitival without the arguments being overtly realized in the syntax, and therefore without the relationships being effectively mediated by the infinitival's verb. Even if we assume, for example, that the infinitival in AICs is a full clause and has a null PRO subject, in AICs such as "Middlemarch is a long book to assign" (sentence (75a)) the argument of assign that is involved in the predication (aside from Middlemarch itself) is the indirect object of assign those to whom the book is assigned and for whom the book is long.

It is true that in AICs like "That is a smart sofa to buy", where smart is judged against the buyer of the sofa, it could be argued that PRO is the argument involved in the predication, representing a generic buyer (assuming that to buy is a full clause). But nominal predicates like sentence (81) ("That is a smart purchase") show that a syntactic element like PRO is not necessary to implicate the agent argument in predication, since a noun's arguments do not have to be syntactically realized (or at least not in all circumstances). ${ }^{24}$

These predicational relationships involving arguments that might not be syntactically realized recall what Williams refers to as "associations" in his work on the argument structure of nouns (Williams 1985). At the core of Williams's paper is the hypothesis that while nouns have an argument structure, that structure is expressed in terms of "implicit arguments" or "argument slots", unlike verbs, whose argument structure is expressed in terms of "syntactic positions". Thus, while both nouns and verbs have an argument structure, and their arguments are "syntactically visible" (p. 300), in NPs it does not matter “... how various argument positions are syntactically realized, [or] in fact whether they are realized" (p. 302), in contrast to CPs, which require the overt realization of the verb's argument structure in certain syntactic positions.

Put another way, Williams's contention is that there are syntactic positions associated with a verb's argument structure, and if those positions are not filled by

\footnotetext{
${ }^{24}$ Williams (1985) examines the hypothesis that nominals have a controllable PRO (the NP PRO theory), but rejects it. As we will see, some researchers contend that the theme or patient argument of nouns must be overt in some circumstances (see Grimshaw 1990 and Roy and Soare 2011).
} 
an overt item, an ungrammatical gap results. Nouns can have the same argument structure as a verb, but since there are no syntactic positions associated with those arguments, no ungrammatical gap will appear if the argument is not syntactically realized. Using purchase to illustrate, sentence (82) is grammatical while sentence (83) is not, even though the noun purchase implies a purchaser and a thing purchased, just as the verb purchase does. The difference is that when inserted in a $\mathrm{CP}$, the verb purchase requires that its internal argument be overtly realized, whereas when inserted in a DP the noun purchase does not require its theme argument to be realized overtly. Nonetheless, purchase's argument structure is semantically active because we know that the purchaser is $I$, and we can reasonably ask "what did you buy?"

(82) I made a foolish purchase

(83) *I foolishly purchased

\subsubsection{4.}

\section{TC anomalies}

The last category of gapped constructions to be dealt with in this section - the anomalies - are constructions that strictly speaking are not object gap constructions at all, since the gap occurs not in the object position, but in a prepositional phrase:

(84) This mattress is too thin to sleep on (L\&F 1974: 536)

A particularly famous "anomalous" TC is (85), which Chomsky looks at in the context of wh-movement (Chomsky 1977: 105).

(85) The violin is easy to play sonatas on

As far as I am aware, the question of whether these gapped structures constitute GDPs (in the case of (84)) or TCs (in the case of (85)), and how they are derived, has not been dealt with or even mentioned in the TC literature, and I did not find 
any study that suggested that they are not TCs, despite the fact that they are not actually object gap constructions.

Sentence (85) is one of a pair of sentences that pose an interesting puzzle for whmovement, which Chomsky commented on first in "On Wh-Movement" in 1977 (pp. 105 et seq.) and then later in Lectures on Government and Binding in 1981 (pp. 310-312):

(86) a. The violin is easy to play sonatas on

b. Sonatas are easy to play on the violin

The puzzle is that although sonatas appears to be in a position susceptible to $w h$ movement, as the sentences in (87) show, wh-movement in sentence (86a) produces an unacceptable sentence (88):

a. John was told to play sonatas on his violin

b. What was John told to play on his violin

*What sonatas is this violin easy to play on

More puzzling still is the fact that while wh-movement of sonatas produces an ungrammatical sentence, wh-movement of violin out of a "peripheral" element in the infinitival does not:

(89) What violin are the sonatas easy to play on

A further element of mystery is introduced by the fact that the unacceptability of wh-movement out of peripheral infinitivals is inconsistent. Chomsky argues (1981: 310-311) that sentence (90b), like (88), is unacceptable because it represents an attempt to effect $w h$-movement out of the infinitival after movement has already taken place to form the TC:

(90) a. The books are easy to convince people to read

b. *Which people are the books are easy to convince to read 
These $w h$-island effects are expected under a null operator analysis. What is particularly mysterious is that the results of movement out of "peripheral" elements in the infinitival can range quite dramatically in acceptability (Chomsky 1981: 311):

(91) a. What violin are the sonatas easy to play on

b. ?Which table is the book easy to put on

c. *How intelligent is John possible to consider to be

Much of the difficulty in the puzzles presented in sentences (86) to (91) is that a number of factors seem to be at work, and it is not easy to determine which one (or more) of them is responsible for judgments of unacceptability. For example, the sentences in (92) (corresponding to the basic expletive formulations of (91a) and (91b)) are syntactically very similar: in both the infinitival is composed of a transitive verb, its internal argument and a locational prepositional phrase:
a. It is easy to play sonatas on the violin
b. It is easy to put the book on the table

But TCs formed from (92b), while formally identical to the TCs formed from (92a), are semantically "degraded" in the sense that they have little (if any) communicative content. If Lasnik and Fiengo (1974) are right, and TCs denote characteristics of their subject, it is difficult to see what characteristic peculiar to books might be communicated by their being easy to put on tables (aside from the fact that they are objects that do not slide off tables) or, conversely, what characteristic of a table might make it particularly appropriate to put books on (aside from the characteristic of having a horizontal surface):

(93) a. Sonatas are easy to play _ on the violin

b. The book is easy to put _ on the table

(94) a. The violin is easy to play sonatas on

b. The table is easy to put the book on 
Sentence (91c) (How intelligent is John possible to consider to be) illustrates another anomaly: expletive and clausal subject constructions that do not have TC counterparts. As the sentences in (95) show, TCs cannot be grammatically formed using possible.

(95) a. It is possible to consider John to be intelligent

b. *John is possible to consider to be intelligent

c. *John is possible to please

Possible sentences are intriguing because impossible forms grammatical TCs:

(96) a. It is impossible to please John

b. To please John is impossible

c. John is impossible to please

Possible poses a difficult problem for any theory that proposes derivation of TCs by argument movement: if the TC is simply a variant of the expletive formulation, formed by movement of the object of the verb in the infinitival to the subject position, replacing an expletive it, then any TC derived from a grammatical expletive formulation should itself be grammatical.

Other adjectives and expressions do not form TCs are those related to value judgments: Rosenbaum (1965: 188) mentions worthwhile and important, but wrong, right, and a mistake are also members of this class:

(97) a. It is wrong to kill wildlife

b. To kill wildlife is wrong

c. *Wildlife is wrong to kill

(98) a. It is right to protect wildlife

b. To protect wildlife is right

c. *Wildlife is right to protect

(99) a. It is a mistake to kill wildlife

b. To kill wildlife is a mistake

c. *Wildlife is a mistake to kill 
In addition to calling into question the assumption that TCs and their expletive "sisters" are syntactically related, these sentences provide an interesting contrast to TCs, and provide support for L\&F's analysis of the semantics of TCs: "wrong to kill" does not express any characteristic of wildlife, and although "wrong" can be said to modify the action "to kill", it does not qualify the doing of the action in the same way the tough-class words like easy and hard do.

\subsection{5.}

\section{What makes a TC tough: the essential characteristics of TCs and their similarities and differences to other object-gap constructions}

Based on the discussion in the preceding sections, I can now set out my working description of TCs:

(i) They are copula constructions.

(ii) Their superficial construction is $\mathrm{DP}+\mathrm{COPULA}+\mathrm{A} / \mathrm{NP}+$ INFINITIVAL. (For simplicity's sake I use NP to refer to nominal tough elements such as a snap, a breeze, and a bitch.)

(iii) The tough element of TCs (the AP or NP immediately preceding the infinitival) appears to qualify the action described by the verb in the infinitival, such that a proposition formed with the full tough predicate (A/NP + INFINITIVAL) does not necessarily entail the proposition whose predicate is formed only of the tough element (A/NP).

(iv) Usually - but not always - the verb in the infinitival is transitive and so selects both an internal and an external argument.

(v) If the verb in the infinitival is transitive, usually - but not always the canonical position of its internal argument is a "blocked" gap that cannot grammatically be filled with a pronoun co-referenced to the subject of the matrix sentence or with a referring expression.

(vi) If the position of the verb's internal argument is gapped, the subject of the matrix sentence is understood as having the semantic role of theme with respect to the verb in the infinitival.

(vii) In addition to "typical" $\mathrm{TC}$, in which the subject of the matrix sentence is understood as the theme of the action expressed in the infinitival, there are "atypical" TCs, in which the blocked gap 
appears in a prepositional phrase in the infinitival, and the matrix subject is understood to "fill" the gap.

(viii) In both typical and atypical TCs, the agent of the action in the verb in the infinitival (or an experiencer PP, depending on one's analysis) can (but need not) be inserted in a for-phrase immediately preceding the infinitival.

(ix) The verb of the infinitival cannot be passivized (in English) in either typical or atypical TCs.

(x) Regardless of whether they are typical or atypical, TCs have two "sister" formulations, an expletive formulation and a clausal subject formulation, constructed from the elements present in the $\mathrm{TC}$, plus $i t$ in the case of the expletive formulation.

The following table summarizes the similarities and differences in TCs, pretty predicates, GDPs, ready predicates, rare predicates, and nominal AICs. For concision's sake "GDPs" includes non-gapped too and enough phrases. "Gap in PP variant" refers to the "atypical" gapped construction, in which the gap appears not in the standard object position but in a prepositional phrase in the infinitival. 


\begin{tabular}{|c|c|c|c|c|c|c|c|c|c|}
\hline & $\begin{array}{l}\text { Co-referential } \\
\text { object gap in } \\
\text { infinitival }\end{array}$ & $\begin{array}{l}\text { Gap in } \\
\text { PP variant }\end{array}$ & For-Phrase & Attributive Use & $\begin{array}{l}\text { Discon- } \\
\text { tinuous } \\
\text { spell-out }\end{array}$ & $\begin{array}{l}\text { Passivized } \\
\text { infinitival }\end{array}$ & $\begin{array}{l}\text { Co- } \\
\text { referential } \\
\text { subject in for } \\
\text { phrase }\end{array}$ & \begin{tabular}{|l|} 
There \\
insertion
\end{tabular} & $\begin{array}{ll}\text { Filled } & \text { gap } \\
\text { under } & \text { for- } \\
\text { phrase } & \end{array}$ \\
\hline TCs & $Y$ & $Y$ & $Y$ & $Y$ & $Y$ & $N$ & $\mathrm{~N}$ & $\mathrm{~N}$ & $\mathrm{~N}$ \\
\hline Pretty & $Y$ & $Y$ & $\mathrm{~N}$ & $N$ & $Y$ & $N$ & $N$ & $\mathrm{~N}$ & $\mathrm{~N}$ \\
\hline GDPs & $Y$ & $Y$ & $Y$ & $Y$ & $Y$ & $Y$ & $Y$ & $Y$ & $Y$ \\
\hline Ready & $Y$ & $Y$ & $Y$ & $\mathrm{~N}$ & $N$ & $Y$ & $Y$ & $\mathrm{Y}$ & $Y$ \\
\hline Rare & $Y$ & No data & $Y$ & No data** & No data** & $N^{*}$ & $\mathrm{~N}^{*}$ & $\mathrm{~N}^{*}$ & $N^{*}$ \\
\hline $\begin{array}{l}\text { Nominal } \\
\text { AICS }\end{array}$ & $Y$ & No data & $Y^{*}$ & $\mathrm{~N}^{*}$ & $Y$ & $\mathrm{~N}^{*}$ & $\mathrm{~N}^{*}$ & $\mathrm{~N}^{*}$ & $\mathrm{~N}^{*}$ \\
\hline
\end{tabular}

*Personal judgment; no confirming data

** I am unable to make a personal judgment on this usage. 


\section{3 \\ Tough Construction Theories}

\section{1.}

\section{Theoretical Puzzles}

As generative grammar evolved from its Transformational roots, first into Government and Binding theory $(\mathrm{G} \& \mathrm{~B})$ and then in the Minimalist Program, research turned to the theoretical challenges that TCs and other object-gap constructions pose.

The challenges are significant, because TCs seem to defy basic tenets of generative grammar.

One of the fundamental principles in the generative tradition is that information encoded in lexical items plays a determining role in the derivation of sentences. In G\&B Theory, that premise holds at Deep Structure and is enunciated, for instance, in the Projection Principle:

Lexical structure must be represented categorically at every syntactic level .... A consequence of the projection principle is, to put it informally, that if some element is "understood" in a particular position, then it is there in syntactic representation, either as an overt category that is phonetically realized or as an empty category assigned no phonetic form .... (Chomsky 1986: 84. Emphasis in the original.)

The Projection Principle operates in tandem with Theta Theory and the Theta Criterion. Theta Theory holds that all predicates, whether verbal or not, have an argument structure (the "lexical structure" referred to by Chomsky), and that the predicate assigns thematic roles to its arguments. The thematic roles, such as agent, patient, theme, goal, source, and location, contain semantic information. The Theta Criterion ensures unicity of theta roles by stipulating that "[e]ach argument bears one and only one $\theta$-role, and each $\theta$-role is assigned to one and only one argument" (Chomsky 1981: 36). 
The problems that TCs pose for the Projection Principle and the Theta Criterion are immediately apparent. If in our prototypical TC, repeated in (100) below, John is understood as the internal argument of please, and accordingly has the $\theta$-role of theme, it must be in the position of the theme argument of please and yet it is not: it is in the position of the subject of the matrix sentence. Easy is also a predicate, and it could be argued that John is an argument of easy and therefore receives a $\theta$ role from easy. At any rate, it is impossible to contend that the John that is the theme of please is not the John that is the subject of the matrix sentence. That being the case, at the syntax/semantics interface John carries two $\theta$-roles, in violation of the Theta Criterion, and is not found in the position that should be occupied by the theme argument of please, contrary to the Projection Principle.

(100) John is easy to please

As suggested above, in (100) easy could be said to have two arguments: one is its complement, the infinitival, and one is John, the subject of the matrix sentence. It follows that easy is a two-argument predicate. The conclusion is less clear, however, when we consider the expletive formulation of John is easy to please:

(101) It is easy to please John

In (101), the thematic problems involving John do not arise, since the argument occupies the position it should as please's internal argument, and holds only one $\theta$-role, but easy seems to have lost an argument (as it were): it still has an infinitival complement, which can receive a thematic role, but the subject of the matrix sentence is $i t$, which is expletive and consequently does not receive a $\theta$ role.

GB Case theory does not offer any solutions to these mysteries. Accusative Case is assigned in a head-complement configuration that holds between a verb and its internal argument: in our case, the head-complement configuration between please and John. This means that John should have accusative Case, and indeed it does in the expletive formulation, as demonstrated by sentence (102), in which 
John is replaced by the pronoun him. Him's accusative case is morphologically marked:

(102) It is easy to please him

Replacing John in sentence (100) shows that it has nominative Case, not accusative:

(103) He is easy to please

Sentence (103) appears to show that in addition to acquiring two $\theta$-roles, failing to appear in the position it should as the theme of the verb please, and appearing as subject of the matrix sentence, John has either failed to acquire or has shed its structural accusative Case and has somehow been assigned nominative Case.

And if all the above questions where not perplexing enough, there is the challenge of explaining how John moves from the position of internal argument of please to the position of subject of the matrix sentence.

In the Minimalist Program many of the concepts of G\&B theory have been abandoned (the Projection Principle and the Theta Criterion are examples), reformulated (Case and Agree) or limited to Logical Form (Theta Theory). However, while the Minimalist Program offers a less rigid theoretical framework and new theoretical resources for analyzing syntactic dependencies, the syntax of tough constructions continues to present just as a much of a challenge as it ever did.

In this chapter we look at the main TC theories developed in the G\&B era and under the Minimalist Program and how they deal with the theoretical puzzles mentioned above. Essentially, they fall into two camps: those that rely on null operators or other null elements, and those that rely only on argument movement. We also have a quick look at some of the work researchers have done on TC-like structures in Romance languages, principally French, Spanish and Romanian, and their interest in the parallel between passive structures and TCs. 
We start the chapter with Chomsky's "On Wh-Movement” (1977). Although this work is, strictly speaking, a transformational theory, it introduces a theory of syntactic movement that is still accepted today and is used, in fact, in TC theories. Equally importantly, it marks the origin of the null operator TC theories.

\section{2.}

\section{Chomsky: Wh-movement and the Null Operator Theory}

The null operator theory has its roots in the transformational analysis of tough constructions found in Chomsky's (1977) “On Wh-Movement", his ambitious project to provide a core English grammar pared down to two transformational rules and three interpretive rules on the co-indexation of nominals (Chomsky 1977: 72):

1. [Transformational Rules:]

a. Move NP

b. Move wh-phrase

2. [Interpretive Rules:]

a. Reciprocal rule: assign to each other the feature [+anaphoric to $i]$ in a structure containing $\mathrm{NP}_{i}$

b. Bound anaphora: assign to a pronoun the feature [+anaphoric to $i]$ in a structure containing $\mathrm{NP}_{i}$, in the context [NP-Possessive $-\mathrm{N}_{x}$ ]

c. Disjoint reference: assign to a pronoun the feature [-anaphoric to $i]$ in a structure containing $\mathrm{NP}_{i}$

The rule of interest to TC studies is, of course, the "move $w h$-phrase" rule. Under Chomsky's analysis, the general rule of $w h$-movement is responsible for the formation of direct and indirect questions, relative clauses, comparative deletion, topicalization, clefting, object-deletion and tough movement rules, and rules for adjective and adjective-qualifier complements (Chomsky 1977: 110), providing a unified explanation for these various phenomena.

The basic rule of $w h$-movement is "move wh-phrase into COMP" (Chomsky 1977: 85). This rule, together with the rules on deletion when $w h$-phrases co-occur with the complementizers that and for, is taken to be responsible for the formation of TCs. Thus, in Chomky's analysis, TCs, such as the classic (104), have the 
structure sketched out in (105) and (106). The subject $X$ is generated in its surface position, but $Y$ is a variable that undergoes $w h$-movement to COMP (105).

(104) John is easy (for us) [to please]

(105) $\mathrm{X}$ is easy (for us) [ $\mathrm{s}^{\prime}$ for PRO to please $\left.\mathrm{Y}\right]$

(106) John is easy (for us) [s:[who for] PRO to please t]

The structure underlying (104) is thus (106), where who (the variable Y in (105)) is interpreted as being about the subject John under predication abstraction. In effect, then, TCs have essentially the same structure as relative clauses, and Chomsky makes this explicit at p. 104 (endnotes in the original omitted):

Thus following our analysis, (121) [John is easy (for us) [to please]] is analogous to (128), and in such cases, we may have the full $w h$-phrase, as in (129):

John is an easy person to please

a. $\quad$ this is an easy violin on which to play sonatas

b. $\quad$ this is a pleasant room in which to work

Whatever the correct analysis of these structures may be, it seems clear that they involve, at some level, a phrase such as (130), as an adjectival modifier:

$$
\begin{aligned}
& \text { a. easy - on which to play sonatas (violin) } \\
& \text { b. pleasant - in which to work (room) }
\end{aligned}
$$

Our analysis simply assumes that the same is true quite generally of easycomplements. In the case of (130), the structures are embedded (presumably, in some manner, as relatives) within an NP with a head; in the case of (121), there is no NP antecedent and the structure must be interpreted as an open sentence, as in topicalization and other examples discussed above. .... (Italics in the original.)

In his subsequent writing, Chomsky fleshes out the wh-movement analysis, reformulating it in accordance with developing G\&B theory, but it does not change in any substantive way. In Knowledge of Language: Its Nature, Origin and Use (Chomksy 1986), he reviews the wh-movement theory in the context of a gapped degree construction (John is too stubborn to talk to; Chomsky 1986: 108 et seq.); by this time the element inserted in the object position of the embedded clause is referred to as an "empty operator". We find a reprise of this discussion in The Minimalist Program (Chomsky 1995: 51-2), and the $\theta$-role problem observed in TCs (which we will examine below) is given as one of the reasons for 
questioning and ultimately discarding the deep-structure/surface structure posited in the Government and Binding framework (Chomsky 1995: 172). The final form of Chomsky's null operator analysis is illustrated in (107) below:

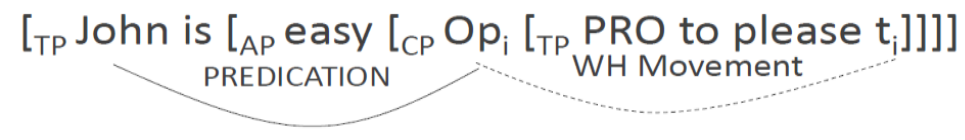

Over the course of his work (Chomsky 1977; 1981; 1986; 1995), Chomsky points out and discusses some of the theoretical challenges that TCs present.

\subsection{1.}

\section{The double for-phrase problem}

One is the double for-phrase problem, discussed in Chomsky 1977 (p. 103). He notes that double for-phrase structures like (108a) do not produce grammatical TCs, even though $w h$-movement could apply, at least in principle ((108b)):
(108) a. it is a waste of time for us [for them to teach us Latin]
b. *Latin is a waste of time for us [for them to teach us]

Chomsky hypothesizes that this effect is produced by a base-stipulated condition to the effect that when there is a for-phrase in the matrix clause of a TC, the subject of the embedded clause must be PRO. The logical consequence of stipulating that PRO is the agent of the embedded clause is that the remaining forphrase is not the agent of the action expressed by the embedded verb, and so must be an experiencer for-phrase. The difficulty with this analysis is that it doesn't seem to reflect how the for-phrase is interpreted. For example, if we replace the subject for-phrase in (108b) with PRO, we get the following sentence:

(109) Latin is a waste of time for us [PRO to teach us]

Sentence (109) doesn't make very much sense, precisely because it seems like we are teaching ourselves. But even if we switch the for-phrases in (108a) around and 
then perform the PRO substitution, we still understand them as doing the teaching, although the teachers of Latin might also be the experiencers of the waste of time:

(110) a. it is a waste of time for them [for us to teach us Latin]

b. Latin is a waste of time for them [PRO to teach us]

There is, however, another potential explanation for the ungrammaticality of (108b). Chomsky's analysis reflects the assumption that the it in (108a) is a true expletive it, without any semantic or syntactic link to the "complement" infinitival. The it, however, could be (and in fact is under Rosenbaum's (1965) analysis) an extraposition it, which can be replaced by the infinitival to produce a sentence that is not only grammatical but semantically equivalent to the expletive formulation:

(111) [for them to teach us Latin] is a waste of time for us

Heycock (2013: 329) observes that the characterization of extraposition it as a true neoplastic is not universal, and that some researchers argue that it has referential content. ${ }^{25}$ Certainly, from a logical point of view, it seems fairly clear that for them to teach us Latin is the semantic subject of the predicate is a waste of time for us, and the same is true even if the for-phrases are dropped:

(112) a. it is a waste of time [to teach us Latin]

b. [To teach us Latin] is a waste of time

If the it in (108a) is an extraposition it with at least a semantic link to the infinitival clause, then we have a straightforward explanation for the

25 Reeves (2010) refers to Chomsky's observation (1981:323) that the it in weather predicates appears to control PRO (sentence a), and to Bennis's (1986) observation of the same control phenomenon in Dutch in extraposed that clauses (which English mimics - sentence b):

a. $\quad \mathrm{It}_{\mathrm{i}}$ sometimes rains [after $\mathrm{PRO}_{\mathrm{i}}$ snowing].

b. $\quad \mathrm{It}_{\mathrm{i}}$ was clear [after $\mathrm{PRO}_{\mathrm{i}}$ having been explained to us] that we were wrong.

In fairness, these arguments do not apply in a straightforward manner to the it in the "expletive" formulation of TCs. 
ungrammaticality of (108b): the matrix predicate already has a subject, making the insertion of a second subject, Latin, ungrammatical.

The implication of this analysis is, of course, that the "expletive" formulation of TCs is not the derivational source of TCs, contrary to Rosenbaum's (1965) assumptions. Another implication is that the apparent lack of an expletive formulation for pretty predicates, GDPs and ready predicates pointed out by Lasnik and Fiengo (1974) is not a lack at all: in fact, none of the object-gap family of constructions have syntactic expletive and clausal correlates.

Although evidence from other languages must be treated with care, it is interesting to note that French also appears to have an extraposition it (an extraposition $i l$, actually) in the "expletive" companion construction to TCs (examples taken from Guérin 2006: 3):
(113)
a. Il est difficile de lire Moby Dick
it is difficult of read.INF Moby Dick
'Moby Dick is difficult to read'
b. De lire Moby Dick est difficile of read.INF Moby Dick is difficult 'To read Moby Dick is difficult'

Curiously, however, in the TC (or TC-like) construction related to the sentences in (113) the infinitival is preceded by the proposition $a$ rather than the preposition $d e$ :

\section{(114) Moby Dick est difficile à lire Moby Dick is difficult to read.INF}

The same sort of effect can be observed in Brazilian Portuguese (BP), which is a pro drop language, although in BP, there is no preposition in the "expletive" formulation, and the preposition that appears in the TC-like construction is $d e$ : 
(115) a. É difícil ler Moby Dick ${ }^{26}$

is difficult read.INF Moby Dick

'It's difficult to read Moby Dick'

b. Ler Moby Dick é difícil

read.INF Moby Dick is difficult

'To read/reading Moby Dick is difficult'

c. Moby Dick é difícil de ler

Moby Dick is difficult of read.INF

'Moby Dick is difficult to read'

As we will see, Romance languages do not allow insertion of for-phrases in TClike constructions, so it is not possible to replicate the double for-phrase in the sentences in (108). Nonetheless, the fact that both French and BP display extraposition it effects and that the corresponding TC-like construction is marked by insertion of a preposition (BP) or a different preposition (French) is at least consistent with the hypothesis that the $\mathrm{TC}$ is not syntactically related to the "expletive" and clausal formulations.

Sentence (108b) has more diagnostic information to offer. Although it is not grammatical, it can be made acceptable by removing one or both of the forphrases:

${ }^{26}$ É difícil de ler Moby Dick, with the preposition de inserted between difícil and ler is also acceptable. This seems to be a true expletive formulation, because *De ler Moby Dick é difícil is ungrammatical, in contrast to the variant without $d e$, which follows the extraposition it pattern. The distinction is easier to see when the object of the verb in the infinitival (and subject of the TC) is plural, because the copula and the adjective inflect for number.

(i) a. É difícil de ler os livros de Melville is difficult of read.INF the books of Melville

b. $\quad$ *De ler os livros de Melville é difícil of read.INF the books of Melville is difficult

c. É difícil ler os livros de Melville is difficult read.INF the books of Melville

d. Ler os livros de Melville é difícil read.INF the books of Melville is difficult

e. Os livros de Melville são difíceis de ler

the books of Melville are difficult of read.INF

f. $\quad *$ Os livros de Melville são difíceis ler the books of Melville are difficult read.INF 
(116) a. Latin is a waste of time for us to teach

b. Latin is a waste of time for them to teach

c. Latin is a waste of time to teach

As we observed above, (116) shows that removing one of the for-phrases forces the remaining for-phrase to be read as the agent of the action expressed by the verb in embedded clause (that is, the teacher of Latin) rather than as the experiencer of wasted time.

Contrary to Chomsky's (1977) hypothesis that the subject of the infinitival must be PRO, Bruening (2014) takes this effect to be evidence that the for-phrase in TCs is a complementizer for, and suggests that the source of ungrammaticality in (108b) is the experiencer for-phrase, an hypothesis that and Keine and Poole (2017) share. Bruening observes that in fact prepositional phrases cannot grammatically be inserted between the tough element and the infinitival (which includes the for complementizer and subject) in either English or French and proposes the generalization that "no PP can occur between the tough-predicate and the nonfinite clause when tough-movement takes place" (Bruening 2014: 709).

The restriction on insertion of elements between the tough element and infinitival seems to be broader in scope: as we saw in section 2.2.3.3, even adverbs like quickly, which can be acceptable if inserted in the infinitival, are disallowed if inserted between the tough element and the infinitival:

(117) *Latin is hard quickly to teach

(118) Latin is hard to teach quickly

The difficulty with the complementizer for-phrase analysis is that if the for-phrase is part of a clausal complement to the TC adjective, for-phrases should be grammatical in attributive use, as discussed in section 2.2.3.3 above. Regardless of the theoretical issues, the data shows that there are restrictions on the insertion of material between the tough element and the infinitival, and it is undeniable that only one for-phrase is allowed. It seems, then, that there may be a linear 
adjacency requirement in TCs, even if they cannot be said to form a lexical unit, as Nanni (1980) proposed.

Another double for-phrase discussed in Chomsky 1977 (p. 103) offers further support for the extraposition it hypothesis:

(119) It is pleasant for the rich for the poor to do the hard work

This sentence has an interesting contribution to make to our investigation of TCs because of the semantic mismatch between what appears to be an "expletive" formulation of a TC and a TC constructed of its elements. If we form a TC from the adjective and the infinitival in sentence (119), we obtain sentence (120):

(120) The hard work is pleasant to do.

This proposition is very different from the assertion that it is pleasant for the rich for the poor to do the hard work. In fact, sentence (119) says nothing about the hard work itself, which may or may not be pleasant to do. If we add the agents of the work to sentence (120), we obtain sentence (121):

(121) The hard work is pleasant for the poor to do

It seems clear here that the speaker believes that the hard work is such that the poor will find the doing of it pleasant. When we revert to the expletive and clausal formulations of our TC (sentences (122a) and (122b)), however, we see a distinct change in meaning unless for the poor is clearly the experiencer of pleasant: the work has ceased being pleasant in itself and instead it is the fact that the poor do the work that the speaker considers pleasant, in contrast to (122c), which asserts that the poor find doing hard work to be pleasant:

(122) a. It is pleasant for the poor to do the hard work

b. For the poor to do the hard work is pleasant

c. To do the hard work is pleasant for the poor 
This raises a perplexing question: if the expletive formulation of TCs and TCs themselves are syntactically related, how can they differ so radically semantically? The extraposition it hypothesis offers an explanation: if it in sentence (119) is syntactically (or semantically, or both) linked to the extraposed infinitival for the poor to do the hard work, then sentences (120) and (121) are not derived from or syntactically related to sentence (119), and thus the semantic mismatch is entirely unremarkable.

\subsection{2.}

\section{Sonatas and violins: wh-movement conundrums, the theta-role problem and the reanalysis proposal}

Chomksy (1977) discusses another problem, which we looked at briefly in section 2.2.4.4 above: the sonatas and the violins. To quote the author himself (Chomsky 1977: 105):

There is a well-known puzzle concerning the application of whmovement to the sentences (133):

(133) a. the sonata is easy to play on this violin

b. the violin is easy to play sonatas on

Consider first (b). The phrase sonatas appears to be in a position susceptible to $w h$-movement; compare (134):

(134) a. John was told to play sonatas on his violin

b. what was John told to play on his violin

But in (133b), wh-movement is impossible. We cannot have (135):

(135) a. *what sonatas is this violin easy to play on

b. $\quad$ *the sonatas that this violin is easy to play on - are in your book

Chomsky hypothesizes that the explanation for the contrast between his (134) and (135) can be found in the fact that because of the wh-movement that occurred to form the sentences in (133), wh-islands were formed, and it is the attempt to extract NPs out of the $w h$-island that accounts for the ungrammaticality. The puzzle comes from the fact that while wh-movement out of $133(\mathrm{~b})$ is unsuccessful, it is possible from 133(a). For ease of reference, Chomsky's 
sentences 133(a) and (b) are reproduced below, with the attempts at whmovement:

a. The sonata is easy to play on this violin

b. [what violin $]_{1}$ is the sonata easy to play on $t_{1}$

a. The violin is easy to play the sonata on

b. *[what sonata $]_{1}$ is the violin easy to play $t_{1}$ on

Chomsky conjectures that the reason for the contrast is that the two sentences have a different underlying structure, and that on this violin in (123a) is a prepositional phrase associated with the verb phrase rather than the adjective phrase as a whole and therefore it is not within the wh-island. Indeed, on this violin does look very much like a PP adjunct, as it can easily be dropped and is a candidate for $w h$-movement.

Chomsky returns to the sonata and violin conundrum and other problems raised by TCs in Lectures on Government and Binding (1981). He proposes that TCs have the deep structure shown in (125a), and that PRO undergoes wh-movement to COMP, resulting in the surface structure in (125b) (p. 309):

\section{(125) a. John is [AP easy [s COMP [s PRO to please PRO]]] b. John is [AP easy $\left[\mathrm{s}^{\prime} \mathrm{PRO}_{1}\left[\mathrm{~s} \mathrm{PRO}\right.\right.$ to please $\left.\left.\left.\mathrm{t}_{1}\right]\right]\right]$}

The embedded subject PRO is arbitrary in reference; the embedded object PRO is coindexed with John in the matrix position, and leaves a trace, which shares the same index. The trace is a variable, since it is $\bar{A}$-bound.

The difficulty with this structure, Chomsky points out, is that it generates a paradox of theta theory because $\theta$-roles cannot be appropriately assigned: if the null operator (called PRO in Chomsky 1981) holds the object position in the embedded clause, the verb in the infinitival cannot discharge its $\theta$-role to the matrix subject; if the matrix subject is inserted in situ in the surface structure, then it is not present at deep structure and theoretically, at least, should not receive a $\theta$ - 
role. And, of course, tough predicates have the expletive formulation (It is easy to please John), in which the subject (in Chomsky's analysis) is not a $\theta$-position. Chomsky suggests, then, that one way around this conundrum is to suppose that tough predicates have a dual lexical entry, one that has a clausal complement but no movement within that complement, and that does not assign a $\theta$-role, and one that has a clausal complement with movement, and that does assign a $\theta$-role (Chomsky 1981: 310).

Another potential approach to the $\theta$-role problem is reanalysis of the TC $A+I N F I N I T I V A L$ string as a complex adjective, leaving the trace $t_{i}$ in (125b) outside the embedded clause, where it is no longer a variable but an anaphor (Chomsky 1981: 312):

An approach to this complex of problems that might be explored is one based on the assumption that the adjective-complement phrase in (1) is subject to reanalysis, with easy-to-please (etc.) taken as a complex adjective. Thus (3ii) becomes (19):

(19) John is $\left[\mathrm{AP}_{\mathrm{A}}[\mathrm{A}\right.$ easy to please $\left.] \mathrm{t}_{i}\right]$

Compare "how easy to please" is John. The trace $t_{i}$, no longer A'-bound, is not a variable but rather an anaphor after reanalysis; it also lacks Case. If it is co-indexed with John, as is an option under the free indexing convention, the sentence is grammatical.

The reanalysis approach resolves the dual lexical representation problem, because the trace is now in a $\theta$-position,

... so we may assume that it transmits its $\theta$-role to its antecedent in the usual way. Therefore, we need no longer assume that the matrix subject position is at $\theta$-position. Correspondingly, there is no need for a dual lexical representation. Adjectives of the easy-category never assign a $\theta$ role to their matrix subject when they have clausal complements; the matrix subject assumes the role of its coindexed trace, exactly as in the case of movement.

The reanalysis proposal does resolve the sonata and violin conundrum: sentence (124b) (*what sonatas is the violin easy to play on) is highly unacceptable because it is the result of attempting to extract sonatas from the reanalyzed complex adjective easy to play sonatas on. In contrast, (123b) (what violin is the sonatas easy to play on) is acceptable because wh-extraction operates from a "peripheral element" (the PP adjunct on the violin), not from the reanalyzed complex adjective easy to play. 
Chomsky's (1981) reanalysis proposal is reminiscent of Nanni's (1980), and, like Nanni's, while it solves some problems, it creates others. On the empirical front, one of the most challenging would be how to deal with for-phrases, which presumably would end up inside the reanalyzed complex adjective.

On the theoretical front, Lasnik and Uriagereka (1988) point out that while the transmission of the $\theta$-role from the anaphoric trace to the matrix subject might work for simple subjects like John, the subject of TCs can be complex, with its own thematic relations:

(126) The man who came into the store yesterday was easy to please

In the end, the contradictions generated by TCs are one of the reasons that Chomsky (1995) gives in The Minimalist Program for abandoning the deep structure/surface structure thesis. His reasoning is that the expletive formulation of TCs shows that the subject position in the matrix sentence is not a $\theta$-position. Since the null operator is inserted in the object position in the embedded infinitival clause, and is assigned a $\theta$-role by the infinitival's verb, it is only after the null operator has moved to spec-C that the matrix subject will receive its $\theta$ role by predication; this, in turn, means that the matrix subject is not present in a $\theta$-position at deep structure, contrary to $G \& B$ principles, under which all arguments must be present in a $\theta$-position at deep structure. Even relaxing the deep structure rules so that the matrix subject receives its $\theta$-role at $\mathrm{LF}$, as proposed in Chomsky (1981), does not resolve the problem because the subject itself can contain an embedded open predicate:

(127) A man who is easy to please is easy to convince. 


\section{3.}

\section{Variations on the null operator theory}

\subsection{1. \\ Rezac and Ā-Agree}

Rezac (2006) develops a variation of the null operator analysis, although in his proposal, the object position of the verb in the infinitival is occupied by the null pronoun pro rather than a null operator, and the embedded object position is linked to the matrix subject by what he refers to as $\bar{A}$-Agree rather than whmovement. A schema of Rezac's proposal is shown in (128):

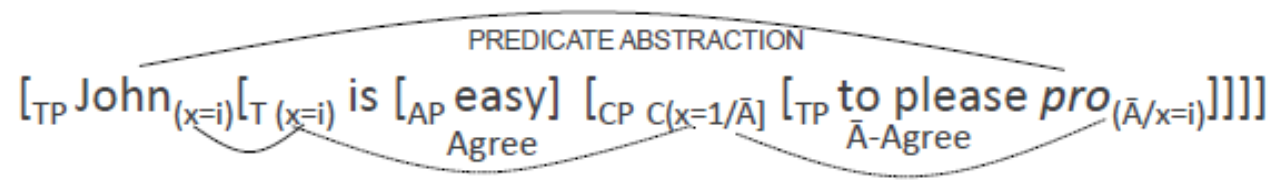

Essentially, Rezac postulates that the index $i$ is a $\varphi$-feature, and that the matrix subject is inserted in its surface position, which is non-thematic. The matrix $\mathrm{T}$ has an unvalued index $\varphi$-feature which probes for a valued index $\varphi$ feature. If it does not encounter a complementizer with $\varphi$-features $(\mathrm{C} \varphi)$, it will continue to probe (via $\bar{A}$-Agree) into the next layers, where it finds a valued index feature on pro, a null pronoun inserted in the thematic object position of the embedded clause. The valuing of the index $\varphi$-feature on $\mathrm{T}$ triggers predicate abstraction, forming a derived open predicate, which is then predicated of the non-thematic subject in the matrix clause, allowing it to be interpreted.

The expletive formulation is derived when the unvalued index $\varphi$-feature on the matrix $\mathrm{T}$ encounters a complementizer with valued $\varphi$-features and a referring expression is inserted as the object of the infinitival's verb.

Rezac's analysis addresses the $\theta$-role problem in TCs by inserting the matrix subject in a non-thematic position (i.e. it does not receive a $\theta$-role from the tough element), and transmitting the subject's thematic role to it via Agree from the null pronoun inserted in the object position of the verb's infinitival, thus avoiding any 
potential Principle $\mathrm{C}$ violations resulting from co-indexation of the subject of the matrix clause with the object of the embedded clause.

The price that his analysis pays is high, however: it posits that indexation is a grammatical feature, and, more importantly, it relies on the insertion of a null pronoun in the object position of the infinitival's verb, even though English is generally held not to be a null pronoun language. He thus dispenses with the null operator, but has to assume that pro is available in the lexicon of English speakers.

\section{4.}

Argument movement analyses: $\mathbf{A}-\overline{\mathrm{A}}-\mathrm{A}$

\subsection{1.}

\section{Hornstein's sideward movement theory}

Hornstein's (2001) theory on the derivation of TCs dispenses with the null operator proposed by Chomsky $(1977 ; 1981 ; 1986 ; 1995)$ and instead postulates cyclical wh-movement of the matrix subject itself, out of the infinitival and into the subject position of the matrix sentence, as illustrated in (130). Hornstein uses the sentence in (129) to illustrate his analysis, so I reproduce it here:

(129) Moby Dick is easy to read

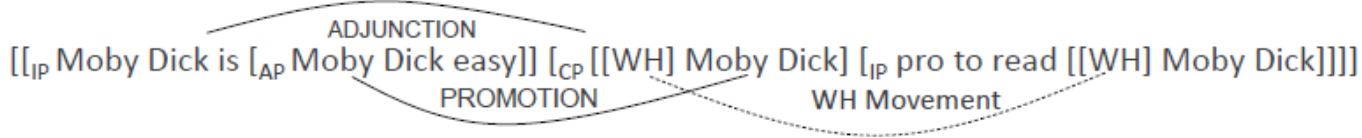

In Hornstein's analysis, the infinitival component of TCs is derived first. Moby Dick has a $w h$-feature attached to it, so that after it is merged with the verb and the non-finite IP is formed, Moby Dick (carrying the $\theta$-role transmitted by the verb) moves to spec-CP by virtue of the $w h$-feature. From the spec-CP site, Moby Dick moves "sideward" out of the adjunct, by "promotion" (the same process that forms relative clauses), into the $\theta$-position associated with easy. After merging with easy and receiving the second $\theta$-role, Moby Dick moves up to spec-IP/TP to check Case. The CP that Moby Dick moved out of is then adjoined to the matrix 
IP/TP, and since the only copy of Moby Dick that has all its features checked is in the spec-IP/TP position, all other copies delete for spell-out.

As can be seen from Moby Dick's accumulation of $\theta$-roles (one assigned by read in the infinitival and the other by easy in the matrix), Hornstein relies on the relaxed $\theta$-criterion proposed by Brody (1993). ${ }^{27}$

He also relies on a number of assumptions, which he makes explicit. Two of the most important are that the tough element (easy in (129)) assigns a $\theta$-role and that the infinitival is an adjunct to the matrix IP/TP. This configuration allows Hornstein's analysis of TCs to avoid the Principle C violations that cause A $-\bar{A}-$ A movement to be improper (since argument movement from one clause into another will result in a referring expression being bound in its domain). Essentially, because the argument (Moby Dick) moves out of an adjunct into a $\theta$ position (via "promotion", the sideward movement of arguments that forms relative clauses), the copies it left behind in the adjunct clause can be deleted, so no referring expression is left to be bound in the adjunct clause, thus bleeding Principle C. This is quite different from movement out of a complement clause, because the moved argument does not move into a $\theta$-position in the matrix. The copies left behind in the complement clause cannot be deleted, causing a referring expression to be bound in its domain.

Hornstein argues that another of the benefits of this configuration is that it can shed some light on the sonatas and violins problem, repeated in (131) to (133) below (where a blank indicates the object gap and wh indicates the site of $w h$ extraction) and discussed in section 3.2.2 above:

It is easy to play the sonata on the violin

a. The violin is easy to play the sonata on

\footnotetext{
${ }^{27}$ Brody argues that more than one argument can be associated with a single $\theta$-role, or, conversely, that more than one $\theta$-role can be associated with a single argument, as long as the requirement of full interpretability is met at LF. Interestingly, unlike Hornstein, whose analysis gives the TC argument two $\theta$-roles, Brody analyzes TCs as having more arguments than $\theta$-roles - the arguments being the null operator and the matrix subject and the $\theta$-role being the one assigned by the verb in the infinitival.
} 
b. *What sonata is the violin easy to play $w h$ on

a. The sonata is easy to play on the violin

b. ?What violin is the sonata easy to play _ on wh

Because the infinitival is an adjunct to the matrix IP, in Hornstein's analysis sonata is located behind a double barrier: the wh-island effect created by movement of the violin out of the infinitival and the barrier created by the IP/TP adjunct. It is this double barrier that gives (132b) the strong ungrammaticality "redolent of the effects one finds in complex noun phrase violations rather than WH island configurations" (Hornstein 2001: 109). ${ }^{28}$

Hornstein's proposal is not without difficulties, however. His analysis relies, as do all the others we have seen, on the premise that the it in the "expletive" formulation is truly expletive, but that is not necessarily a sound premise, again for the reasons pointed out by L\&F (1974) and discussed in section 3.2.1.

The sideward-movement-from-adjunct theory might be said to be more streamlined than the null operator theory, since it dispenses with the null operator, but in order to do so, it attaches a "relative" wh-feature (i.e. the type of $w h$-feature found in relative clauses) directly to a referring expression. Thus, in a certain sense, Hornstein's analysis includes part of the operator analysis, dispensing only with the LF process of co-indexation.

\subsection{2.}

\section{Obata and Epstein's feature-splitting analysis}

Obata and Epstein (2008, 2011) build on Chomsky's (2007, 2008) $\varphi$-featureinheritance system $^{29}$ to develop a feature-splitting analysis of improper movement, of which TCs are one variety. Given the premise that the head of the

\footnotetext{
${ }^{28}$ Although this analysis provides an explanation for the strong ungrammaticality of (132b), it does not explain the weak ungrammaticality of sentence (133b), since what violin would also presumably encounter at least two barriers to movement.

${ }^{29}$ Chomsky, N. 2007. Approaching UG from below. In Interfaces + recursion = language? ed. U. Sauerland \& H.-M. Gärtner, 1-29. New York: Mouton de Gruyter.

Chomsky, N. 2008. On phases. In Foundational issues in linguistic theory: Essays in honor of Jean-Roger Vergnaud, ed. R. Freidin, C.P. Otero \& M.L. Zubizarreta, 133-166. Cambridge, MA: MIT Press.
} 
Tense phrase does not have features of its own but rather "inherits" them when the Complementizer is merged into the derivation, and that likewise the Verb phrase head inherits features from the light $\mathrm{v}$ phrase head when it is merged, Obata and Epstein suggest that improper movement can be accounted for by "splitting" grammatical features between $\mathrm{C} \& \mathrm{~T}$ and $\mathrm{v} \& \mathrm{~V}$ in various configurations. Their analysis also relies on the premise that the null Case feature that can be found in $\mathrm{C} / \mathrm{T}$ (which accounts for null Case on PRO), can also arise in v/V.

In their 2008 paper, the authors sketch out a possible derivation for TCs like the classic John is easy to please based on the null Case feature in v/V. To put it very simply, when the infinitival component of a TC is being derived, Case (the null Case feature [uCase]) is split off from v and is inherited by V, where it Agrees with the Case feature on John in the object position of the infinitival's verb, assigning null Case. John's other features ( $\varphi$ features and the Operator feature) are attracted by the Edge Feature on v, while John's valued Case feature is sent off to the interfaces with V. Presumably, the Operator feature on John then moves it to spec-C, where its $\varphi$ features are available to enter into Agree with the $\varphi$ features on T, revising John's Case to nominative and moving John into spec-T.

Although Obata and Epstein's proposal is not fully worked out, a few problems are immediately apparent. One is whether it can plausibly be argued that null Case is a feature carried by v/V. The other is how Case on John can be revised if its Case feature has been sent to the interfaces and is no longer available for operation.

\subsection{3.}

\section{Hartman and the defective intervention argument}

Hartman (2011) lends support to the $\mathrm{A}-\overline{\mathrm{A}}-\mathrm{A}$ theory by arguing that tough constructions show defective intervention effects, which are evidence of argument movement. He points out that defective intervention effects are observed in French and Italian tough-like constructions (Hartman 2011: 390-1), and that these effects are entirely expected if the sentences in (134b) and (135b) are formed by 
movement of cette couleur and questi colori from the position of the embedded verb's object to the position of matrix subject:

(134) a. Il est difficile (pour les chiens) de voir cette couleur. it is difficult (for the dogs) of see.INF this color 'It is difficult (for dogs) to see this color'

b. Cette couleur est difficile (*pour les chiens) à voir. this color is difficult (*for the dogs) to see.INF 'This color is difficult (for dogs) to see'

(135) a. È difficile (per i cani) vedere questi colori. is difficult (for the dogs) see.INF these colors 'It is difficult (for dogs) to see these colors'

b. Questi colori sono difficili (*per i cani) da vedere. these colors are difficult (*for the dogs) of see.INF 'These colors are difficult (for dogs) to see'

Hartman contends that for-phrases in English TCs do not generate defective intervention effects because they introduce the subject of the embedded infinitival under a complementizer for, which heads a non-finite CP. When the for-phrase is substituted by an experiencer PP headed by another preposition such as on, the expected defective intervention effects are produced:

(136) a. It was very hard (on me) to give up sugar

b. Sugar was very hard (*on me) to give up

However, as Bruening (2014) and Keine and Poole (2017) point out, the defective intervention or blocking effect attributed to the experiencer PP is obtained whenever a phrase (any phrase) intervenes between the AP and the infinitival, as discussed in sections 2.2.3.2.3 and 3.2.1. and illustrated in (137) and (138) below. Accordingly, we cannot conclude that the ungrammaticality of Hartman's "disambiguated" TCs is necessarily the result of defective intervention. 
(137) Cette couleur est difficile (*aujourd'hui) à voir.

this color is difficult (*today) to see.INF

'This color is difficult (*today) to see'

(138) Questi colori sono difficili (*oggi) da vedere.

these colors are difficult (*today) of see.INF

'These colors are difficult (*today) to see'

Hartman's conclusion that the for-phrase in TCs is a complementizer for can also be questioned, as the evidence from attributive use of TCs shows (see section 2.2.3.3). If the for-phrase is part of the non-finite complement clause, it should be acceptable in attributive use.

Another difficulty is that Hartman's sentences do not all contain tough class adjectives. One of the distinguishing characteristics of TCs is that the tough element describes the action in the infinitival (L\&F 1974), so that the complex A+INFINITIVAL does not entail the simple AP, unlike pretty predicates in which the adjective clearly relates to the matrix subject, not the infinitival. On this criterion, many of Hartman's "disambiguated" examples (Hartman 2011: 4) seem to be pretty predicates, not TCs, since the adjective modifies the matrix subject, not the action in the infinitival. In fact, L\&F (1974) distinguish tough on predicates from tough for formulations, and the difference between the two is quite apparent in sentence (139a) (Hartman's 9(c)):

(139) a. It was tough on me to lose my wife

b. It was tough for me to lose my wife

c. It was tough to lose my wife

d. My wife was tough for me to lose

Sentences (139a) and (139d) are particularly interesting examples because they demonstrate very clearly the difference between an experiencer PP + clausal subject versus a canonical TC formulation. Clearly the proposition in (139a), (139b), and (139c) concerns the emotional suffering of the speaker following his wife's death, not the difficulty of losing his wife in, say, a crowd (139d). 


\subsection{4.}

\section{Hendrick and the smuggling approach}

Hendrick (2013) offers a somewhat different analysis of TCs. He adapts Collins' smuggling approach ${ }^{30}$ to suggest that in the derivation of TCs, after the head of the VP in the infinitival has moved to the head of vP, the VP raises to spec-C, carrying with it the object of the embedded clause. Because the embedded CP is a complete proposition semantically, once the VP to spec-C movement has occurred, the CP constitutes a phase and is sent off to the PF interface, leaving the embedded object on the leftward edge of the phase, allowing it to "escape" through the AP.

\subsection{5.}

\section{Brillman: Comparing GDPs and TCs}

Brillman (2015) ${ }^{31}$ takes a comparative look at TCs and GDPs, and concludes that while both constructions involve improper movement $(A-\bar{A}-A)$, TCs involve argument movement only, with the internal argument of the embedded clause moving up into the matrix clause to occupy the subject position. GDPs, in contrast, rely on internal null operator movement to form the GDP. She adopts Hartman's (2011) model for her analysis of TCs; for GDPs, she argues that the gapped infinitival is a CP complement to a Degree head. The Degree head, like T, has $\varphi$-features that Agree with $\varphi$-features on the null operator inserted in the object position of the verb in the infinitival, triggering movement of the operator to specDeg; the link between the operator and the matrix subject is semantic. Another crucial difference between TCs and GDPs is that while TCs do not assign a $\theta$-role to the matrix subject, GDPs do. The fact that the matrix subject in TCs is not a $\theta$-position accounts for the fact that TCs have an expletive formulation (unlike GDPs) and for the movement of the argument in the embedded object position to the matrix subject position. Brillman's analyses are illustrated below (figures from Brillman 2015: 3).

\footnotetext{
${ }^{30}$ Collins, C. 2005. A Smuggling Approach to the Passive in English. Syntax 8:81-120.

${ }^{31}$ Brillman (2017) also deals with TCs and GDPs, but her focus is on subject raising and antilocality constraints in the two constructions. She uses the argument-movement model for TCs in her dissertation, but does not take a position as to whether the argument-movement model is better than the null object model, noting only that each has its advantages and drawbacks.
} 
(140)

(3) Ian is tough for Anneke to talk to.

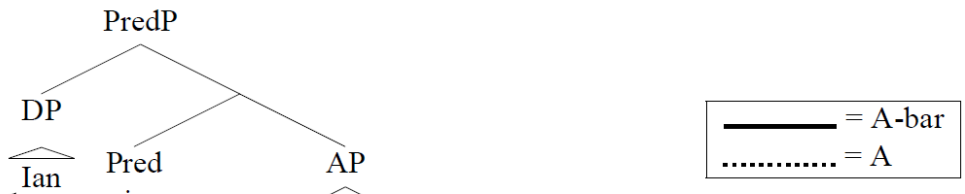

(4) Ian is shy enough for Anneke to talk to

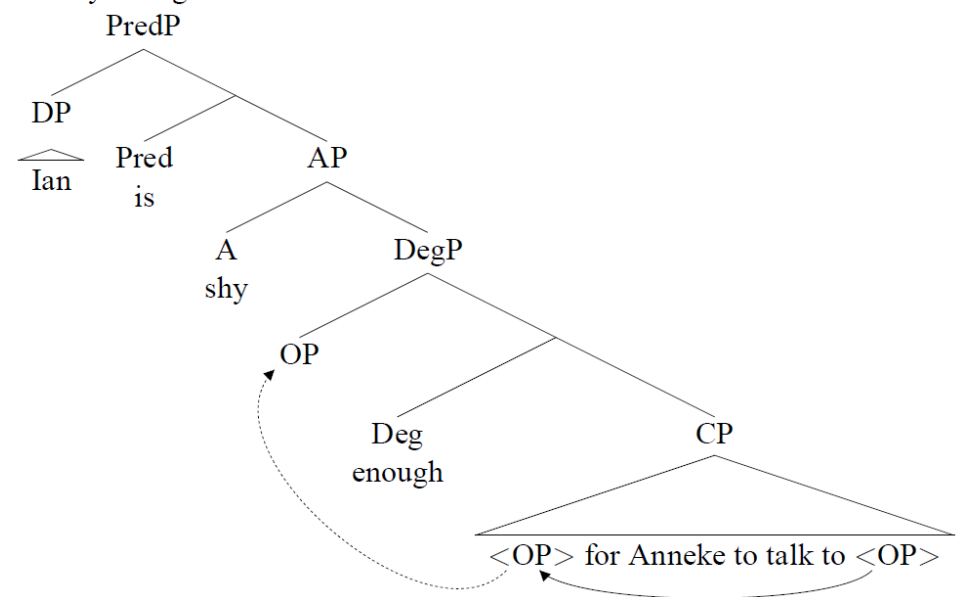

Brillman's focus is GDPs rather than TCs, but her analysis of TCs, based as it is on Hartman's (2011), is open to the same questions as his.

\subsection{6.}

\section{TCs and middles}

In her doctoral dissertation, "They are tough but also middle": diferentes estruturas para sentenças com predicado tough (2009), Oliveira argues that TCs of the John is easy to please type and middles share part of their derivation, as illustrated in the schemata below (Oliveira 2009: 109-110): 
(141) Bureaucrats are easy to bribe

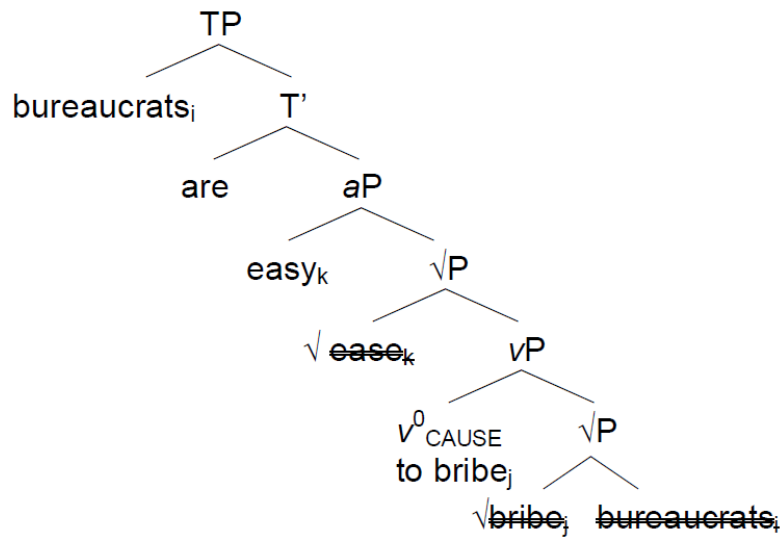

(142) Bureaucrats bribe easily

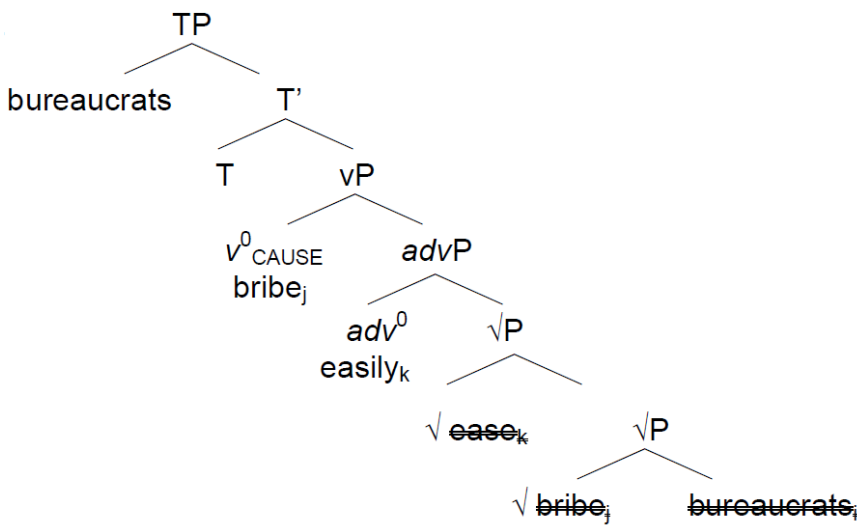

As (141) and (142) show, in Oliveira's analysis, the lexical core of both TCs and middles is the same, and is composed of the lexical roots of the verb and the verb's internal argument. In the case of TCs, this core is selected by a v head, forming a vP that lacks the usual verbal superstructure containing the Voice head and the Functional head responsible for checking the accusative Case of the internal argument of the verb. The defective vP is selected by a lexical root head $(\sqrt{ }$ - ease in the easy to bribe example), which projects a lexical root phrase. This $\sqrt{ } \mathrm{P}$ is selected in turn by an adjective head, and ease moves to $\mathrm{a}^{0}$, becoming the adjective easy, resulting in a configuration in which the defective $\mathrm{vP}$ is complement to an adjectival head. When the aP is selected by $\mathrm{T}$, the internal argument of the vP, in the absence of the VoiceP and FP layers in the infinitival, moves up to specT. In the case of middles, the advP is formed before the vP, but as in TCs, the lack of a Voice and Functional layer above the vP allow the internal argument of the verb to move up to spec T. 
One of the main features of TCs that inspired Oliveira's analysis of TCs as middles is the lack of an external argument in the infinitival, and this absence of an external argument in the infinitival has attracted the interest of scholars investigating TCs in Romance languages, as we will see in section 3.6.

Another interesting aspect of Oliveira's work on TCs is that unlike most researchers, she deals with stranded prepositions in TCs, as in (143) below (Oliveira 2009: 95):

(143) a. This problem is tough to deal with

b. Peter is easy to rely on

c. Those children are tough to look after

Following Hornstein and Weinberg (1981), ${ }^{32}$ Oliveira proposes that in structures where a verb is followed by PP, the V-PP sequence is interpreted as a verb followed by a direct object (V-DP). The preposition is annexed by the verb, losing its Case-checking capacity, with the result that the DP complement to the P head has its Case checked by the verb. Because the vP in Oliveira's derivation of TCs lacks the Voice and Functional layers that could assign case to the DP following reanalysis, the DP's grammatical features remain active, allowing it to move to spec-T. Restructuring is permitted, however, only when the PP is within the domain of the verb; if it has scope over the entire sentence, restructuring is unavailable and the preposition cannot be stranded. For example, sentence (144) can be interpreted to mean either that John was on the boat when he came to a decision, or that John chose the boat. In the first case, [PP on the boat] has scope over the entire sentence, but in the second, the PP is limited to the domain of the verb. Sentence (145), with its stranded preposition, can only be interpreted as the boat John chose.

(144) John decided on the boat

(145) The boat that John decided on

${ }^{32}$ Hornstein, N. \& Weinberg, A. 1981. Case theory and preposition stranding. In: Linguistic Inquiry 12:55-91. 
Ahn and Sailor (2014) independently arrive at the conclusion that TCs are derived in the same way as middles, although unlike Oliveira's (2009) analysis, their proposal is merely sketched out. They observe that the vast majority of gaps in infinitival clauses are "subject gaps", and ask what it is about tough constructions and object-gap too clauses that forces a gap to appear in the object position. Their answer is that TCs and object-gap too clauses also have subject gaps, and that the for-phrases that can appear in TCs and object-gap constructions are not embedded subjects. This double-gap configuration means that the empty category in the object position can be promoted to subject by the same operation that creates middles: as Ahn and Sailor put it, TC and object-gap too clauses select for an infinitival clause bearing middle voice (Ahn and Sailor 2014: 2).

\section{5.}

\section{Combining Null Operator and Argument Movement Theories}

\subsection{1. \\ Hicks and the Complex Null Operator}

In "Tough Constructions and their Derivation" (Hicks 2009), Hicks combines elements of the null-operator hypothesis and the argument-movement theory. $\mathrm{He}$ hypothesizes that TCs are formed by a "complex null operator", which is essentially a DP in which a null D selects a nominal complement composed of an Operator head with a DP complement. ${ }^{33}$ This complex is merged in the embedded object position, and has its Case valued by little $\mathrm{v}$, before moving to spec-CP. When the matrix $\mathrm{T}$ is merged, the DP in the complement position of the operator head moves to spec TP, as illustrated in the follow schema:

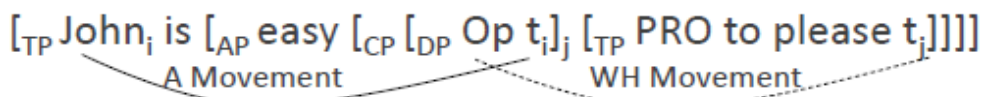

\footnotetext{
${ }^{33}$ Fong and Ginsberg (2014) build on Hicks's idea that the derivation of TCs involves a complex operator but implement it in another grammatical model, which postulates that like computer programs, natural language uses a stack mechanism.
} 
Hicks's analysis overcomes the $\theta$-theory problems faced by simple null-operator analyses by providing two DPs to match the two $\theta$-roles in TCs. He distinguishes GDPs and pretty predicates on the grounds that their subject is generated in the matrix, where the adjective assigns a $\theta$-role, but argues that his complex null operator can be extended to GDPs and pretty predicates, uniting all null object constructions, if the smuggled DP complement in the Operator complex is replaced with PRO, which presumably is left in spec-C of the infinitival rather than raising to spec- $\mathrm{T}$ in the matrix clause. It is not entirely clear, under this analysis, if there is a double PRO in GDPs and pretty predicates (one in spec-C and one in spec-T of the infinitival).

\section{6.}

\section{Some proposals from Romance languages}

This section looks at data and theories proposed by a few researchers into TC-like structures in Romance languages. It is by no means a comprehensive survey of the work on TCs done in other languages: instead, the section focuses on two proposals, one dealing with Spanish and one with French, which treat TCs as a type of passive structure, another proposal on French TCs that suggests that the infinitival is a nominal, and a study on Romanian TCs that reveals intriguing parallels with the English forms.

\subsection{1.}

\section{TCs and passives}

Some researchers suggest that derivation of TCs may be similar to the derivation of passives. In their study of double passives in Spanish, Bosque and Gallego (B\&G) (2011) observe that Spanish not only allows double passives, but the passive and active voice can alternate between the matrix and the embedded clauses (pp. 11-12; passive in boldface):

(147) a. La ermita fue construida en el siglo XIV the church be-3.SG built in the century XIV 'The church was built in the $14^{\text {th }}$ century.' 
b. La ermita fue empezada a ser construída em el siglo XIV the church be-3.SG started to be built in the century XIV

"The church was started to be built in the $14^{\text {th }}$ century."

(148) La ermita empezó a ser construida en el siglo XIV the church began-3.SG to be built in the century XIV

'The church began to be built in the $14^{\text {th }}$ century."

$$
\begin{aligned}
& \text { La ermita fue empezada a construir em el siglo XIV } \\
& \text { the church be-3.SG begun to be built in the century XIV } \\
& \text { 'The church started to be built in the } 14^{\text {th }} \text { century.' }
\end{aligned}
$$

$B \& G$ interpret constructions of the type in (149), where the verb in the matrix clause is in the passive voice but the verb in the embedded clause is in the active voice, to be "covert passives". Referring to a sentence having a similar structure to (149) (B\&G 2011: 36),

(150) [тр Ese productoi $\mathrm{T}$ fue [vp empezado [ a [vp utilizar $t_{\mathrm{i}}$ ]]]] that product be-3.SG started to use 'That product started to be used'

They hypothesize that the lexical verb (corresponding to the infinitival utilizar) projects a $\mathrm{vP}$ that lacks an external argument and is $\varphi$-defective (i.e. passive), and therefore unable to assign accusative Case. Since the internal argument of the verb (ese producto) did not receive Case in the $\mathrm{vP}$, it receives nominative Case after Agreeing with the matrix $\mathrm{T}$. The passive morphology on the matrix verb (empezar) is retrieved or copied from the covertly passive embedded verb.

$\mathrm{B} \& \mathrm{G}$ propose that this is precisely what happens in tough constructions, at least in Spanish. In their view, the verbs in the infinitival complement of TCs in Spanish are also $\varphi$-defective (i.e. passive), and their passive nature is “....induced by the modal nature of the matrix adjective, which aligns these constructions with derived adjectives with -ble: creíble (Eng. Credible), admirable (Eng. Admirable), terrible (Eng. Fearful), and so on.” (p. 38). 
As the authors point out, this theory is very attractive, because it accounts in a straightforward manner for the facts that: (a) the agent of the action expressed by the infinitival can be introduced in a por-phrase (151); (b) the infinitival can be expressed in either the active or the passive voice (152); ${ }^{34}$ (c) alternation with the reflexive is permitted (153); and (d) TCs can be formed only with transitive verbs (154) (B\&G 2011: 39):

(151) Un recurso penal imposible de rechazar por cualquier jurado.

a appeal penal impossible of refuse by any jury

'A penal appeal impossible for any jury to refuse'

(152) Una obra digna de $\{$ ver / ser vista $\}$

a play worth of see/be seen

'A play worth seeing'

(153) Los datos están todavía pendientes de \{confirmar / confirmarse the data be-3.PL yet pending of confirm / to be confirmed 'The data must still be confirmed'

(154) Eso es difícil de $\{$ contar / entender / *llegar / *ir / *crecer $\}$ that be-3.SG hard of \{tell / understand/arrive/go/grow\} 'That is hard to \{tell / understand / arrive / go / grow \}'

The attraction of the passive theory is not limited to Spanish, however. Guérin (2006), in her study of French TCs, also points to the resemblance between TCs and passives. French TCs differ somewhat from the Spanish (and the English) because the proposition $\grave{a}$ (to) is found in the TC formulation, while its expletive and clausal counterparts use the proposition de (of), as the following sentences show (Guérin 2006: 1):

\footnotetext{
${ }^{34}$ This alternation between the active and the passive is possible in Brazilian Portuguese as well. $O$ livro é fácil de ser traduzido (the book is easy to be translated) is perfectly acceptable, although most speakers prefer $O$ livro é fácil de traduzir (the book is easy to translate). Personal communication, Daniel de Brito Machado, UnB (August 2016).
} 
(155) (pour Marie) Jean est difficile (*pour Marie) à/de comprendre (pour Marie) (for Mary) John is difficult (for Mary) à/de understand (for Mary) '(for Mary) John is difficult (for Mary) to understand (for Mary)'

(156) Il est difficile (pour Marie) de/*à comprendre Jean it is difficult (for Mary) de/*à understand John 'It is difficult (for Mary) to understand John'

(157) (de/*à) lire Moby Dick est difficile (de/*à) read Moby Dick is difficult 'To read/reading Moby Dick is difficult'

Guérin distinguishes between "expletive" and clausal counterparts to TCs and TCs themselves on the basis of the particles de and $a$. $D e$ is a complementizer, taking a non-finite complement, while $\grave{a}$ is the head of a defective vP. This division is reflected in the lexicon as well, because tough adjectives have two mutually exclusive subcategorization grids, one contemplating a $\mathrm{CP}$ complement (de formulations) and one a v $\mathrm{P}$ complement (à formulations).

Guérin's focus, however, is on TCs (or à-constructions, in Guérin's terminology). Like Bosque and Gallego, Guérin believes that the infinitival in TCs is a defective $\mathrm{vP}$, although the defect is not in the lack of $\varphi$-features, but in the lack of specifiers to host the verb's external argument (although this may be a distinction without much difference). In Guérin's conception, the $\mathrm{vP}$ is headed by $\grave{a}$, which is a passive morpheme. When $\grave{a}$ merges with $\mathrm{VP}$, and the verb moves from $\mathrm{V}_{0}$ to $\mathrm{v}_{0}, \grave{a}$ "absorbs the verb's external theta-role and object Case feature." (Guérin 2006: 17). Tough adjectives are one-place raising predicates in Guérin's analysis, so that once the vP complement merges with the tough adjective, the tough adjective will raise the verb's internal argument to the matrix subject position. A schema of Guérin's proposal is shown in (158) below (adapted from Guérin 2006: 14).

(158) [IP $\operatorname{Jean}_{\mathrm{i}}$ [est [AP difficile [vP à comprendre ${ }_{\mathrm{j}}\left[\mathrm{vP}\left\langle\right.\right.$ comprendre $\left.\left.\left.\left.\left.>_{\mathrm{j}}\langle\mathrm{Jean}\rangle_{\mathrm{i}}\right]\right]\right]\right]\right]$ Jean est difficile à comprendre Jean is difficult to understand.INF 
The parallels with passives are clear: both TCs and passives have the defective (specifier-lacking) vPs, and both operate only with transitive verbs. Essentially, where TCs have $a ̀$ in the head of $\mathrm{vP}$, passives have passive morphology such as en (in English).

\subsection{2.}

\section{TCs and nominals}

Authier and Reed (2009), in their analysis of French tough constructions, also favor an argument-movement analysis, based on the similarity between French TCs and passives, a similarity remarked on by Guérin (2006) among others in French, and by researchers in other Romance languages (Bosque \& Gallego 2011, for example). Differently from Guérin and Bosque \& Gallego, however, Authier and Reed (A\&R) conclude that the absence of an external argument in the infinitival's verb indicates not a defective $v P$ and a passivization-like transformation, but instead a nominalization of the verb, marked by the infinitive suffix -er, -ir, or -re. On nominalization, the verb loses its Case-marking abilities, with the result that the internal argument is attracted by the tensed T, and its Case feature is valued as nominative.

$A \& R$ present a number of data to support their analysis of infinitivals as deverbalized nominals. In exploring the similarities between passives and French TCs, A\&R observe that the parallel breaks down in certain cases (A\&R 2009: 6, sentences 11 and 12):

(159) a. Le camion a été chargé de tomates the truck has been loaded of tomatoes 'The truck was loaded with tomatoes'

b. Il sera facile de charger le camion de tomates it will-be easy of load.INF the truck of tomatoes 'It will be easy to load the truck with tomatoes'

c. *Le camion sera facile de charger de tomates the truck will-be easy to load.INF of tomatoes 
(160) a. Le sapin a été décoré de guirlandes the tree has been decorated of garlands

'The tree was decorated with garlands'

b. Il sera facile de décorer le sapin de guirlandes it will-be easy to decorate the tree of garlands 'It will be easy to decorate the tree with garlands'

c. *Le sapin sera facile de décoré de guirlandes. the tree will-be easy to decorate of garlands

But not only can the ungrammatical French TCs in (159c) and (160c) be rescued by replacing the preposition de with avec des, avec des is precisely the prepositional expression found in the nominal equivalents of the infinitival. As A\&R put it (A\&R 2009: 8):

...[w]hat has gone unnoticed until now, however, is that the Tough-movement infinitives in (11) through (14) are ungrammatical only when they are followed by those complements that are disallowed in their corresponding argument-taking event nominal, as the paradigm in (17) through (19) illustrates.

The "rescued" versions of $(159 \mathrm{c})$ and $(160 \mathrm{c})$ are shown below, with the corresponding nominal:

(161) a. Le camion sera facile à charger avec des tomates the truck will-be easy to load.INF with some tomatoes

b. Le chargement du camion avec des tomates the loading of-the truck with some tomatoes

(162) a. Notre sapin sera facile à decorer avec des guirlandes our tree will-be easy to decorate.INF with some garlands

b. La décoration de notre sapin avec de guirlandes the decoration of our tree with some garlands

Another intriguing piece of evidence discussed in A\&R's paper is sentences that contain par-phrases (A\&R 2009: 11-12): 
(163) a. Bien que ce saut soit difficile à exécuter par un débutant although this jump is difficult to execute.INF by a beginner 'Although this jump is difficult for a beginner to execute'

b. Ces abstractions ne sont faciles à visualiser que par les grands peintres. these abstractions are easy to visualize.INF only by the great painters 'These abstractions are easy only for the great masters to visualize'

As A\&R point out, although as a rule French does not allow by-phrases in TCs, they are not impossible. More curious still is the fact that par-phrases, like byphrases in English, identify the agent of the action in passives and nominals. French par-phrases therefore seem to offer something of a parallel to for-phrases in English.

More evidence that the embedded subject argument is suppressed in French TCs is found in the fact that external argument cannot be modified by tous (all), unlike other infinitives in French (A\&R 2009: 10):

(164) a. Je dirai à ces garçons de (tous) partir (tous) en Italie I will-say to these boys of (all) to-go (all) to Italy 'I will tell these boys to all go to Italy'

b. Il serait facile de (tous) contenter (tous) Paul It would-be easy of (all) to-please (all) Paul

'It would be easy for everyone to please Paul'

c. *Paul serait facile à (*tous) contenter (*tous)

Paul would-be easy to (all) to-please (all)

'Paul would be easy for everyone to please'

This leads A\&R to the conclusion that "it appears that French Tough-movement infinitives do not have a canonical, syntactically realized (and phonologically null) subject, a conclusion that accords with the hypothesis that they are, in fact, nominal in nature and therefore have a suppressed external argument." (A\&R 2009: 9). Following the work of Grimshaw (1990), they suggest that the French 
TC infinitives are, in fact, complex event nominals, in which the external argument can be suppressed, but the internal argument must be overtly realized.

\subsection{3.}

\section{Romanian tough constructions: similarities to English TCs}

In his study of tough constructions in Romanian, Giurgea (2013) presents data that show surprising similarities between Romanian TCs and English TCs. According to Giurgea (2013), the infinitival in Romanian TCs is the supine, an infinitival form that is formally identical to the masculine singular past participle of the verb from which it is derived. It is preceded by the particle de (of) or by prepositions, ${ }^{35}$ and although Giurgea does not give any examples, he mentions in a footnote that use of the supine as a nominal is still productive (Giurgea 2013: 123).

Romanian TCs are intriguing because, unlike other Romance languages, the tough element does not agree with the subject in either predicative or attributive use, even though the copula does inflect for number in the predicative formulation (Giurgea 2013: 119):

a. o teorie greu de înţeles (Attributive TC) a theory $(F)$ hard.MSG of understand.SUP

'A theory hard to understand'

b. Aceste teorii sunt greu de înţeles (Predicative TC) these theories(F) are hard.MSG of understand.SUP

'These theories are hard to understand'

Instead, the adjective takes the masculine singular form, which is the same default (unmarked) morphology found on the supine's environment.

Giurgea even gives an example (sentence (166b)) that at least superficially looks very much like a prenominal attributive TC. Unfortunately, Giurgea provides just

\footnotetext{
${ }^{35}$ Unfortunately, there are no examples of supines preceded by a proposition other than $d e$ in Giurgea's paper.
} 
a gloss without a translation and says only that (166a) is the "impersonal construction" while (166b) and (166c) are TCs (Giurgea 2016:124):

(166) a. E greu de rezolvat atâtea probleme.

is hard.MSG of solve.SUP so-many problems

'It's hard to solve so many problems'

b. Sunt greu de rezolvat problemele

are.3PL hard of solve.SUP problems-the

c. Atâtea probleme sunt greu de rezolvat. so-many problems are.3PL hard.MSG of solve.SUP

Again like TC infinitivals in English, the Romanian supine can be used to form purpose relative clauses, and can form the predicate in copular sentences even in the absence of a tough element (Giurgea 2013: 126):

(167) a. cărţi de citit

books of read.SUP

'Books to (be) read'

$\mathrm{a}^{\prime}$ cărţi greu de citit

books hard of read.SUP

'Books hard to read'

b. Cărţile sunt de citit (de către elevi) până mâine.

books-the are of read.SUP by pupils until tomorrow

'The books are to be read (by the pupils) until tomorrow'

b' Cărţile sunt greu de citit (de către copii).

books-the are hard of read.SUP by children

'The books are hard to read (for children)'

There does seem to be a slight difference between English and Romanian when the supine is used alone, since it has "a deontic necessity or teleological possibility meaning" (Giurgea 2013:126). The "deontic necessity" meaning seems to correspond the meaning of the passive infinitival in English (cf. Giurgea's translation of (167a)), and this is borne out by the fact that the "bare" supine 
predicate allows not only a PP containing the agent of action in the supine but also what appears to be an adverbial phrase, as seen in sentence (167b) above.

A significant difference between Romanian and English, however, is that in Romanian adverbs and adjectives are morphologically identical, and indeed in traditional grammars the tough element is taken to be an adverb (Giurgea 2013: 125), so that the TC in (167b') would be equivalent to something like "The books are read by the children with difficulty".

Nonetheless, the fact that the tough element does not agree with the matrix subject in Romanian is very intriguing, and calls to mind L\&F's (1974) contention that in English the tough element modifies the action expressed by the verb in the infinitival (see section 2.2.3.4 above). English adjectives do not inflect to show agreement with their subject, so it is not possible in English to determine morphologically whether the tough element modifies the matrix subject or the infinitival. Romanian does have agreement morphology, however, and the Romanian data seems to support the hypothesis that the tough element modifies the infinitival: both elements show the same default or unmarked morphology, regardless of the number and gender of the matrix subject.

The lack of morphological distinction between adverbs and adjectives is a characteristic that Romanian shares with German and Dutch (Giurgea 2013: 134), and Giurgea uses this characteristic to support his "relabeling" analysis of TCs in Romanian, illustrated in the schema in (168) below:

$$
\left[\operatorname{PredP}_{\mathrm{DP}}\left[\operatorname{Pred}^{0}\left[\mathrm{CP} \mathrm{A}\left[\mathrm{CP} \mathrm{de}+\mathrm{V}\left[\mathrm{supP}_{\mathrm{DP}} \mathrm{t}_{\mathrm{V}}\left[\mathrm{vP} \mathrm{t}_{\mathrm{V}}\left[\mathrm{vP} \mathrm{t}_{\mathrm{V}} \mathrm{t}_{\mathrm{DP}}\right]\right]\right]\right]\right]\right]\right]
$$

The author argues that TCs in Romanian are multi-headed constituents: the internal head is the tough element, which selects the supine as its complement; the external head, however, is the supine's head, a complementizer. The $\mathrm{A}+\mathrm{CP}$ constituent is thus relabeled as a CP, and this relabeling accounts for the lack of agreement on the tough element (Giurgea 2013: 127). Under this analysis, the matrix subject is inserted in the derivation in the position of internal argument of 
the verb that becomes the supine; the subject moves to the matrix subject position by A-movement. Although different in the details, the result of Giurgea's analysis recalls Nanni's (1980) and Chomsky's (1981) reanalysis proposals, in which the A+INFINITIVAL string becomes a complex adjective. 


\section{4 \\ A contrarian exploration of TCs and other object-gap constructions}

In 1965, Rosenbaum pondered whether the various formulations of certain adjectival predicates - including what later came to be known as tough constructions - were related. He hypothesized that that they were, and that TCs were syntactically derived from their clausal and expletive "sisters".

The premises that followed from Rosenbaum's hypothesis framed the TC question and have informed, to a greater or lesser degree, subsequent research. As we saw in Chapters 2 and 3, much of the data on TCs and other object gap constructions remains unexplained, and TC theories sometimes raise as many questions as they answer.

In this chapter, I propose a contrarian approach to TCs, to see if saying "no" to Rosenbaum's question about the relatedness of TCs and their sister formulations can reveal avenues of inquiry that may be fruitful in the study of TCs and other object-gap constructions.

The chapter is organized as follows: first, I state the contrarian position on Rosenbaum's (1965) premises (section 4.1); second, I propose a theoretical model consistent with the rejection of those premises (section 4.2); and third, I sketch out the arguments in favor of the contrarian model, based largely on the data and insights of earlier researchers into TCs (sections 4.2.1 and 4.2.2). I then conclude the chapter by discussing how for-phrases can be incorporated into the contrarian model and by looking at prenominal, attributive use of TCs (sections 4.2 .3 and 4.2.4). 


\section{1. \\ Saying no to Rosenbaum}

In section 2.1, I suggested that four premises underlie Rosenbaum's (1965) analysis of TCs:

A. TCs and the clausal and expletive formulations are syntactically related;

B. TCs are derived from the expletive (and ultimately the clausal) formulation;

C. The infinitival is the complement of the tough element; and

D. The infinitival is a sentence (or, in more recent terminology, a complementizer phrase).

The contrarian position to the first premise - that TCs and the clausal and expletive "sister" formulations are not syntactically related - necessarily entails the negation of the second premise, since derivation implies syntactic relatedness. This contrarian position is not a new one: it is, after all, the working hypothesis of Lasnik and Fiengo (1974). The hypothesis has substantial support in the data, as we saw in our review of the TC puzzles in Chapter 2 (cf. section 2.2.3.2).

It also has the immediate benefit of providing an answer to the question of why TCs have expletive and clausal formulations and pretty predicates, GDPs, and ready predicates do not: the answer is that none of them do. The expletive and clausal correlates to TCs are explained by the fact that the tough element can be felicitously predicated of the to-infinitive; in the other constructions, predicating the adjective of the to-infinitive does not produce an acceptable sentence:

(169) a. To please John is easy

b. It is easy to please John

c. John is easy to please 
(170) a. *To look at flowers is pretty ${ }^{36}$

b. *It is pretty to look at flowers

c. Flowers are pretty to look at

(171) a. *To fool Mary is too smart

b. *It is too smart to fool Mary

c. Mary is too smart to fool $^{37}$

(172) a. *To sell the house is ready

b. *It is ready to sell the house

c. The house is ready to sell

From the contrarian position, the relationship between TCs and their sister formulations is purely semantic: If John is easy to please, it follows that it is easy to please him.

The contrarian position to Rosenbaum's (1965) premise C - that the to-infinitive is not a complement to the tough element - only has one adherent that I am aware of: Hornstein (2001), whose theory on TCs makes the to-infinitive an adjunct to the matrix clause.

The contrarian position to premise $\mathrm{C}$ is that the to-infinitive is not selected by the head of the AP that (usually) forms the TC predicate, and thus is not sister to head A. The implications of this hypothesis will be explored in the next section.

Lastly, the contrarian position to premise $\mathrm{D}$ - that the to-infinitive is not a sentence (a complementizer phrase) - is assumed by a number of researchers, as we have seen. L\&F (1974) took the position that the to-infinitive in TCs, in pretty predicates and in GDPs without for-phrases is a VP; the defective vP analysis

\footnotetext{
${ }^{36}$ A. Saab (personal communication, May 2018) observes that in Argentinian Spanish, Es lindo mirar las flores (literally, it's pretty to look at the flowers) is acceptable. This may be because lindo is rather like nice in English - a generically positive evaluator. It's nice to look at flowers is acceptable in English too.

37 "To fool Mary is smart" is much more acceptable than the version with the degree word too. This is unsurprising, because smart can be predicated of an infinitival clause: "It is smart to finish your homework before going out", for example.
} 
finds support among researchers into TC-like constructions in Romance Languages (Guérin (2006); Bosque and Gallego (2011)); Authier and Reed (2009) argue that the infinitive is a deverbal nominal. As far as I am aware, however, there is no proposal that takes a contrarian position on both premise $\mathrm{C}$ and premise D, as I do in this chapter.

\section{2.}

\section{A contrarian proposal: the one-size-fits-all model}

Under the contrarian proposal I argue for in this Chapter, TCs (and all other object-gap constructions we examined in this thesis) share the following "one size fits all" syntactic structure:

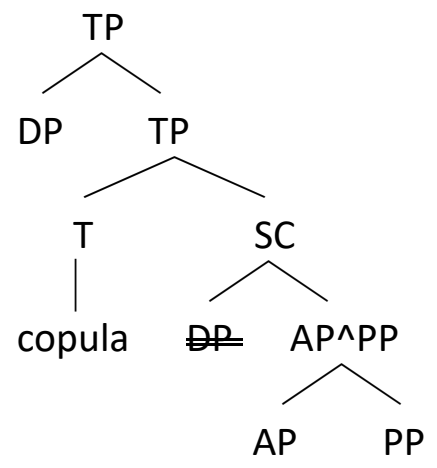

The schema in (174) shows how the one-size-fits-all theoretical model would apply in the classic TC John is easy to please, while (175), (176) and (177) illustrate a pretty predicate, a GDP and a ready predicate, respectively. 
(174) John is easy to please

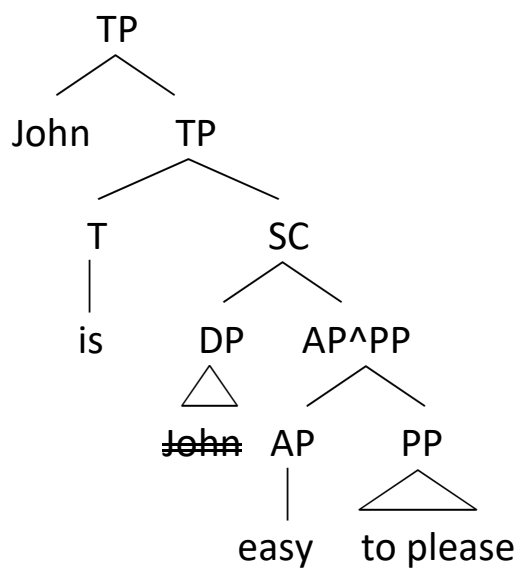

(175) The flowers are pretty to look at

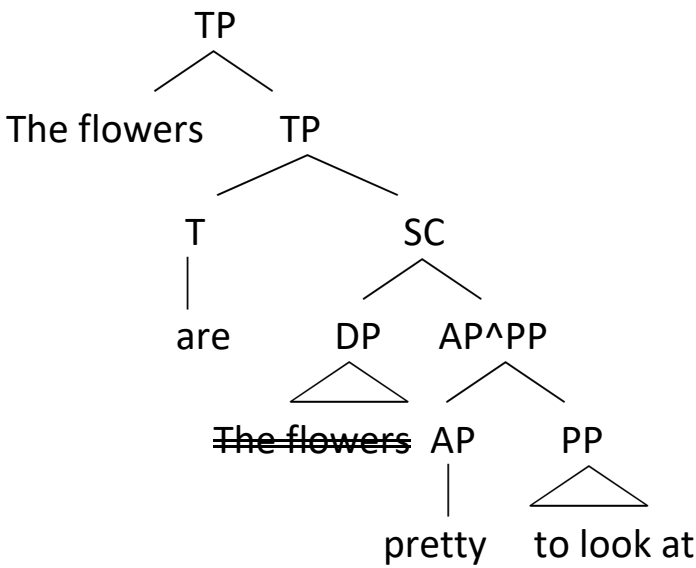


(176) The bed is too hard to sleep on

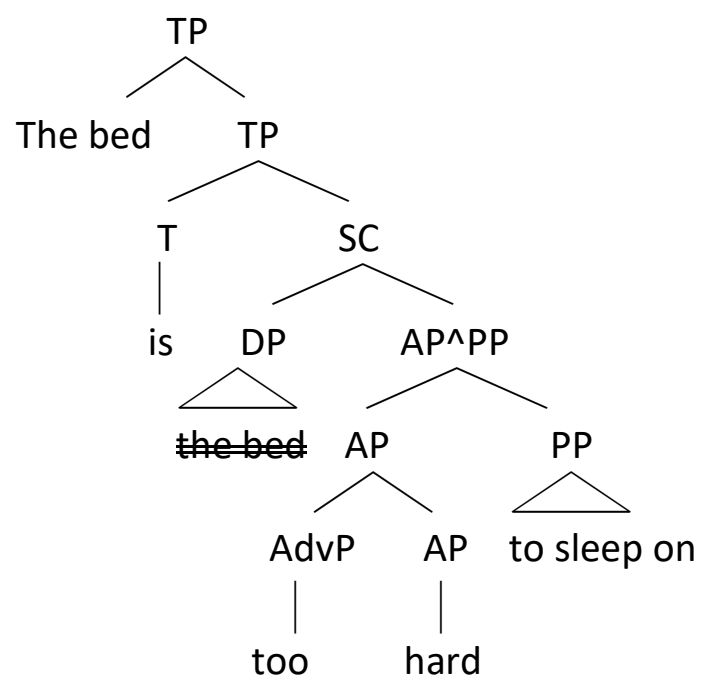

(177) The house is ready to paint

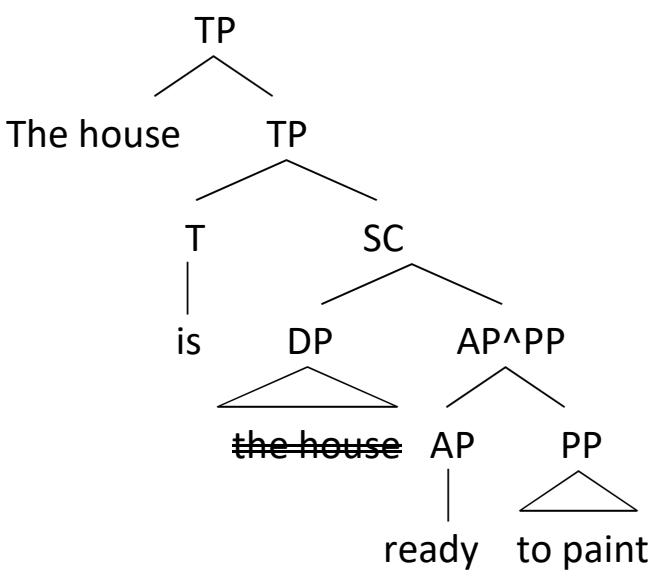

I call the model "one-size-fits-all" to reflect the contrarian stance that the model describes the basic syntactic structure of all four object-gap constructions - TCs, pretty predicates, GDPs, and ready predicates - examined in this work, and that the differences between the constructions can attributed to semantic factors and to syntactic-semantic interactions. The discussion that follows, however, focuses primarily on TCs, because of limitations of time and space. In particular, I do not address the role and effects of the licensing too or enough in GDPs, or the fact that "ungapped" and passive to-infinitives are allowed in GDPs and ready predicates. 


\subsection{1. \\ A contrarian alternative to Premise C: the non-verbal predication paradigm}

One aspect of TCs that is universally recognized in the research but receives very little attention is that TCs, along with the other object-gap constructions examined in this thesis, are copular constructions. It may seem uncontroversial to observe that copular constructions involve non-verbal predication, but this observation has important implications. The fact is that, having taken the position that the toinfinitive is not a complement to the tough element, but an adjunct to it, the usual derivation of the tough predicate, in which the tough element selects an infinitival complement (shown in (178) below), is not available, and some other means of forming the tough predicate must be found.

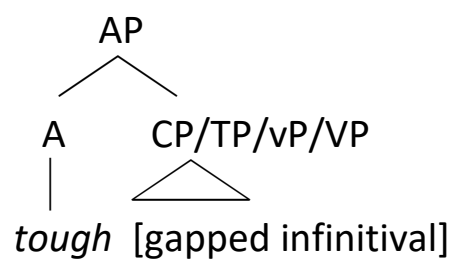

Fortunately, Moro (2000) and Carreira (2015) offer an alternative to the infinitival complement configuration, and it is their paradigm of non-verbal predication that inspires the one-size-fits-all contrarian model shown in (173), along with Hornstein and Nunes's (2008) hypothesis that adjunction structures are label-less concatenates.

In his work on predication and ambiguity of projection, Carreira (2015) looks at three non-verbal predication environments: secondary predication, small clauses, and nominal modification. Like Moro (2000), he conceives of predication in these environments as adjunction of maximal projections (and thus symmetrical); unlike Moro, he introduces dissymmetry not by movement but by projection of either the subject or the predicate, so as to ensure asymmetric c-command. In Carreira's analysis, then, either the subject or the predicate can project, and what will determine projection is the environment in which the predication occurs. The following table (adapted from Carreira 2015: 36) illustrates Carreira's proposal: 
(179)

\begin{tabular}{|l|l|l|}
\hline Secondary Predication & Predication in Small Clauses & Nominal Modification I \\
\hline $\begin{array}{l}\text { John [V ate [DP[DP } \\
\text { steak] [AP raw]]]] }\end{array}$ & $\begin{array}{l}\text { He [v considers [AP[DP John] [AP } \\
\text { intelligent]]]] }\end{array}$ & $\begin{array}{l}\text { [DP [D The [NP [AP raw] [NP } \\
\text { Steak]]]] }\end{array}$ \\
\hline
\end{tabular}

Thus, for Carreira, the difference between Secondary Predication - Object predication structures, Primary Predication - Small Clause Complement, and Nominal Modification - Attributive (Carreira 2015: 54; my translation):

$\ldots$ is the result not only of which [element] projects, but also what selects the structure, since: (i) in the attributive relation, the relation is established inside the DP, that is to say, head D selects the predication structure and the element that projects in this structure is the NP; (ii) in the case of secondary predication of the object, head V selects the DP that is the subject of the predication structure (since it is with the DP that V has a thematic relationship) and in this predication relationship the DP projects; (iii) as for the case of SCs, head V selects the AP, to which it relates thematically, and the element that projects in this predication structure is the AP.

Not only is Carreira's model minimalist in that he dispenses with a predicational projection like den Dikken's RELATOR or Bowers' functional category Pr, discussed in Heycock (2013:338-340), the fact that the predication structure is formed by adjunction ensures that the non-projecting element in the dyad is within the minimal domain ${ }^{38}$ of the head that selects the predication structure and thus able to establish a thematic relationship with that head. This ambiguity in the nonprojecting element's domain means that all three elements - the adjoined maximal projections and the selecting head - are in a local relationship with one another.

\footnotetext{
${ }^{38}$ Chomsky (1995: 163) defines minimal domain as follows:

For any set $\mathrm{S}$ of categories, let us take $\operatorname{Min}(\mathrm{S})$ (minimal $\mathrm{S}$ ) to be the smallest subset $\mathrm{K}$ of S such that for any $\gamma \in S$, some $\beta \in \mathrm{K}$ reflexively dominates $\gamma$.

Like Carreira (2015), I find Hornstein, Nunes and Grohmann's (2005: 149) definition more accessible:

The Minimal Domain of $\alpha$, or $\operatorname{MinD}(\alpha)$, is the set of categories immediately contained or immediately dominated by projections of the head $\alpha$, excluding projections of $\alpha$.
} 
Carreira does not examine predication in a copular environment, but his predication of maximal projections in non-verbal predication environments dovetails quite neatly with Moro's (2000) conception of copular constructions (small clauses and copular sentences) as points of symmetry in syntax that result when two maximal projections are merged, creating a predicative nucleus.

The architecture of Moro's analysis of small clauses and copular sentences is shown in (180) and (181) below:

(180)

Small Clause

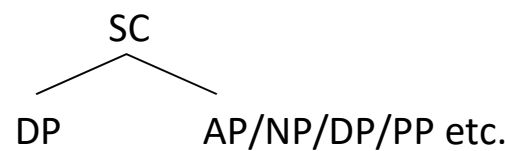

(181) Copular Sentence

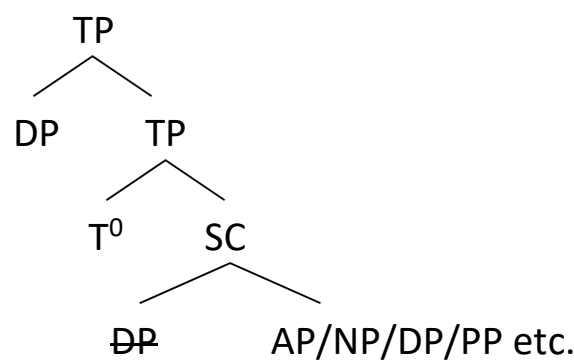

As the schemata above show, in Moro's theory, copular sentences can be conceived of as tensed small clauses, since they are formed when the copula selects a small clause and one of the elements of the clause (the subject of predication in canonical copular sentences) moves to the specifier position above the copula. ${ }^{39}$

Although Moro's (2000) and Carreira's (2015) analyses are similar in that they both posit non-verbal predication by adjunction of maximal projections, they differ in how the point of symmetry created by that adjunction is resolved. Under Moro's theory of dynamic antisymmetry, movement of one of the adjoined elements dissolves a point of symmetry that would otherwise cause the derivation to crash; for Carreira, the point of symmetry is resolved by the direction of prediction, so that it is the projection to which a new element is adjoined that projects. ${ }^{40}$ Furthermore, Carreira argues that small clauses are constituents, while

\footnotetext{
${ }^{39}$ Moro (2000) labels the copula as V. I prefer to use label the copula as T to stress the distinction between non-verbal and verbal predication environments. The architecture (to use Moro's term) shown in (181) is Moro's, however. Only the label on the copula is changed.

${ }^{40}$ Under Kayne's (1994) Linear Correspondence Axiom, phrase structure determines linear order, and asymmetric c-command maps into linear precedence. Since asymmetric c-command
} 
Moro contends that they are not. These are questions that, while fascinating, we must leave aside for reasons of time and space.

The third major influence on the contrarian model is Hornstein and Nunes (2008 $\mathrm{H} \& \mathrm{~N})$ and their conception of adjoined structures as label-less concatenates. Returning to Carreira (2015) for a moment, we saw that in his model of nonverbal predication structures, Carreira elects to have one of the adjoined maximal projections (re)project, thus establishing asymmetric c-command of one adjoined element over the other. However, he does consider the possibility that on adjunction neither of the two elements projects, and that which element will (re)project out of the adjunction depends on the environment the predication structure finds itself in and the selecting head in that environment (Carreira 2015: 71). Looked at this way, predication by adjunction of maximal structures creates not only ambiguity of domain but also ambiguity of projection, so that the predication structure is at once both or either of its two elements.

$\mathrm{H} \& \mathrm{~N}$ provide a more detailed theoretical framework for this ambiguity of (re)projection. For them, Merge can be broken down into two operations: Concatenate and Label. Merge of arguments necessarily involves both Concatenation of the argument with the $\mathrm{V}$ head and Labeling of the concatenate as a projection of $\mathrm{V}$. In the case of adjuncts, however, the adjoined structure is Concatenated with the projection which it adjoins, but not necessarily Labeled. In other words, adjuncts are not necessarily integrated into the projection to which they are adjoined, and can simply "dangle off" it, remaining visible in the syntax and available for other syntactic operations. At the same time, once the Concatenate is Labelled (i.e. the adjunct is integrated into the projection to which it is adjoined), the adjunct ceases to be visible and is no longer available for further syntactic operations.

determines linear precedence, symmetric structures cannot linearize because it is impossible to tell which of the elements in symmetric c-command should come first. In his theory of dynamic antisymmetry, Moro (2000) argues that symmetric structures like small clauses drive movement, since moving one of the elements in symmetric c-command permits linearization (precedence is not relevant when only one element remains to linearize). In Carreira's (2015) theory, antisymmetry is established by reprojection of one of the adjoined elements, because the nonprojecting element then has asymmetric c-command over the projecting element, allowing linear precedence to be mapped. 
$\mathrm{H} \& \mathrm{~N}$ illustrate their hypothesis using the $\mathrm{V}$ projection and its adjuncts in the sentence John said he would eat the cake in the yard with a fork in the afternoon. They model the expression eat the cake in the yard with a fork in the afternoon as follows:

$$
\begin{aligned}
{\left[\mathrm{v}_{\text {eat }}{ }^{\wedge} \text { the-cake }\right]^{\wedge} } & { }^{\wedge} \text { in-the-yard } \\
& { }^{\wedge} \text { with-a-fork } \\
& \wedge^{\wedge} \text { in-the-afternoon }
\end{aligned}
$$

As (182) shows, the adjuncts can be thought of as "dangling off" the V projection, and which of the adjuncts forms an integral part of the $\mathrm{V}$ projection is ambiguous, since Labeling can encompass none, some, or all of them. Which of the adjuncts has been integrated can be detected by movement - the fronting of the $\mathrm{V}$ projection. If an adjunct has not only been Concatenated with the $\mathrm{V}$ but the Concatenate has been Labeled, the adjunct will move with the $\mathrm{V}$ projection. If Labelling has not occurred, the adjunct will be left in place. In sentence (183a), only the string eat the cake has moved, showing that the adjuncts were not integrated into the $\mathrm{V}$ projection ((183b)):

(183) a. and eat the cake he did in the yard with a fork in the afternoon

b. $\left[\mathrm{v} \text { eat }{ }^{\wedge} \text { the-cake }\right]^{\wedge}$ in-the-yard ${ }^{\wedge}$ with-a-fork ${ }^{\wedge}$ in-the-afternoon

In contrast, in (184a), the string with a fork has moved along with eat the cake, showing that the V projection has been Labeled to include that adjunct (184b):

(184) a. eat the cake with a fork he did, in the yard in the afternoon

b. $\quad\left[\mathrm{v}\left[\mathrm{v} \text { eat }{ }^{\wedge} \text { the-cake }\right]^{\wedge}\right.$ with-a-fork $]{ }^{\wedge}$ in-the-yard ${ }^{\wedge}$ in-the-afternoon

We will return to the notion of Labeling when discussing TCs in prenominal use (section 4.2.4). For the time being, our interest is in the notion that adjoined structures are ambiguous and, if not Labeled, the adjunct is available for syntactic operations. $\mathrm{H} \& \mathrm{~N}$ do not consider non-verbal predication environments but adapting their hypothesis to predication by adjunction of maximal projections 
yields interesting results. Under the contrarian model, prior to being selected by head T, the predicative core of TCs is structured as follows:

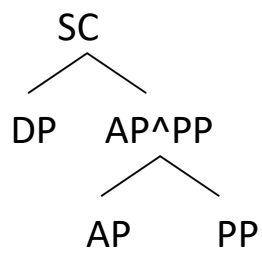

If the concatenate formed by adjunction of AP and PP remains unlabeled, both elements are available for further Concatenation with DP, and indeed instead of $\mathrm{SC}$, the result of adjoining $\mathrm{DP}$ to the $\mathrm{AP}^{\wedge} \mathrm{PP}$ concatenate might be labeled as $\mathrm{DP}^{\wedge} \mathrm{AP}^{\wedge} \mathrm{PP} .{ }^{41}$ There is much that is attractive about this configuration from the contrarian point of view, since it would allow the DP to Concatenate with both elements of the TC predicate before the predication structure is selected by $\mathrm{T}^{0}$ and the DP moves to spec-T.

Some evidence that is consistent with the contrarian model comes from floating quantifiers. If we assume with Sportiche $(1988)^{42}$ and other proponents of the stranding analysis of quantifier float that floating quantifiers are left behind when the nominal element they quantify is moved, then it appears that the subject of tough (with its quantifier) and other object-gap constructions is inserted after formation of the predicate and prior to selection of the SC by the T head, since the

\footnotetext{
${ }^{41}$ J. Nunes points out (personal communication, May 2018) that in Hornstein and Nunes's (2008) analysis, adjuncts to VPs are precisely that: adjuncts to a verbal phrase. The VP is never the adjunct to the adjoined phrase, and consequently the two adjoined phrases do not have equal status, as they do in Carreira's (2015) model and the contrarian proposal made here. Nunes suggests that Chomsky's (2013) hypotheses that Merge results in an unordered pair between two elements, and that ordering and labeling are separate operations from Merge, may provide a better theoretical construct for the contrarian proposal than H\&N's. Certainly there is much that is sympathetic to the contrarian proposal in Chomsky (2013). In particular, the idea that subjectpredicate constructions may not effectively be labeled and may have a semantic interpretation is intriguing, since it tends to support the argument made here that in non-verbal predicational environments the maximal projections composing the predicate can remain "unlabeled" and available for semantic interpretation as atoms. Chomsky (2013) describes subject-predicate structures as symmetrical structures resulting from Merge of two maximal projections, a TP predicate and an NP subject to form the pair $\{\mathrm{NP}, \mathrm{TP}\}$. This paradigm is somewhat different from paradigm of non-verbal predication adopted in the contrarian proposal, in which the predicate is formed prior to Merge of the T head.

${ }^{42}$ Sportiche, D. 1988. A Theory of Floating Quantifiers and its Corollaries for Constituent Structure. Linguistic Inquiry vol. 19, no. 3. Cambridge, MA: The MIT Press. pp. 425-449.
} 
quantifier all can be floated only immediately after the copula. Floating it after the tough element or the to-infinitive (or after the to) yields unacceptable sentences:

(186) a. All the boys are easy to please

b. The boys are all easy to please

c. *The boys are easy all to please

d. *The boys are easy to please all

e. *The boys are easy to all please

Even under a more limited stranding analysis, such as Boskovic's (2004), which postulates that quantifiers cannot be floated in $\theta$-positions but are adjoined acyclically to the element they quantify, (186) is evidence that the subject of the tough predicate occupied a pre-copula position, even if it was not necessarily inserted there.

Takami (1998) analyzes passivization, tough constructions and quantifier float as predication structures subject to a functional constraint that he calls the Predication Constraint. Unfortunately, time does not allow for a close examination of his proposal, ${ }^{43}$ but his analysis of floating quantifiers merits at least a brief mention because it is so congenial to the contrarian model of non-verbal predication. Very simply put, Takami argues that floated quantifiers are secondary subjects of prediction and that as subjects of predication they must have a predicate. The absence of a predicate strands the floated quantifier, making it unacceptable. Thus, in Takami's analysis, the contrast in (187) can be explained by the fact that all is stranded without a predicate in (187b), while in (187a), the guests and all share the predicate arrived:

(187) a. The guests all arrived

b. *The guests arrived all

\footnotetext{
${ }^{43}$ From the contrarian point of view adopted here, Takami's observations and data suggest that not only tough constructions but also passives and floating quantifiers might be analyzed syntactically as non-verbal predication structures formed by adjunction of maximal projections. Unfortunately, space and time constraints do not allow us to take the contrarian exploration down this tantalizing path.
} 
Likewise, when quantifiers are floated off the object, the contrast between the sentences in (188) can be explained by the fact that the quantifier is followed by a predicate related to the object in (188a), but is left stranded in (188b):

(188) a. John considers his friends all to be honest

b. *John likes his friends all

At any rate, under Takami's (1998) analysis of floating quantifiers as subjects of secondary predication structures, the fact that the quantifier all can only be felicitously floated immediately after the copula is consistent with the contrarian model of TCs, in which the adjoined tough element and to-infinitive are predicated directly of the subject.

Having proposed a "contrarian" syntactic structure in response to Premise C, we can now tackle the toughest of Rosenbaum's premises, Premise D.

\subsection{2.}

\section{A contrarian alternative to Premise D: the infinitival is a PP, not a CP}

In this section, I present arguments to support the proposition that the to-infinitive of TCs and the other object-gap constructions (shown as a PP in the schema of the one-size-fits-all proposal in (173)) has the following structure:

(189)

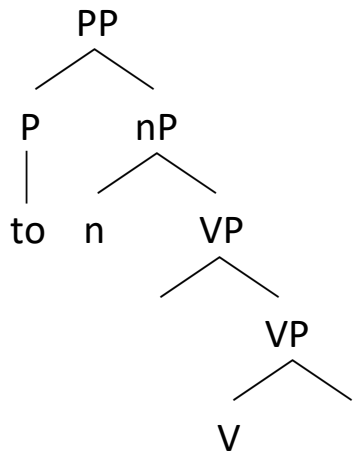

As the model in (189) makes clear, the contrarian position to Premise D involves, in fact, two propositions: first, that the verb in the to-infinitive is nominalized, and second, that the to in the to-infinitive is a preposition in function as well as in 
form, and that it selects the deverbal nominal to form a prepositional phrase. We will deal with the nominalization issue first.

\subsubsection{1.}

\section{Nominalization of the verb}

The motivation behind the nominalization hypothesis is that it holds out the tantalizing possibility of eliminating the need for a syntactic link between the object gap in the to-infinitive and the matrix subject - and it is this link, of course, that constitutes the central problem presented by TCs and other object-gap constructions. The purest contrarian position to the theoretical problem presented by the gap is therefore to say "there is no gap".

The idea that infinitives are nominal in nature is not a novel one. Chierchia (1985) and Chierchia and Turner (1988) suggest that finite VPs are propositional functions (i.e. functions from individuals into propositions), while non-finite VPs (which correspond to to-infinitives) are their individual correlates. In Chierchia's words, "[t]he feature [- finite] maps propositional functions (such as the semantic values of kisses Mary) into their correlates (i.e. to kiss Mary), which can be thought of as actions or states." (Chierchia 1985: 436; my emphasis). What Chierchia is saying, essentially, is that while a finite verb is a function that must be saturated with arguments, a non-finite verb can be an argument; conversely, a finite verb cannot be an argument and a non-finite verb cannot be a propositional function.

Chierchia's (1985) description of to-infinitives accords very well with evidence from to-infinitives in English. As mentioned in passing in our discussion of TCs in Romanian (Giurgea 2013), a to-infinitive can compose the entire predicate in copular structures in English, just as in Romanian:

(190) a. You are to blame

(Huddleston \& Pullum 2002: 1250)

b. The house is to let

(Huddleston \& Pullum 2002: 1250) 
c. My books are to read and love and re-read again ${ }^{44}$

d. Toys are to play with, right? ${ }^{45}$

e. That chocolate cake is to die for ${ }^{46}$

Like TCs, the subject of these sentences is understood as the theme of the action expressed in the to-infinitive, and like TCs, the to-infinitive seems to express a property, purpose or characteristic of the subject: No one blames you (190a), the owner does not lease the house (190b), I do not read or love or re-read my books (190c), and no one plays with the toys (190d), or dies for the cake (190e).

This is a curious effect, because if the subject of the predicate had merged with the verb in the derivation of the predicate, then a new syntactic object should have been formed, composed of the verb and its complement, and corresponding semantically to blaming you, letting the house, reading the books, playing with the toys and dying for the cake. Indeed, as the sentences in (191) below illustrate, that is precisely what happens when the subject of the predicates in (190) is inserted in the object position:

(191) a. To blame you is easier than trying to understand you

b. To let the house where I grew up is going to be hard on me

c. To read my books and love them and re-read them again is a permanent delight

e. To play with toys is an important part of childhood

e. To die for chocolate cake would be foolish, but this is so good I'd almost be willing to make the sacrifice

While the to-infinitives in (191) are still arguments, they no longer express properties or characteristics but actions - actions as concepts rather than events. It looks, then, like it is the absence of the verb's internal argument that allows the to-infinitive to express a property or characteristic.

\footnotetext{
${ }^{44} \mathrm{http}: / /$ theinspiredroom.net/2017/04/27/rooms-with-books/. Comment posted by Nicki on 27 April 2017. Accessed 5 November 2017.

${ }^{45}$ https://www.amazon.co.uk/Jurassic-World-Velociraptor-Charlie-Action/dp/B00PS1D5GW Customer review by rayJ posted 2 June 2015. Accessed 5 November 2017.

${ }^{46}$ https://dictionary.cambridge.org/dictionary/english/to-die-for. Accessed 5 November 2017.
} 
I note here that to-infinitive predicates also support the contrarian premise that TCs are not syntactically related to their clausal and expletive "sisters", because although to-infinitives can be made into TCs by the insertion of a tough element, ${ }^{47}$ to-infinitive predicates do not have an expletive formulation, as the following sentences show:

(192) a. You easy are to blame

b. The house is easy to let

c. My books are easy to read and love and re-read again

d. Toys are easy to play with, right?
(193) a. *It is to blame you
b. *It is to let the house
c. *It is to read and love and re-read my books again
d. *It is to play with toys, right?

Interestingly enough, Chierchia expressly refers to the transformation effected by the non-finite feature as nominalization (Chierchia 1985: 436, footnote 19). He points out that although [- finite] is morphologically realized on the verb, the individual correlate produced by the feature must encompass the entire VP: the complex property kiss'(mary), not just the relation kiss'. Chierchia is concerned with sentences in which a finite verb takes an infinitival complement, ${ }^{48}$ and his work therefore does not contemplate non-finite verbs that lack their internal argument - our "gapped" infinitives. Nonetheless, neither does his work exclude the possibility that a VP could be nominalized even though it had not first been saturated by its internal argument. And curiously, although Chierchia (1985) does not touch on tough constructions at all, he opens his discussion of the problem of properties and predication with a tough construction: Wisdom is hard to find (Chierchia 1985: 418).

\footnotetext{
${ }^{47}$ With the exception of this cake is to die for.

${ }^{48}$ Such as John wishes to leave.
} 
Although Williams's (1985) work on the argument structure of nouns does not deal with the question of whether infinitives are (or can be) nominal ${ }^{49}$ his proposal is not incompatible with Chierchia's idea that to-infinitives are nominalized finite verbs.

As we saw in section 2.2.4.3 above, Williams (1985) contends that both nouns and verbs have an argument structure that is "syntactically visible" enter into "associations" (or what I refer to in section 2.2.4.3 as predicational relationships). The difference between the two categories is the way in which the argument structure is expressed. In the case of nouns, the structure is expressed in terms of "implicit arguments" or "argument slots", unlike verbs, whose argument structure is expressed in terms of "syntactic positions". Since nouns do not have syntactic positions that must be filled, Williams argues that in NPs it does not matter how the arguments are realized or even whether they are (overtly) realized.

It is precisely this flexibility in the realization of a nominal's arguments that suggests that the "gap" in the infinitive might not be a gap at all.

Put another way, Williams's contention is that there are syntactic positions associated with a verb's argument structure, and if those positions are not filled by an overt item, ${ }^{51}$ an ungrammatical gap results. Nouns can have the same argument structure as a verb, but since there are no syntactic positions associated with those arguments, no ungrammatical gap will appear if the argument is not syntactically realized.

To take a hoary chestnut of an example, the noun destruction has both an agent argument and an object argument. The arguments can be realized in a number of configurations, with both the agent and the object argument appearing in the genitive:

\footnotetext{
${ }^{49}$ In point of fact, he refers to to-infinitives as clauses, and assumes they have the null subject PRO, with the clear implication that the to-infinitive contains a verb, not a noun.

${ }^{50}$ Williams (1985) uses the term "syntactically visible" but "semantically active" might be more accurate.

${ }^{51}$ Of course, in null subject and null object languages, the syntactic position would be filled even though the argument is not phonetically realized.
} 
(194) a. The destruction of Rome by the barbarians

b. Rome's destruction by the barbarians

c. The barbarians' destruction of Rome

The agent argument can be omitted:

(195) a. The destruction of Rome

b. Rome's destruction

But not the object:

(196) a. *The destruction circa $390 \mathrm{BCE}$

b. *The barbarians' destruction circa $390 \mathrm{BCE}$

One interesting aspect of (196b) is that it is ungrammatical only if the barbarians are meant to be the agents of destruction; furthermore, the necessary reading of (196b) (and the only grammatical reading in the absence of another overt argument that could serve as the object of destruction) is that it was the barbarians who were destroyed circa 390 BCE, and this is so despite our knowledge that it was the barbarians who were the destroyers, not the destroyed.

Another interesting aspect of the sentences in (194) to (196) is that they are DPs: non-verbal predication environments. What seems to be happening is that although both the agent and the theme arguments of destruction can be realized in the genitive, and when there is no other overt argument that can serve as theme, the argument that is overtly realized is forced to take on the theme role.

These observations are not new: in fact, Authier and Reed (2009) rely on them to support their argument that the infinitive in French TCs has nominal properties, citing Grimshaw (1990). In A\&R's analysis, the infinitive acts as a "complex event nominal", which has an obligatory object.

The contention that the infinitive in TCs is a complex event nominal is particularly attractive in light of more recent work, cited by Roy and Soare 
(2011), suggesting that the eventive interpretation in deverbal nominals is driven by their internal structure (Roy and Soare 2011:§3):

Another option explored in recent works (Alexiadou 2001, Borer 2001, 2003,2005 ) would be that the source of the event which is present in eventive deverbal nominals is indeed structural, and relates to the presence in such nominal of a true event-related (either verbal or aspectual) structure. In this case, the observed properties are mere linguistic computation: functional layers that typically characterize verbs are responsible for similar properties in both verbs and derived nominals.

From this perspective, the "obligatory object" argument structure of event nominals is simply the manifestation of the verbal functional layer in the derivation of the nominal. If a nominal is derived from a verb that selects an internal argument, the argument structure of the derived nominal will necessarily also have an "internal" or theme argument, although the way in which the argument is realized syntactically is different from its underlying verb. The "obligatory object" theory also fits well with Chierchia's (1985) assertion that the individual correlates of verbs encompass the entire VP, not just the relation expressed by the verb, since it is the internal argument that delimits or defines the event.

Authier and Reed (2009) favor a movement analysis for French TCs, despite the nominalization of the infinitive. The contrarian position is somewhat more radical: the complex predicate formed by adjunction of the deverbal to-infinitive and the tough element is predicated directly of the subject of the TC, which never occupies the syntactic position of internal argument.

Instead, we understand the subject of the $\mathrm{TC}$ as the theme in the argument structure of the nominalized verb because of the "obligatory object" requirement associated with eventive nominals. One could go even further down the contrarian path and speculate that this is true of all deverbal predicates, be they adjectival or nominal, derived from verbs that have an internal argument, for the simple (but essential) reason that the internal argument defines or delimits the event. Adjectives derived from eventive verbs, for example, can only be felicitously 
predicated of the theme of the action expressed by the verb from which they are derived:

(197) The city is destroyed

(198) The Christmas presents are carefully hidden from the children

(199) I went for a hike in the woods and came back stung all over

Another piece of evidence in support of the nominalization hypothesis comes from the sonatas and violins puzzle (cf. section 3.2.2) and Hornstein's (2001) observation that the ungrammaticality of sentence (200a) below is "redolent of the effects one finds in complex noun phrase violations rather than $\mathrm{WH}$ island configurations" (Hornstein 2001: 109).

(200) a. This violin is easy to play sonatas on

b. *What sonatas is this violin easy to play on

Under the nominalization hypothesis, sentence (200b) is, in fact, something rather like a complex noun phrase violation. According to the contrarian proposal, the to-infinitive is a PP composed of the preposition to and its complement, the nominalized VP [vp play sonatas on]. ${ }^{52}$ Extracting the internal argument from [n[vP play sonatas on]] is therefore akin to a complex noun phrase violation, and produces the same sense of ungrammaticality that extracting Typee from the complex noun phrase the man who wrote Typee does ((201b)):

(201) a. Moby Dick is by the man who wrote Typee

b. *What book is Moby Dick by the man who wrote

The arguments presented here in support of the contrarian nominalization hypothesis are far from conclusive. Nonetheless, they are intriguing, particularly in light of our brief discussion of Attributive with Infinitive Constructions. As we saw in section 2.2.4.3, in AICs like Middlemarch is a long book to assign, there is a semantic link between long and those to whom Middlemarch will be assigned,

\footnotetext{
52 Stranded prepositions, like linearization, are a problem that the contrarian proposal recognizes but does not address.
} 
even though the "assignee" argument is not overtly realized. AICs therefore lend support to the contrarian proposition that it is the argument structure of the infinitive that is implicated in predication in TCs (and other object-gap constructions), not the actual arguments of the verb from which the infinitive is derived.

Another intriguing aspect of copular predicates formed of an adjective plus an infinitive is that the category of the adjective seems to have a role to play in determining which of the to-infinitive's argument "slots" the subject of the predicate will occupy. Chomsky (1977: 109-110), for example, remarks on the difference between (202) and (203):

(202) John is easy to please

(203) John is eager to please

In (202), John is clearly the "pleasee", while in (203) he is equally clearly the "pleaser". Sentences (202) and (203) form an interesting contrast to (204) and (205):

(204) a. *John is easy to leave ${ }^{53}$

b. John is easy to catch

c. *John is easy to catch the train

(205) a. John is eager to leave

b. *John is eager to catch

c. John is eager to catch the train

Sentences (202) and (203) are both grammatical because please can be either transitive and intransitive, but the sentences in (204) and (205) show that eagerclass adjectives (which seem include emotional states and moral characteristics like wise) cannot felicitously co-occur with "object-gapped" two-argument infinitives, while easy-class adjectives cannot felicitously co-occur with

\footnotetext{
${ }^{53}$ This sentence is infelicitous if the intended meaning is that leaving would be easy for John; if the intended meaning is that John is the type of person that others find easy to part ways with, then it is felicitous.
} 
infinitives that do not have an object "gap", either because they only have one argument, or because the internal argument was inserted prior to nominalization.

These effects can be described syntactically by one of the tough theories (in the case of the easy sentences) or control (in the case of the eager sentences), but the idea that the syntactic structure of the sentences in (202) to (205) apparently varies according to the semantic classification of the adjective is not a very comfortable one: one of the most basic tenets of generative grammar is that the combinatorial system operates independently of the semantic content of the syntactic objects that are combined.

The examples above show that it can be argued that the clues as to which argument configuration the to-infinitive must have, and which argument "slot" John can occupy, are at least in part semantic, and depend on the class of the adjective in the predicate. It is possible, therefore, that the predicational relationships between the subject and the argument structure of the infinitive in this type of copular sentence are resolved at LF rather than computed in the syntax.

A broader survey of copular sentences containing to-infinitives in the predicate would be an interesting line of research, to discover what, if any, patterns emerge, and if there are more correlations between the argument structure of the toinfinitive and the other elements involved in propositions of the type we observed with eager-class and easy-class adjectives. A more extensive and more systematic empirical corpus would certainly provide a firmer basis for theoretical discussion on the syntax/semantic interface in object-gap constructions. It could also offer some insights into our sensitivity to implicit argument structure in lexical items and how implicit argument structure interacts with the syntax and in semantics.

If the nominalization hypothesis is shown to have a solid empirical base, the benefits would be significant. The first, and greatest, would be that the "gap" in object-gap constructions would cease to be a syntactic gap and consequently there would no longer be a need for a syntactic link between the "matrix" subject and 
the gap: instead, the association between the subject of the predicate and the argument structure within the predicate would be made semantically, at LF.

A second, and still important, advantage of the nominalization hypothesis is that it has the potential to provide a unified explanation of to-infinitives in copular predicates. Nominalization by selection of the VP by a little-n head preserves the argument structure of the lexical verb, but provides considerable flexibility in how that argument structure is realized. Under the contrarian analysis, it is possible for a VP to be nominalized with its internal argument in the canonical syntactic position, but the presence of the internal argument is not necessary. Once the verb is nominalized, the fact that its internal arguments may not have been inserted ceases to be a fatal ungrammaticality: unlike verbs, the arguments of nouns do not have to be overtly realized.

\subsubsection{2.}

\section{The to in the to-infinitive is a functional preposition}

Having argued in the previous section that the to-infinitive in TCs (and other object-gap constructions) contains a nominalized verb, it is tempting to follow Chierchia (1985), who sees nominalization as encompassing the entire toinfinitive. This position has some support in Authier and Reed (2009), who treat the infinitive morphology on French verbs (-er, -ir, and -re) as nominalizing suffixes. By analogy, the to in English to-infinitives would be a nominalizing particle. A nominal infinitive would also work quite neatly for TCs, in which the adjectival component of the predicate qualifies the action expressed by the infinitive component. A nominal infinitive even finds some morphological support in Romanian, where the tough element shows default morphology (presumably reflecting the unmarked supine) rather than agreeing with the subject (Giurgea 2013: 119; see section 3.6.3 above).

A nominal to-infinitive faces certain structural difficulties, however. Under the syntactic model I have adopted, non-verbal predication operates by adjunction of maximal projections, which means that the predicate formed with a nominal toinfinitive would have the following structure: 
(206)

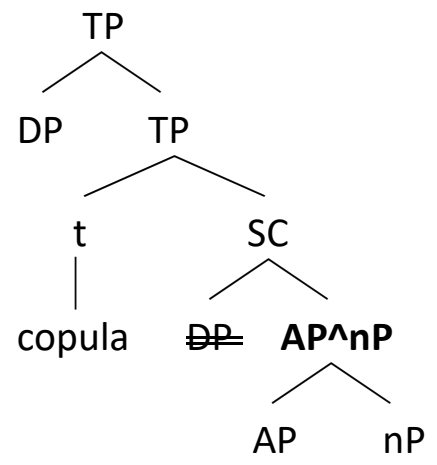

The difficulty, of course, is that adjectives are predicated of nominal elements, so there is nothing to distinguish the configuration in (206) from nominal modification (Carreira 2015; see section 4.2.1 above). And while there is a certain superficial attraction to the idea of the adjective modifying the infinitive in TCs, that attraction does not exist at all in the other object-gap constructions, where it seems clear that the predicate is adjectival, with the infinitive modifying the adjective.

An argument in favor of the PP hypothesis (rather than against the $\mathrm{nP}$ hypothesis) is that almost all nominal modifiers of adjectives are introduced by a preposition. The only exceptions are due, like, unlike, and worth (Huddleston \& Pullum 2002: 546). If the nominalization hypothesis is correct, then it is much more likely that the deverbal nominal would fall under the general rule on nominal modifiers than under the exception.

There is another possibility: nominalization affects the entire to-infinitive, with the to acting as a nominalizing particle, but the to-infinitive is selected by a prepositional head, and the to in the to-infinitive reverts to its prepositional origins (Huddleston \& Pullum 2002: 1184-5). An alternative explanation is that the preposition to heads the $\mathrm{PP}$ and selects the to-infinitive. On spell-out, the prepositional to and the nominalizing to elide.

The PP adjunct hypothesis is also theoretically attractive because it would align English TCs with TC-like structures in the other languages we have seen in this 
study. French, for example, uses the preposition à+infinitive (Jean est difficile à comprendre); Spanish uses de+infinitive (Eso es difícil de contar), as does BP (Moby Dick é difícil de ler); Romanian also seems to use de+infinitive (Atâtea probleme sunt greu de rezolvat). A model in which a bare infinitive is selected by a prepositional head to form a to-infinitive may also reflect the preposition's role as Case assigner in nominal modifiers and potentially provide a unified syntactic analysis for all nominal modifiers, including to-infinitives.

\subsection{3.}

\section{The for-phrase is a PP adjunct}

Under the contrarian proposal, the for-phrase cannot be a complementizer phrase because I have rejected the premise that the infinitive in TCs is a clause and argued instead that the to-infinitive itself is a prepositional phrase. Having excluded the complementizer for option, the only other category open to the forphrase is a PP. The one-size-fits-all model in (207) includes an extra PP to accommodate the for-phrase and the schema in (208) shows how the model would apply to John is easy for Bill to please.

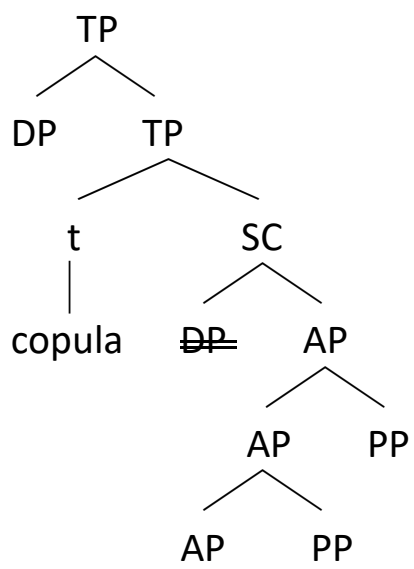


(208)

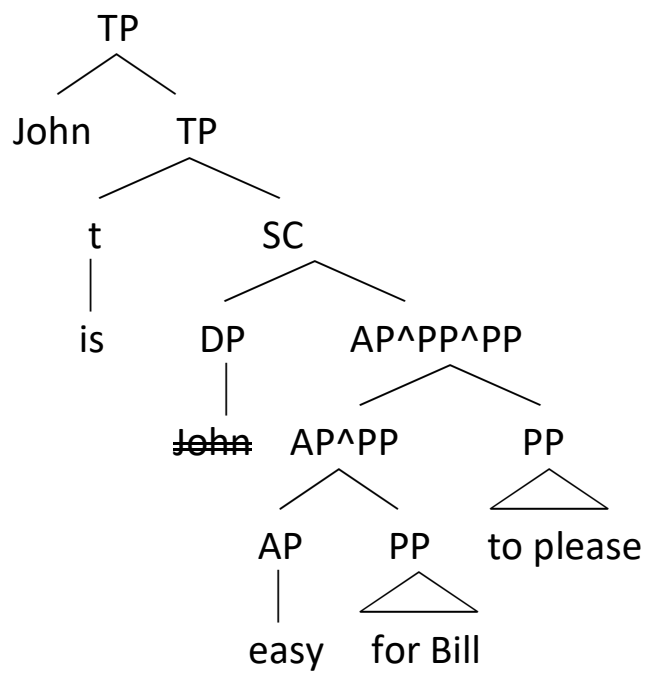

An alternative to the configuration in (207) is to have the for-phrase PP adjoin to the to-infinitive PP, as shown in (209) below:

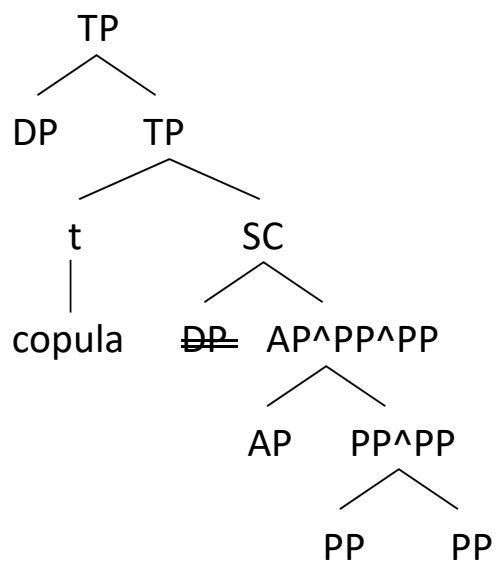

There are (at least) two difficulties with this alternative. The first is that adjoining projections of the same category creates a particularly symmetrical point of symmetry that would prevent linearization and cause the derivation to crash. ${ }^{54}$ One way around this problem would be to suppose that one PP is predicated of the other, and the direction of predication would determine which of the PPs projects,

\footnotetext{
${ }^{54}$ Predication by adjunction of maximal projections presents potential problems for linearization, and indeed Carreira (2015: 136) concludes that his theory is incompatible with Kayne's (1994) Linear Correspondence Axiom. Certainly, in the structure proposed in (209) there is a linearization problem under the LCA because it is impossible to establish asymmetric c-command between the PPs, thus impeding linearization. Like Carreira, I leave the question of linearization of TCs and other object-gap constructions to future investigation.
} 
according to Carreira's theory (2015). This solution has its own problems, however. It is not at all obvious that one PP can be predicated of another PP; and even if it were possible, is [PP for Bill] predicated of [PP to please], or vice-versa? In this configuration, we cannot even fall back on the empirical observation that PPs modify APs, not vice-versa, and so presume that the AP projects, with the PP having c-command over the AP as a result.

A second way to resolve the point of symmetry would be to suppose, as discussed in section 4.2.2.2, that the to-infinitival is an $\mathrm{nP}$, with the to serving as a nominalizing particle. In that case, the prepositional for-phrase could be predicated of the $\mathrm{nP}$ to-infinitival, and the $\mathrm{nP}$ would project, resolving the point of symmetry. The difficulty with this solution is the same one pointed out in section 4.2.2.2 - we end up with an $\mathrm{AP}$ adjoined to an $\mathrm{nP}$, a configuration that is characteristic of nominal modification.

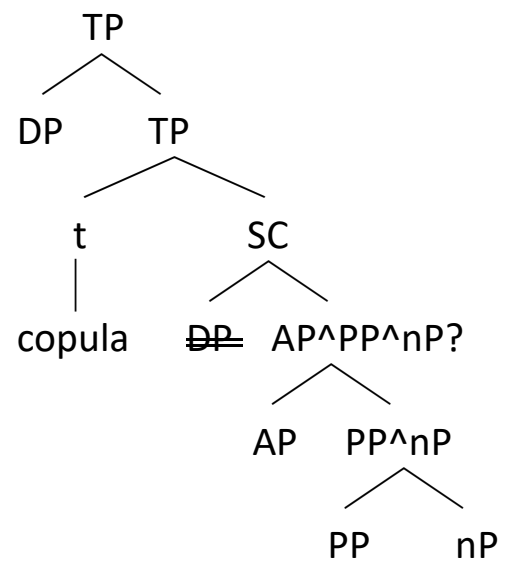

The second objection to the structures in (209) and (210) is that semantically the for-phrase seems to be more related to the AP component than to the infinitive component of the TC predicate.

This intuition on the nature of the for-phrase is more easily illustrated by replacing the infinitive component of the predicate with a common noun that has a "two slot" argument structure. Think, say, of a football match (soccer game for North Americans) in which Fulano is the goalkeeper and Sicrano is a forward. 
The TCs are shown in (211) and the common noun counterparts in (212) and (213):

(211) a. That save was tough for Fulano to make.

b. That goal was easy for Sicrano to make.

(212) a. That was a tough save for Fulano.

b. That was a tough save by Fulano.

(213) a. That was an easy goal for Sicrano.

b. That was an easy goal by Sicrano.

The contrast between (212a) and (213a), in which the agent argument is realized in a for-phrase and (212b) and (213b), in which the agent argument is realized in a by-phrase, is informative. Although the distinction between the two is subtle, it is real: when the save or the goal is tough (or easy) for the player, it was tough for him to make the save or the goal, although it might not have been tough (or easy) for another player; when the save or the goal is easy (or tough) by the player, then the save or the goal would have been easy or tough for any other player. It appears, then, that if the agent is manifested in a for-phrase, the for-phrase qualifies the adjectival element: a "tough-for-Fulano" save and an "easy-forSicrano" goal. When the agent is in a by-phrase, the by-phrase appears to qualify a noun that has already been modified by the adjective in the predicate.

Aside from providing further support for the contention that for-phrases in TCs are adjoined to the AP, this distinction provides insights into why pretty predicates do not allow for-phrases. If we replace the tough element with a prettyclass adjective, we see a distinct change in meaning:

(214) a. That was an amazing save for Fulano.

b. That was an amazing save by Fulano.

(215) a. That was a beautiful goal for Sicrano.

b. That was a beautiful goal by Sicrano.

In sentences (214a) and (215a), the for-phrase is ambiguous. Fulano might be the person who evaluates the save as amazing (although in that case, it would be more 
usual to see the for-phrase at the beginning of the sentence); Fulano might be someone who bet on the game and was going to lose the bet when Sicrano made his beautiful goal and saved Fulano from losing; or Fulano might have made the save and the save was amazing, judged against his other saves (or lack of saves). What is clear, however, is that amazing does not qualify Fulano's effort in making the save, nor does beautiful qualify Sicrano's effort in making the goal. If we operate a further transformation on these sentences and make them into pretty predicates, we see that these observations remain true:

(216) a. For Fulano, that save was amazing to see

b. That save by Fulano was amazing to see

c. That save was amazing to see

d. That save was amazing *for Fulano/*by Fulano to see

(217) a. For Sicrano, that goal was beautiful to watch

b. That goal by Sicrano was beautiful to watch

c. That goal was beautiful to watch

d. That goal was beautiful *for Sicrano/*by Sicrano to watch

In pretty predicates, a for-phrase inserted between the pretty element and the toinfinitive is disallowed because, unlike TCs, the pretty element does not qualify the degree of difficulty in performing the action in the to-infinitive; instead, the to-infinitive qualifies or focuses the scope of the adjective.

Finally, it is interesting to note that a for-phrase is not felicitous in conjunction with a pretty-class adjective even in the absence of a to-infinitive, in contrast to tough-class adjectives, too and enough predicates (but not the adjective without the degree word), and ready:

(218) a. *The goal was beautiful for me

b. The save was easy for Fulano ${ }^{55}$

c. Sicrano is too clever for the goalie

d. *Sicrano is clever for the goalie ${ }^{55}$ But note that the sentence is infelicitous if the subject does not have a "two slot" argument
structure: *The table is easy for Fulano; *The table is easy. 
e. The team is ready for Fulano

A third possible structure for TCs having a for-phrase is inspired by a difference in infinitival complements to prepositions in Portuguese and in English. While writing this thesis, I sent the following message in Portuguese to my advisor (the English translation appears below the Portuguese):

(219) A linearização é complicada demais para eu comentar inteligentemente The linearization is complicated too much for I comment.INF intelligently 'Linearization is too complicated for me to comment on intelligently'

The interesting thing about this sentence and its English translation is that in standard Brazilian Portuguese (BP) the agent argument of comentar shows nominative case, while in English the agent argument of comment on shows accusative case. In contrast, in standard BP, when a DP follows a preposition in the absence of an infinitive, the DP (which in these cases is not an agent) bears dative case, as shown in (220): ${ }^{56}$

Deixa um pouco para mim

Leave a little for me

'Leave some for me'

The fact that the agent argument in standard BP does not have dative case suggests that it is not the complement of the preposition, and that instead the infinitive is the preposition's complement. And as (221) shows, it is possible for the infinitive to appear without an overt agent argument (i.e. with a generic interpretation of the agent):

(221) A linearização é complicada demais para comentar inteligentemente The linearization is complicated too much for comment.INF intelligently 'Linearization is too complicated to comment on intelligently'

\footnotetext{
${ }^{56}$ In non-standard BP, this contrast has been washed way, and the dative is used:

(i) Deixa um pouco para mim (fazer)

Leave some for me (to do)
} 
If we assume that the nominalization hypothesis applies to BP as well as to English, and boldly hypothesize further that $e u$ is inserted in spec-nP, ${ }^{57}$ the derivation of (219) can be shown schematically as follows:

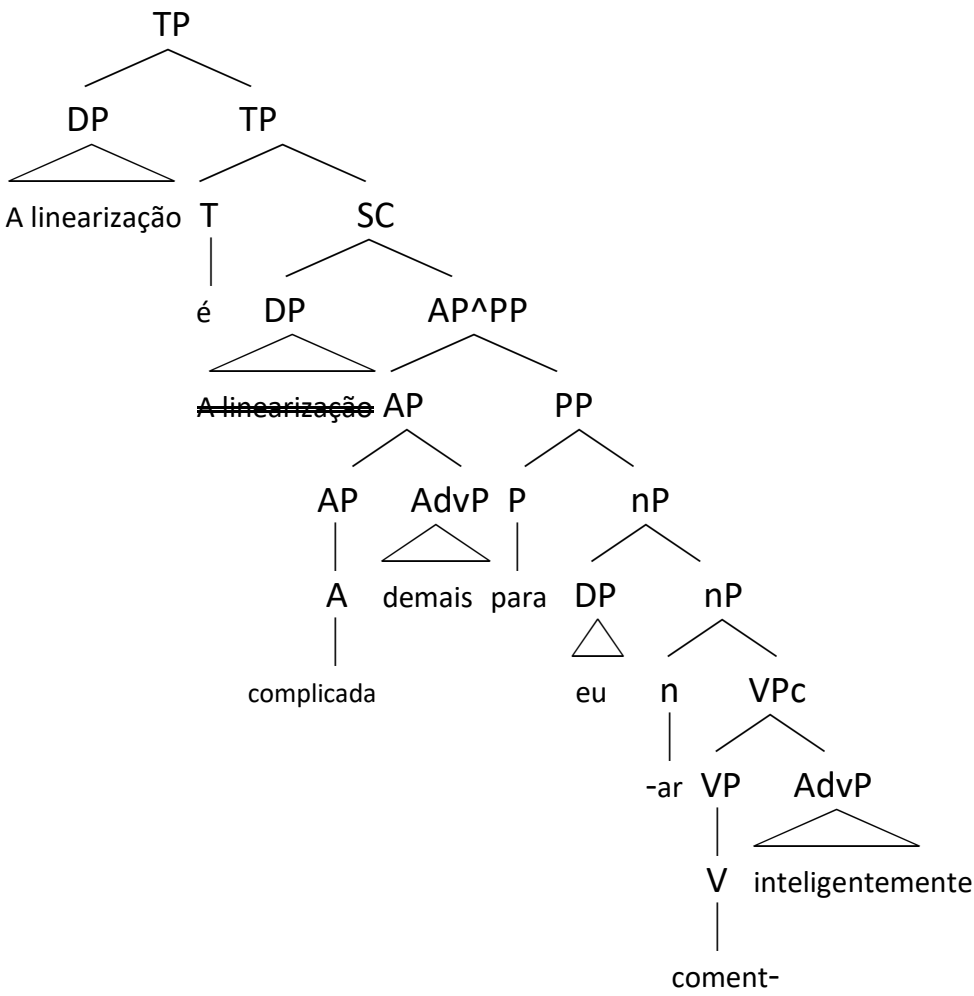

The same derivation cannot apply to the English translation of (219), because the agent argument me shows accusative case, suggesting that it, not the to-infinitive, is the preposition's complement, and has had its Case feature checked by the preposition. ${ }^{58}$ Furthermore, under the contrarian proposal, the to-infinitive is a PP,

${ }^{57}$ Pires (2006) distinguishes between inflected and uninflected infinitives in BP. Both are TPs, but only inflected infinitives carry a full set of $\varphi$ features, which allows the nominative case of the external argument to be checked in spec-T of the infinitival clause. This analysis, of course, is not available under the contrarian proposal.

${ }^{58}$ It could be contended that me carries default case, which is held to be accusative in English (Schütze 2001, among others), and that, just as in BP, the infinitive is an nP with me in spec-nP. Two arguments can be made against this contention. The first is that we have adopted, for the reasons set out above, the premise that the to-infinitive is a PP, not an $\mathrm{nP}$. On that premise, we are left with a configuration where $\mathrm{P}$ head for would have to select a prepositional complement, which seems unlikely. The second is that unlike infinitives in BP, the agent argument of bare infinitives in English can show either nominative or accusative case if the infinitive stands alone (Haegeman 1994: 159, footnote 2):

(i) He go there? Impossible.

(ii) Him attack Bill? Never.

The agent argument of to-infinitives, however, if overt, always shows accusative case and toinfinitives with overt agent arguments can never stand alone: they must be introduced by a for- 
and therefore would not be selected by another P head. ${ }^{59}$ The English translation, however, is a GDP and a copular structure. Thus, according to the contrarian proposal, the "one-size-fits-all" model should apply, and the sentence should be derived by adjunction of maximal projections. If we hypothesize that in English (contrary to our analysis of BP) the agent argument is not inserted in spec-nP, but that the to-infinitive is predicated of the agent argument, the DP and the PP will form a small clause (shown in boldface type in (223)), out of which the DP is selected by for, which will check accusative Case on the DP. The derivation produced under these hypotheses is shown in the following schema:

(223) Linearization is too complicated for me to comment on intelligently

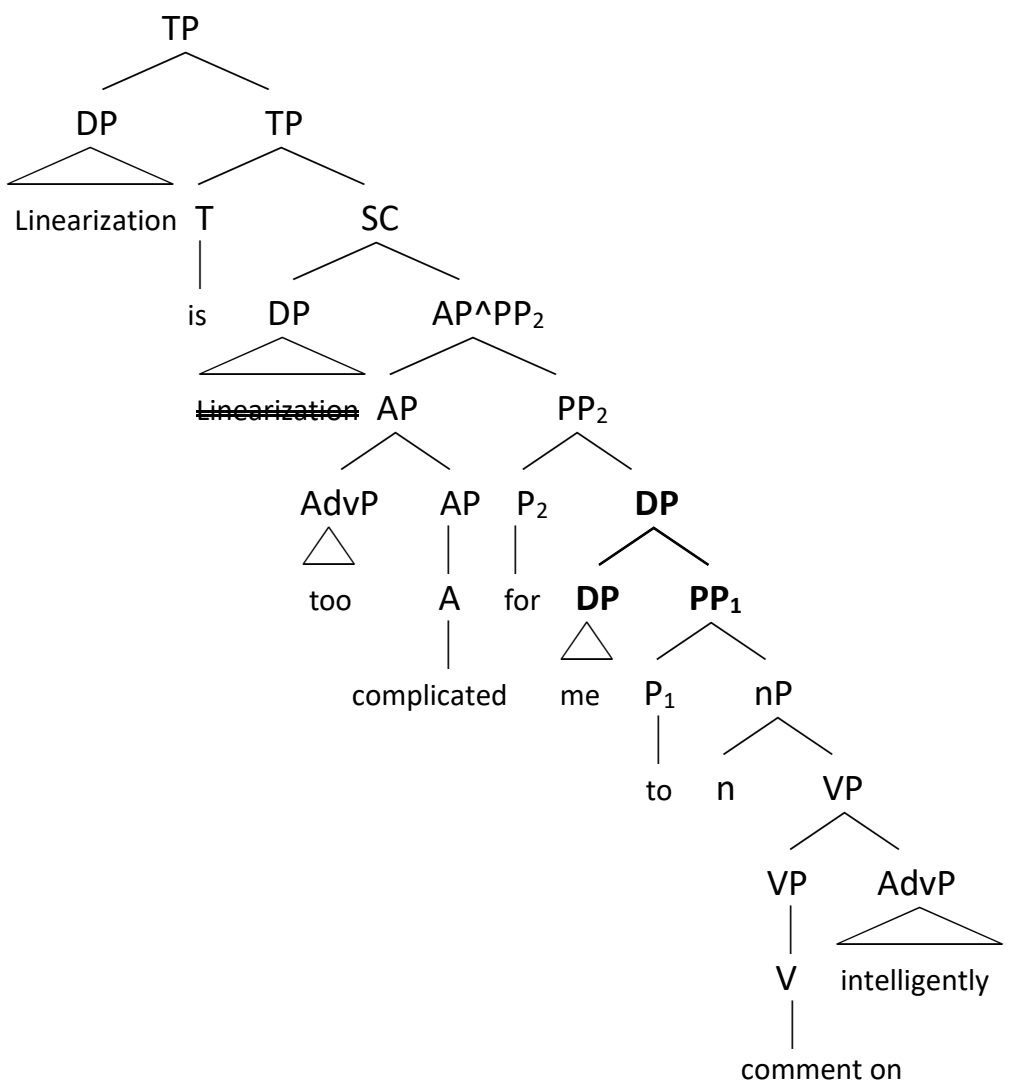

phrase or be inserted in an ECM environment. These facts are consistent with the hypothesis that for selects the DP me, not a PP or an $\mathrm{nP}$, and checks the Case feature on me.

59 This observation suggests yet another interpretation of the derivation shown in (222). Rather than being read as inserted in spec-nP, [DP eu] can interpreted as the subject of predication of [nP comentar], forming a small clause. Under this interpretation, the derivation of (222) is essentially identical to the derivation of its English counterpart in (223). The only difference is that since the infinitive is an $\mathrm{nP}$ (i.e. a nominal element suitable for selection by a prepositional head), unlike English to-infinitives, the $\mathrm{nP}$ is selected by [P para], leaving [DP eu] to show default case, which is nominative in standard BP. This analysis is also consistent with Chomsky's (2013) contention that there is no specifier position as such, just Merge of phrases, resulting in a symmetrical structure $\{\mathrm{XP}, \mathrm{YP}\}$. 
The derivation in (223) is intriguing for a number of reasons. First, by introducing another functional head, it introduces asymmetry into the structure and conveniently reduces the number of PP adjuncts to the AP to one, mitigating linearization problems. Second, the structure of $\mathrm{PP}_{2}$, with its embedded prepositional phrase, is remarkably like the $\mathrm{CP}$ structure proposed by some researchers into TCs, in which the for is a $\mathrm{C}$ head that selects an infinitival TP clause. The embedded PP structure can be thought of, then, as an adaptation of the complementizer for proposal to a non-verbal predication environment. Third, if the hypothesis that a small clause (indicated in boldface type in the schema) can be formed by adjunction of the to-infinitive PP to a DP is on the right track, the same analysis could apply to other non-verbal predication environments in which to-infinitives occur, such as infinitival relative clauses. As illustrated in (224), under the hypotheses put forward in the contrarian proposal, an infinitival relative clause like John is the man to see would have a syntactic structure very similar to John is easy to please, except that the to-infinitive would be adjoined to a DP rather than an AP. Both sentences would be instances of a nominal modifier (the nominalized verb) located in a prepositional phrase (headed by the to of the toinfinitive), and from a formal point of view, at the point in the derivation when maximal projections are adjoined, John is the man to see would be no different from John is the man of the hour.

John is easy to please


These, however, are speculative notes on how the model proposed here could be put to service outside the domain of TCs. As such, they go beyond the scope of this work.

\subsection{4.}

\section{Prenominal TCs: revisiting reanalysis}

The contrarian proposal on TCs in prenominal use is not very contrarian: rather, it is an adaptation of the reanalysis hypothesis first put forward by Nanni (1980) (cf. section 2.2.3.3) for TCs in attributive use, as illustrated in (225):

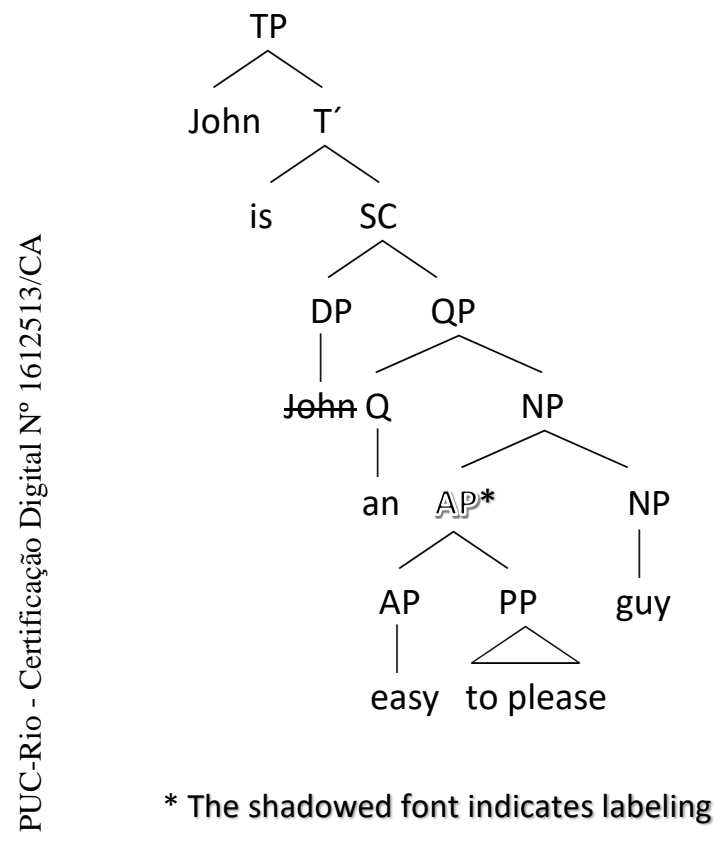

Nanni (1980) proposed that TCs in attributive use are formed from the A+INFINITIVAL string, according to rules operating in the lexical component of the grammar. Once formed, attributive TCs have no internal structure and are inserted in the NP in the same way as simple adjectives.

My proposal for TCs in attributive use is similar, although I make use of H\&N's (2008) Labeling hypothesis rather than lexical rules. In our discussion of H\&N's analysis of adjuncts in section 4.2.1, we focused on label-less concatenates. Now we will turn our attention to labelled concatenates. 
Labeling occurs when the adjunct to a $\mathrm{V}$ projection is incorporated into the projection on concatenation and the concatenate is labeled V. Put in Carreira's (2015) terms, the VP reprojects out of the adjunction. The interest of Labeling for prenominal TCs are its effects: to quote $\mathrm{H} \& \mathrm{~N}$, "a labeled concatenate is a complex atom. Atoms have no accessible innards." (H\&N 2008: 67).

This, of course, is precisely the effect we need to avoid the empirically-observed rule that "complements" (adjuncts in the contrarian proposal) are disallowed when adjectives are used prenominally (cf. section 2.2.3.3 and footnote 15). If a TC is Labeled as a projection of $\mathrm{A}$ after concatenation with the to-infinitive, then its internal structure will not be accessible to the combinatorial system. The toinfinitive adjunct will not be detected and so will not result in ungrammaticality, but its semantic contribution will be retained. Under the contrarian proposal, in attributive use a TC would be Labeled as AP following Concatenation, and then adjoined to the NP it modifies:

(226) an easy to please guy

[QP [Q an] [NP [AP [AP easy $]^{\wedge}[\mathrm{PP}$ to please $\left.]\right]^{\wedge}[\mathrm{NP}$ guy $\left.\left.]\right]\right]$

I open a parenthesis here to observe that Carreira's model of non-verbal predication together with H\&N's analysis of adjuncts shed light on the empirical rule that "complements" are disallowed in prenominal use of adjectives. The "no complements in attributive use" rule is entirely mysterious if the "complements" are true syntactic complements - i.e. phrases selected by the A head, as they are under most TC theories - since the complement is inside the AP and should not be visible in the syntax once the A head has projected. Under Carreira's model, the "complement" to the adjective is a maximal projection adjunct, which, if unlabeled, remains syntactically visible after adjunction. As illustrated in (227) below, the adjunct is left "dangling off" (in H\&N's terminology), available for further syntactic operations:

(227) *The pretty to look at flowers

[DP [D the $]$ [NP [AP pretty $]^{\wedge}[\text { PP to look at }]^{\wedge}[\mathrm{NP}$ flowers $\left.\left.]\right]\right]$ 
The question remains, however, as to why "complements" to adjectives are disallowed in the attributive position, and we touch on this question below.

First, however, we must address a difficulty that the Labeling analysis faces: under "one-size-fits-all" model, pretty predicates have exactly the same syntactic structure as TCs, and yet pretty predicates are not acceptable in attributive use. Why, then, is Labeling available for TCs (and some GDPs) and not for pretty predicates?

The answer to this difficulty, I believe, is that Labeling is possible for TCs because their semantic content is evenly distributed between their two maximal projections, so that the meaning of the whole is different from the meaning of its parts. In contrast, in pretty predicates, the to-infinitive modifies the adjective, but does not alter its essential meaning. Put another way, in easy-to-please, to please does not "dangle off" easy; instead the adjunction of the two elements creates an entirely new attribute, easy-to-please, that is Labeled A. In contrast, in pretty to look at, to look at merely "dangles off" pretty, modifying it, but not creating a new attribute.

There remains the larger question of why "complements" to adjectives are disallowed in attributive use (unless the concatenate has been Labeled as an atomic adjective). Carreira's (2015) reprojection analysis offers one potential explanation. Under his proposal, predication determines which of the two adjoined phrases will project. In the one-size-fits-all model, therefore, the AP projects because the to-infinitive PP is predicated of it, and the NP projects because the $\left[\mathrm{AP}\left[\mathrm{AP}^{\wedge} \mathrm{PP}\right]\right]$ is predicated of the $\mathrm{NP}$, causing a change in the direction of predication, as shown in (228). This change in the direction of predication may be the cause of the ungrammaticality of the PP adjunct. The nominal modification environment is by definition one in which modifiers are predicated of NPs, and it may be that the environment is exclusive, so that predicational relationships that do not involve the noun are disallowed. 
(228)

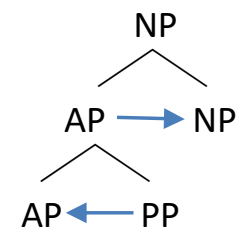

Another possible explanation is that complex adjectives formed by adjunction of maximal projections cause linearization problems because unless they are Labeled, all elements in the complex remain visible in the syntax. As the schema in (228) shows, the NP could be said to dominate two phrases, contrary to the Linear Correspondence Axiom (Kayne 1994).

The fact that for-phrases are disallowed in prenominal TCs follows from the observations made above. If prenominal TCs are in fact Labeled, becoming atomic adjectives, then a for-phrase will be disallowed because the to-infinitive in the TC will no longer be a distinct syntactic object with a semantically active argument structure; and without the to-infinitive's argument structure, a forphrase referring to the agent of the action expressed by the deverbal nominal will be infelicitous. This conclusion finds some support in the fact that even if the forphrase is moved to a post-nominal position, it remains infelicitous:
a. *John is an easy for Bill to please guy
b. *John is an easy to please guy for Bill

Sentence $(229 \mathrm{~b})$ is particularly interesting because it offers evidence that the prenominal TC has effectively been Labeled as an atomic adjective and has lost its argument structure. In contrast, a for-phrase is felicitous in (230), where it appears to be licensed by the noun goal (which presumably has an argument structure that includes the agent that makes the goal). Moreover, the for-phrase is more acceptable in the discontinuous spell-out configuration shown in (231) than in either (229a) or (229b):

(230) That was an easy goal for Fulano 
(231) John is an easy guy for Bill to please

The fact that (231) is more acceptable than either of the sentences in (229) also tends to reinforce the suspicion that TCs in the discontinuous spell-out configuration are not equivalent to TCs in attributive use, either syntactically or semantically (cf. section 2.2.3.3). 


\section{5 \\ Conclusion}

\section{1. Discoveries made on the contrarian exploration}

The contrarian exploration of TCs shows that arguments exist to support a syntactic model for TCs and other object-gap constructions that does not rely on the premise of a syntactic link between the gap in the to-infinitive and the subject of the tough predicate. Working instead from the hypothesis that the to-infinitive is a deverbal nominal, as suggested for French TCs by Authier and Reed (2009), the gap in the infinitive is no longer a gap created by movement of the internal argument of infinitive's verb but the result of nominalization of an eventive verb without its internal argument. ${ }^{60}$ Because most nominal "complements" to adjectives are found in prepositional phrases, the contrarian proposal suggests that the to in the to-infinitive is a functional preposition.

Under a model of predication by adjunction of maximal projections adapted from Moro's (2000) and Carreira's (2015) theories of non-verbal predication, the syntax of TCs in the contrarian proposal can be modeled as an AP (or other tough element like a snap, a breeze, or a bitch) and its PP adjuncts, one of which is the to-infinitive and one the optional for-phrase, which is predicated of the subject, forming a "predicative nucleus", to use Moro's term. The contrarian proposal also makes use of Hornstein and Nunes's (2008) analysis of adjuncts to model the predicative nucleus as a label-less concatenate in which each element is available for concatenation with the others.

Within the predicative nucleus, the "obligatory object" requirement attached to eventive nominals (observed by Grimshaw (1990) and applied by Authier and Reed (2009) in the context of French TCs), operates to identify the subject of the

\footnotetext{
${ }^{60}$ One of many issues still to be addressed is the PP gap in atypical TCs and the extent to which the nominalization hypothesis holds for those constructions.
} 
tough predicate as the theme of the action or state expressed by the nominalized verb. The contrarian proposal suggests that this model is a "one-size-fits-all" structure that can apply to all the object-gap constructions examined in this work and, potentially, to all copular predicates formed of an adjective and a toinfinitive.

The contrarian exploration also revealed that semantics and the argument structure of the deverbal nominal, and the interaction between the argument structure and the other elements in the predicative nucleus, seem to play a significant role in TCs and other object-gap constructions. For-phrases appear to be felicitous only in a predicate in which the adjective (or other tough element) describes the action expressed by the to-infinitive, as in the case of TCs, or which express a relation of degree, as in the case of GDPs and ready predicates. Pretty predicates, in which the adjective is oriented toward the subject, and which do not express degree, do not allow for-phrases, even though their to-infinitive has the same agent-theme argument structure as TCs, GDPs, and ready predicates.

In the spirit of the reanalysis proposal made by Nanni (1980), the contrarian proposal suggests that TCs are felicitous in attributive use, despite the restriction on complements to adjectives in attributive use, because TCs are Labeled as atomic adjectives. In the Labeling process, the complex TC loses its argument structure, and consequently a for-phrase is not felicitous with attributive TCs.

The syntactic model adopted in the contrarian exploration also produced an incidental insight into the fact that complements to adjectives are disallowed in attributive use. If in TCs the complement is assumed to be sister to an adjective head, then the infelicity of the complement is mysterious because it should not be visible in the syntax. Under the theory of non-verbal predication by adjunction of maximal projections, however, the "complement" is a maximal projection adjoined to the AP, and thus visible in the syntax.

By postulating a simple copular syntactic structure and relying on semanticsyntactic interaction between the elements in the non-verbal predicative nucleus, the contrarian proposal is able to account for many of the empirical TC puzzles. 


\section{2. \\ Future expeditions}

The contrarian exploration of TCs produces interesting findings, but much more work needs to be done to test the proposal and determine if it can be sustained. The contrarian proposal must still be tested against a much broader and more systematically organized corpus of data on copular predicates that include toinfinitives in general and "object-gap" to-infinitives specifically. A better empirical foundation will also make it possible to explore further the early findings on the role played by argument structure in the semantics of copular predicates.

The nominalization hypothesis in particular must be carefully tested because it encounters two very large "elephants in the room": Control (PRO) theory (in the context of TCs, Chomsky 1977, 1981, 1986, and 1995; see section 3.2) and stranded prepositions (in the context of TCs, Oliveira 2009; see section 3.4.6). The standard theoretical analysis of to-infinitives is that they are TPs, with the to forming the T head, and PRO in the subject position. In rejecting Rosenbaum's premise that in TCs the to-infinitive is a clausal complement to the tough element, the contrarian proposal also tacitly rejects PRO theory, at least in copular predicates. While the nominalization hypothesis and PRO theory both arise out of the same empirical observation - the fact that an overt subject is not required in to-infinitives - the nominalization hypothesis needs a much firmer empirical basis before it can be said to challenge PRO theory.

The standard theory on stranded prepositions is that they result from whmovement (Chomsky 1977). The nominalization hypothesis is inconsistent with a movement analysis of stranded prepositions, but the contrarian exploration has not offered an alternative explanation for objectless prepositions in $t o$-infinitives.

Since the contrarian proposal adopts a model of predication based on adjunction of maximal projections, it encounters linearization problems under Kayne's (1994) Linear Correspondence Axiom because of the apparent impossibility of establishing asymmetric c-command between adjuncts in TCs (and other object- 
gap constructions). Whether these linearization problems can be resolved within Kayne's LCA (or another theory of linearization) presents an interesting line of inquiry into the structure of copular predicates and another test of the contrarian proposal.

Even if the contrarian proposal does not prove to be sustainable, we hope that the review of the data and theory on tough and other object-gap constructions that inspired the proposal will be useful in future work on TCs. We also believe that the theory of predication by adjunction of maximal projections opens up interesting lines of inquiry and promises to be a useful syntactic model not only for copular predicates but also for the analysis of prenominal attributive modification in English.

In English, the title of this thesis is a play on words; the title in Portuguese ${ }^{61}$ takes a more realistic view of how the tough nut will eventually be cracked - by gnawing away until the marrow is reached at last.

\footnotetext{
${ }^{61}$ Roendo um osso duro - gnawing a hard bone.
} 


\section{Bibliography}

ABNEY, S. The English Noun Phrase and its Sentential Aspect. 1987. 234 p. Ph.D. Dissertation. Department of Linguistics and Philosophy, Massachusetts Institute of Technology, Cambridge, MA, 1987.

AHN, B.; SAILOR, C. Obligatory Object Gaps in Infinitival Clauses. Presented at the Linguistic Society of America (LSA) 2014 Annual Meeting, 2 January 2014, Minneapolis, MN.

ANDERSON, D. L. The Acquisition of Tough-Movement in English. 466 p. Doctoral dissertation. Research Centre for English and Applied Linguistics, Faculty of English, University of Cambridge, UK. 2005. Available at http://www.ling.cam.ac.uk/psych/Acq_of_TM.html. Accessed 11 June 2017.

AUTHIER, J-M; REED, L. French Tough-movement revisited. In: Probus 21 (2009), pp. 1-21.

BECKER, M; ESTIGARRIBIA, B; GYLFADOTTIR, D. Tough adjectives are easy to learn. 2012. $36^{\text {th }}$ BUCLD Proceedings. Available at http://www.bu.edu/bucld/files/2012/07/becker-36.pdf.

BOSKOVIC, Z. Be Careful Where You Float Your Quantifiers. In: Natural Language \& Linguistic Theory 22. The Netherlands: Kluwer Academic Publishers, 2004. pp. 681-742.

BOSQUE, I.; GALLEGO, A. Spanish double passives and related structures. In: Revista de estudos Linguísticos da Universidade do Porto, no. 1, vol. 6, 2011. pp. 9-50.

BOUTAULT, J. A Tough Nut to Crack: A Semantico-Syntactic Analysis of Tough-Constructions in Contemporary English. In: Syntaxe et sémantique, vol. 12, no. 1, 2011. pp. 95-119. Available at https://www.cairn.info/revue-syntaxe-et-semantique-2011-1-page-95.htm.

BRILLMAN, R. Tough Constructions in the Context of English Infinitives. 2017. 237 p. Doctoral dissertation. Department of Linguistics and Philosophy, Massachusetts Institute of Technology, Cambridge, MA. Available at http://hdl.handle.net/1721.1/113784. Accessed 28 February 2018.

BRILLMAN, R. Improper Movement in Tough Constructions and Gapped Degree Phrases. University of Pennsylvania Working Papers in Linguistics. V. 21 : Iss. 1, 2015. Article 4.

BRODY, M. $\theta$-Theory and Arguments. In: Linguistic Inquiry. V. 24(1). Cambridge, MA: The MIT Press, 1993. pp. 1-23. 
BRUENING, B. Defects of Defective Intervention. In: Linguistic Inquiry v. 45 (4), Cambridge, MA: The MIT Press, 2014. pp. 707-719.

CARREIRA, M. Predicação e ambiguidade de projeção. 2015. 193 p. Tese de doutorado, Universidade Federal do Paraná, Curitiba - PR.

CHIERCHIA, G. Formal Semantics and the Grammar of Predication. In: Linguistic Inquiry. Vol. 16, no. 4, Summer 1985. pp. 417-443.

CHIERCHIA, G.; TURNER, R. Semantics and Property Theory. In: Linguistics and Philosophy 11, 1988. pp. 261-302.

CHOMSKY, N. On Wh-Movement. In: Formal Syntax. Peter W. Culicover, Thomas Wasow, Adrian Akmajian, coordinators. New York, NY: Academic Press, Inc., 1977. pp. 71-132

CHOMSKY, N. Lectures on Government and Binding. $5^{\text {th }}$ ed. Dordrecht, The Netherlands: Foris Publications Holland, 1981.

CHOMSKY, N. Knowledge of Language: Its Nature, Origin, and Use. New York, NY: Praeger Publishers, 1986.

CHOMSKY, N. The Minimalist Program. $20^{\text {th }}$ anniversary edition. Cambridge, MA: MIT Press, 1995.

CHOMSKY, N. Problems of Projection. In: Lingua 130. 2013. pp. 33-49.

COLLINS, C. A Smuggling Approach to the Passive in English. In: Syntax 8. 2005. pp. 81-120.

FERREIRA, M. Argumentos Nulos em Português Brasileiro. 2000. 113 p. Dissertação de mestrado. Universidade Estadual de Campinas.

FLEISHER, N. A Crack at a Hard Nut: Attributive-Adjective Modality and Infinitival Relatives. In C.B. Chang and H.J. Haynie, eds., Proceedings of the 26th West Coast Conference on Formal Linguistics. 2008. pp. 163171. Somerville, MA: Cascadilla.

(http://www.lingref.com/cpp/wccfl/26/paper 1669.pdf). Accessed 27 August 2017

FLEISHER, N. On the Absence of Scope Reconstruction in Tough-Subject A-Chains. In: Linguistic Inquiry. V. 44(2). 2013. Cambridge, MA: The MIT Press, pp. 321-332.

FLEISHER, N. Rare-class adjectives in the tough construction. In: Language. v. 91(1). Linguistic Society of America, 2015. pp. 73-108.

FLEISHER, N. Attributive adjectives, infinitival relatives, and the semantics of inappropriateness. In: Journal of Linguistics 47. 2011. pp. 341-380.

FONG S.; GINSBURG J. A New Approach to Tough-Constructions. In Proceedings of the 31st West Coast Conference on Formal Linguistics. Robert E. Santana-LaBarge, ed. Somerville, MA: Cascadilla Proceedings Project, 2014. pp.180-188.

GIURGEA, I. 2013. Romanian tough-constructions and multi-headed constituents. In: Romance Linguistics 2013: Selected papers from the 43rd Linguistic Symposium on Romance Languages (LSRL), New York, 17-19 April 2013, Edited by Christina Tortora, Marcel den Dikken, 
Ignacio L. Montoya and Teresa O'Neill. [Romance Languages and Linguistic Theory, 9] (pp. 119-138)

GRIMSHAW, J. Argument Structure. Cambridge, MA: MIT Press, 1990. GUÉRIN, V. On Tough Constructions in French. In: Working Papers in Linguistics, vol. 37(1). 2006. University of Hawai'i at Mānoa.

HAEGEMAN, L. Introduction to Government and Binding Theory. 2nd ed. Oxford, UK: Blackwell Publishers Ltd., 1994.

HARTMAN, J. Intervention in tough-constructions. In Proceedings of the 39th Meeting of the North East Linguistic Society (NELS 39), 2011. eds. Suzi Lima, Kevin Mullin, and Brian Smith, 387-397. Amherst, MA: GLSA.

HENDRICK, R. A Problem For/Of Tough Movement. 2013. http://ling.auf.net/lingbuzz/001921.

HEYCOCK, C. The Syntax of Predication. In: DIKKEN, M. d. (ed). The Cambridge Handbook of Generative Syntax. Cambridge, UK: Cambridge University Press, 2013. pp. 322-352.

HICKS, G. Tough-Constructions and Their Derivation. In: Linguistic Inquiry, Cambridge, MA: The MIT Press, v. 40, n. 4, Fall 2009. pp.535566.

HOLMBERG, A. Am I Unscientific? In: Natural Language \& Linguistic Theory. v. 18. The Netherlands: Kluwer Academic Publishers, 2000. pp. 837-842

HORNSTEIN, N. Move! A Minimalist Theory of Construal. Oxford, UK: Blackwell Publishers Inc., 2001.

HORNSTEIN, N. \& NUNES, J. Adjunction, Labeling, and Bare Phrase Structure. In: Biolinguistics 2.1:057-086. 2008. http://www.biolinguistics.eu.

HORNSTEIN, N., NUNES, J., \& GROHMANN, K. Understanding minimalism. Cambridge, UK: Cambridge University Press, 2005.

HUDDLESTON, R. \& PULLUM, G. 2002. The Cambridge Grammar of the English Language. Cambridge, UK: Cambridge University Press, 2002.

KAYNE, R. 1994. The antisymmetry of syntax. Cambridge, MA: MIT Press, 1994.

KEINE, S.; POOLE, E. 2017. Intervention in tough-constructions revisited. January 2017. Available at http://ethanpoole.com/papers/keine-poole2017-intervention-tough-constructions.pdf.

LASNIK, H.; FIENGO, R. Complement Object Deletion. Linguistic Inquiry v. 5(4), 1974. Cambridge, MA: The MIT Press, 535-371

LASNIK, H.; URIAGEREKA, J. 1988. A Course in GB Syntax: Lectures on Binding and Empty Categories. Cambridge: MIT Press, 1988. 
MIKKELSEN, L. Copular Clauses. In Heusinger, K., Maienborn, C. and Portner, P. (eds.) Semantics. Volume 2. Berlin, Boston: De Gruyter Mouton, 2011. pp. 1805-29.

MORO, A. Dynamic Antisymmetry. Cambridge, MA: MIT Press, 2000.

MORO, A. The Equilibrium of Human Syntax: Symmetries in the Brain. New York, NY: Routledge, 2013.

NANNI, D.L. On the Surface Syntax of Constructions with Easy-Type Adjectives. In: Language. V. 56(3). 1980. Linguistic Society of America, pp. 568-581.

OBATA, M.; EPSTEIN, S. Feature-Splitting Internal Merge: Improper Movement, Intervention, and the $A / \bar{A}$ Distinction. In: Syntax 14:2 June 2011, 122-147 Blackwell Publishing Ltd., Oxford, UK and Malden, MA, USA.

OBATA, M; EPSTEIN, S. Building (proper) improper movement structures. Paper presented at the Ways of Structure Building conference, University of the Basque Country, Vitoria-Gasteiz, Spain (November 2008). http://ehutb.ehu.es/es/serial/85.html.

OLIVEIRA, I. "They are really tough, but also middle": diferentes estruturas para sentenças com predicado tough. 2009. 174 p. Tese de doutorado, Universidade Estadual de Campinas, Campinas - SP.

PESETSKY, D. Phrasal movement and its discontents: Diseases and diagnostics. In: Diagnosing syntax, ed. Lisa Cheng \& Norbert Corver, Oxford: Oxford University Press, 2013. pp.123-157.

PIRES, A. The Minimalist Syntax of Defective Domains: Gerunds and Infinitives. Amsterdam/Philadelphia: John Benjamins Publishing Company, 2006.

POOLE, E; KEINE, S; MENDIA, J. A. 2016. It's tough to reconstruct. 6 April 2016: GLOW 39, Göttingen (poster). Available at http://wwwbcf.usc.edu/ keine/handouts/Poole_Mendia_Keine_reconstruction.pdf.

POSTAL, P.; ROSS, J. ¡Tough Movement $\mathrm{Si}$, Tough Deletion No! Linguistic Inquiry v. 2 (4), 1971. Cambridge, MA: The MIT Press, pp. 544-546. Retrieved from http://www.jstor.org/stable/4177660

POSTAL, P. Cross-Over Phenomena. New York, N.Y.: Holt, Rinehart and Winston, Inc., 1971.

POSTAL, P. On raising: One rule of English grammar and its theoretical implications. Cambridge, Massachusetts: MIT Press, 1974.

RADFORD, A. The Syntax of Attributive Adjectives in English and the Problems of Inheritance. Revised version of a paper entitled "The Syntax of Attributive Adjectives in English: Abnegating Abney" presented at the Colloquium on Noun Phrase Structure, University of Manchester, 1989. (http://privatewww.essex.ac.uk/ radford/PapersPublications/adjectives.ht $\mathrm{m})$.

RADFORD, A. Minimalist Syntax Revisited. 2006.

http://courses.essex.ac.uk/lg/lg514 
REEVE, M. Clefts. 2009. PhD Thesis, University College London. 2009. 268 pages.

REZAC, M. On tough movement. In: Cedric Boeckx (ed.) Minimalist Essays. Amsterdam: John Benjamins, 2006. pp. 288-325.

ROSENBAUM, P.S. The Grammar of English Predicate Complement Constructions. 1965. 228 p. Doctoral dissertation, Massachusetts Institute of Technology, Cambridge, MA.

ROY, I. \& SOARE, E. Nominalizations: new insights and theoretical implications. In: Recherches linguistiques de Vincennes 40 (2011). pp. 7-23

SCHÜTZE, C. On the Nature of Default Case. In: Syntax 4:3, December 2001, pp. 205-238.

TAKAMI, K. Passivization, Tough-Movement and Quantifier Float: A Functional Analysis Based on Predication Relation. In: English Linguistics 15. 1998. pp. 139-166.

TRUSWELL, R. Adjectives and Headedness. Oxford Working Papers in Linguistics, Philology and Phonetics 10:1-19. 2005. (http://www.lingphil.ox.ac.uk/download/OWP2005.pdf). Accessed 27 August 2017.

WILLIAMS, E. PRO and Subject of NP. In: Natural Language and Linguistic Theory 3. 1985. pp. 297-315.

ZWART, J-W. Easy to (re)analyse: tough-constructions in minimalism. In Marion Elenbaas and Suzanne Aalberse, eds., Linguistics in the Netherlands 2012. Amsterdam: John Benjamins, 2012. pp. 147-158. 